MIRLEY DE CARVALHO

\title{
Limiares auditivos tonais em altas freqüências e emissões otoacústicas em portadores da desordem pigmentar do tipo vitiligo
}

Dissertação apresentada ao Programa de Pósgraduação em Fisiopatologia Experimental da Faculdade de Medicina da Universidade de São Paulo para obtenção do título de Mestre em Ciências.

Área de concentração: Fisiopatologia Experimental

Orientadora: Dra Renata Mota M. Carvallo

São Paulo

2004 
D edico este trabalho aos meus

pais, Acilino e Ivone, pelo exemplo de dignidade e de caráter que sempre quero seguir, por compreenderem e reverterem todos os momentos difícieis, ensinando a viver com coragem elutar com perseverança.

M e orgulho de ser sua filha 


\section{AGRADECIMENTOS}

À minha querida orientadora Prof.a Dra. Renata Mota Mamede Carvallo, por todo apoio e convivência desde o início de minha formação, com quem tanto aprendi e cresci profissionalmente, meus sinceros agradecimentos.

Às Prof.as Dra. Ida Lichti, Dra Marisa Frasson de Azevedo e Dra Maria Angelina Nardi de Souza Martinez pelas valiosas sugestões no exame de qualificação.

Às fonoaudiólogas e amigas Fernanda Burguetti, Milaine Dominice Sanfins, Cristiane Pereira dos Santos, Ieda Maria Ishida, Liliana Almeida Rosa, Rina Araújo, Letícia Puricelli pelo carinho sincero compartilhado;

As amigas Ana Lúcia Vidal e Viviane Fontes pela torcida e apoio para construção deste trabalho;

Ao querido Carlos Alberto Ignácio de Oliveira, com quem compartilhei os momentos finais deste trabalho; 
Aos meus irmãos Glaucio e Ariene, que sempre estão presentes em minha vida, torcendo por mim;

Às queridas fonoaudiólogas Mônica Jubran Chapchap e Flávia Ribeiro, profissionais respeitáveis e de integridade invejável, minha gratidão por acreditar em mim profissionalmente;

Às fonoaudiólogas e amigas de trabalho Edilaine Ogeda, Fabiana Gonçalves e Fernanda Vancine, pelo companheirismo, carinho e apoio constantes;

À Dra. Claudia Giuli Santi, dermatologista que abriu as portas para que o trabalho pudesse ser realizado no Hospital das Clínicas;

Ao Prof. Dr. Luiz Carlos Cucé, por aprovar o projeto para que fosse executado com a coloboração da Divisão de Clínica Dermatológica do HC-FMUSP ;

Ao Jimmy Adans Costa Palandi, pela análise estatística deste trabalho;

Ao Daniel Soares pelas correções finais referentes à Língua Portuguesa;

A todos aqueles que se dispuseram a participar deste estudo, agradeço especialmente. 
Finalmente, a todos que direta ou indiretamente participaram de mais uma etapa de minha vida profissional. 


\section{SUMÁRIO}

Lista de Abreviaturas e Símbolos

Lista de Figuras

Lista de Tabelas

Resumo

Summary

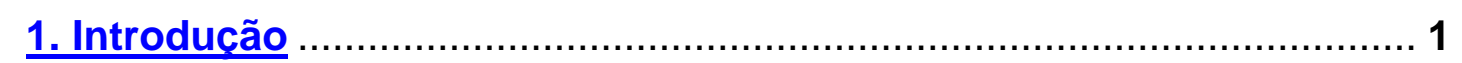

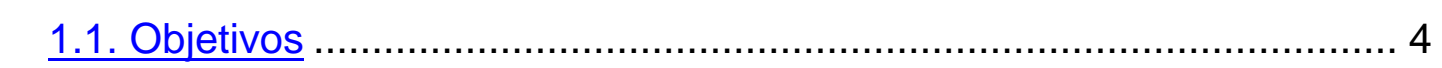

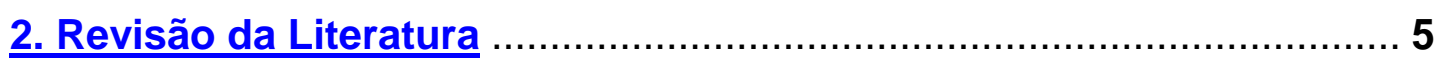

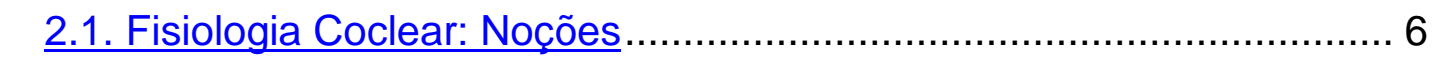

2.2. Desordem Pigmentar do Tipo Vitiligo e Audição ......................... 10

2.3. Audiometria Em Altas Freqüências ...................................... 14

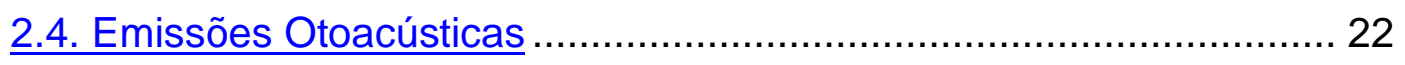

3. Métodos $\ldots \ldots \ldots \ldots \ldots \ldots \ldots \ldots \ldots \ldots \ldots \ldots \ldots \ldots \ldots \ldots \ldots \ldots \ldots \ldots \ldots \ldots \ldots \ldots \ldots, 31$

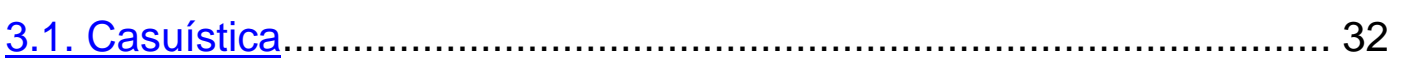

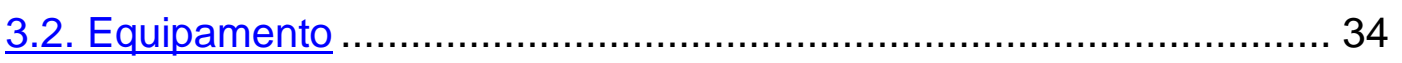

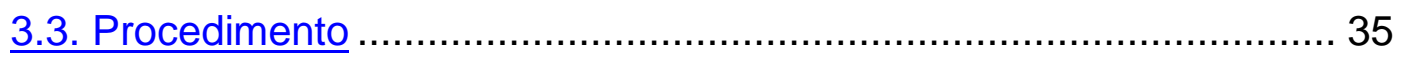

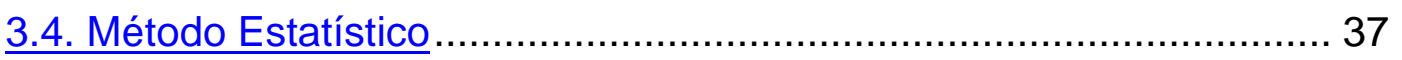

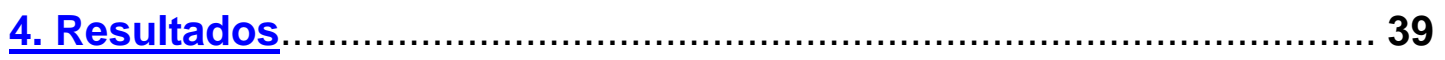

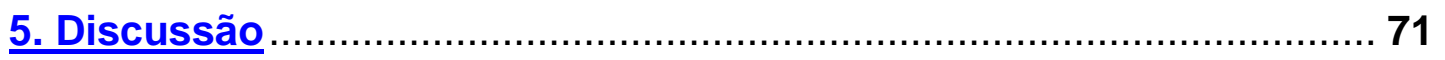

6. Conclusões $\ldots \ldots \ldots \ldots \ldots \ldots \ldots \ldots \ldots \ldots \ldots \ldots \ldots \ldots \ldots \ldots \ldots \ldots \ldots \ldots \ldots \ldots \ldots \ldots, 85$

7. Anexos $\ldots \ldots \ldots \ldots \ldots \ldots \ldots \ldots \ldots \ldots \ldots \ldots \ldots \ldots \ldots \ldots \ldots \ldots \ldots \ldots \ldots \ldots \ldots \ldots \ldots . . \ldots 7$

5. Referências Bibliográficas $\ldots \ldots \ldots \ldots \ldots \ldots \ldots \ldots \ldots \ldots \ldots \ldots \ldots \ldots \ldots \ldots . \ldots \ldots$

\section{Apêndice}




\section{LISTA DE ABREVIATURAS E SÍMBOLOS}

\begin{tabular}{|c|c|}
\hline AF & Alta Freqüência \\
\hline ABR & Audiometria de Tronco Encefálico \\
\hline CCE & Célula Ciliada Externa \\
\hline $\mathrm{CCl}$ & Célula Ciliada Externa \\
\hline daPa & decapascal \\
\hline$d B$ & decibel \\
\hline dBNA & Decibel nível de audição \\
\hline dBNPS & Decibel nível de pressão sonora \\
\hline DPA & Distúrbio de Processamento Auditivo \\
\hline EOAE & Emissões Otoacústicas Espontâneas \\
\hline EOAPD & Emissões Otoacústicas - Produto de Distorção \\
\hline EOAs & Emissões Otoacústicas \\
\hline EOAT & Emissões Otoacústicas Transientes \\
\hline $\mathrm{f1}$ & Estímulo de tom puro de EOAPD de freqüência mais baixa \\
\hline f2 & $\begin{array}{l}\text { Estímulo de tom puro de EOAPD de freqüência mais } \\
\text { baixa }\end{array}$ \\
\hline $\mathrm{Hz}$ & Hertz \\
\hline $\mathrm{KHz}$ & Kilo Hertz \\
\hline
\end{tabular}




\section{LISTA DE FIGURAS}

Figura 1. Média dos limiares tonais de 250 a $8000 \mathrm{hz}$ do grupo controle para

a orelha direita e orelha esquerda. ......................................................43

Figura 2. Distribuiccão das médias dos limiares tonais de $250 \mathrm{a} 8000 \mathrm{~Hz}$ do

grupo com vitiligo para a orelha direita e orelha esquerda. .......................... 45

Figura 3. Box Plot dos limiares tonais de $250 \mathrm{a} 8000 \mathrm{~Hz}$ para os grupos

controle (c) e vitiligo (v) .........................................................................4 47

Figura 4. Diferença das médias dos limiares tonais nas freqüências de $250 \mathrm{a}$

$8000 \mathrm{hz}$ dos grupos controle e com vitiligo .................................................. 47

Figura 5. Média dos limiares de altas freqüências de 9000 a $20000 \mathrm{~Hz}$ do

grupo controle para a orelha direita e orelha esquerda. .............................50

Figura 6. Média dos limiares de altas freqüências de 9 a $20 \mathrm{kHz}$ do grupo

com vitiligo para a orelha direita e esquerda. ...............................................52

Figura 7. Box Plot dos limiares para altas freqüências de $9000 \mathrm{a} 20000 \mathrm{~Hz}$

para os grupos controle (c) e com vitiligo (v) ..........................................54

Figura 8. Diferença das médias dos limiares em altas freqüências de $9000 \mathrm{a}$

$20000 \mathrm{~Hz}$ dos grupos controle e com vitiligo................................................54

Figura 9. Média das respostas das EOAPD do grupo controle na orelha

direita e orelha esquerda. ................................................................................. 57

Figura 10. Média das respostas das EOAPD do grupo com vitiligo na orelha

direita e orelha esquerda. .............................................................................. 59

Figura 11. Diferença das médias das respostas das EOAPD dos grupos

controle e com vitiligo. .....................................................................................61 
Figura 12. Média da relação sinal/ruído das EOAPD do grupo controle na orelha direita e orelha esquerda. ......................................................................64 64

Figura 13. Média da relação sinal/ruído das EOAPD do grupo com vitiligo na orelha direita e orelha esquerda ....................................................................66

Figura 14. Box Plot do nível de resposta das EOAPD do grupo controle (c)

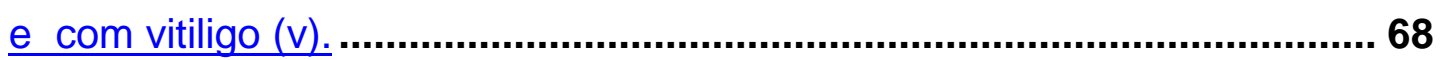

Figura 15. Comparacão da média da relação sinal/ruído das EOAPD dos grupos controle e com vitiligo........................................................................68

Figura 16. Gráfico de dispersão para a freqüência de $6348 \mathrm{~Hz}$ para o grupo

Controle. ................................................................................................. 70

Figura 17. Gráfico de dispersão para a freqüência de $6348 \mathrm{~Hz}$ para o grupo

vitiligo ....................................................................................................... 70 


\section{LISTA DE TABELAS}

Tabela 1........................... Análise descritiva da variável idade para cada grupo

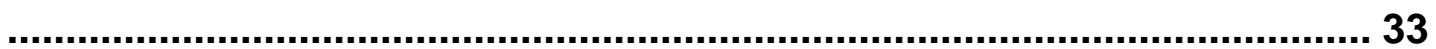

Tabela 2. Número de orelhas com limiares menor/ maior que 25 dBNA nos

grupos controle e com vitiligo.....................................................................42

Tabela 3. Comparação dos limiares tonais em dBNA para as freqüências de 250 a $8000 \mathrm{~Hz}$ nas orelhas direita e esquerda no grupo controle................ 42

Tabela 4. Comparação dos limiares tonais de $250 \mathrm{a} 8000 \mathrm{~Hz}$ na orelha direita e orelha esquerda para o grupo com vitiligo........................................................ 44

Tabela 5. Análise descritiva dos limiares tonais em dBNA nas freqüências de 250 a $8000 \mathrm{~Hz}$ do grupo controle e com vitiligo ............................................46

Tabela 6. Comparacão dos limiares em altas freqüências de 9000 a 20000 $\mathrm{Hz}$ na orelha direita e orelha esquerda para o grupo controle......................49

Tabela 7. Comparação dos limiares de altas freqüências de 9000 a 20000 Hz para o grupo com vitiligo....................................................................... 51

Tabela 8. Análise descritiva dos limiares para altas freqüências de 9000 a $20000 \mathrm{~Hz}$ do grupo controle e com vitiligo .................................................. 53

Tabela 9. Comparação das respostas das EOAPD na orelha direita e orelha esquerda para o grupo controle.

Tabela 10. Comparacão da média das respostas das EOAPD na orelha direita e orelha esquerda do grupo com vitiligo..............................................58

Tabela 11. Comparação das respostas das EOAPD para o grupo controle e com vitiligo ...........................................................................................60 
Tabela 12. Quantidade de orelhas que apresentaram respostas nas EOAPD quanto à relação sinal/ruído...........................................................................62

Tabela 13. Comparação da relação sinal/ruído das EOAPD para a orelha direita e orelha esquerda no grupo controle ....................................................63

Tabela 14. Comparacão da relação sinal/ruído das EOAPD para a orelha direita e orelha esquerda no grupo vitiligo ....................................................65 65

Tabela 15. Análise descritiva da média da relação sinal/ruído do grupo controle e com vitiligo ............................................................................6 67

Tabela 16. Correlação entre altas freqüências e emissões otoacústicas produto de distorção .......................................................................................69

Tabela 17. Análise descritiva da variável idade para cada grupo sem os indivíduos com mais de 60 anos................................................................... 88 Tabela 18. Análise descritiva dos limiares tonais de 250 a $8000 \mathrm{~Hz}$ do grupo controle e com vitiligo sem os indivíduos com mais de 60 anos................... 89

Tabela 19. Análise descritiva dos limiares para altas freqüências de $9000 \mathrm{a}$ $20000 \mathrm{~Hz}$ do grupo controle e com vitiligo sem os indivíduos com mais de 60 anos ................................................................................................................ 90

Tabela 20. Análise descritiva da média da relação sinal/ruído do grupo controle e com vitiligo sem os indivíduos com mais de 60 anos................... 91 


\section{RESUMO}

CARVALHO, M. - Limiares tonais em altas frequências e emissões otoacústicas em portadores de desordem pigmentar do tipo vitiligo [dissertação]. São Paulo: Faculdade de Medicina, Universidade de São Paulo; 2004. 99p.

INTRODUÇÃO: O vitiligo é uma doença que se caracteriza por uma despigmentação adquirida da pele devido à perda de melanócitos, podendo comprometer as funções da orelha interna. Considerando esta relação entre pigmentação e audição, poucos estudos tem sido direcionados para o tema. A utilização da moderna tecnologia pode contribuir para a detecção precoce de alterações auditivas. OBJETIVO:Verificar a contribuição da audiometria em altas freqüências (9 a $20 \mathrm{kHz}$ ) e das emissões otoacústicas na identificação de alterações da função coclear em indivíduos portadores de desordem pigmentar do tipo vitiligo, comparando-as com as respostas do grupo controle composto por indivíduos não portadores. MÉTODO: Foram submetidos à avaliação 60 indivíduos, da raça branca, sem queixa auditiva e história de comprometimento de orelha média, sendo 30 indivíduos com vitiligo e 30 sem a desordem pigmentar. Foram aplicados procedimentos para pesquisa dos limiares audiométricos entre 0,25 a $20 \mathrm{kHz}$ e emissões otoacústicas por produto de distorção, analisados quanto ao nível das respostas e relação sinal/ruído. RESULTADOS: Não foi evidenciada diferença entre os grupos na análise da audiometria convencional $(0,25$ a 8 $\mathrm{kHz}$ ). Nas altas freqüências (9 a $20 \mathrm{kHz}$ ) foram observadas diferenças estatisticamente significante entre os grupos, sendo que o grupo com vitiligo apresenta limiares em nível elevado de intensidade quando comparados ao grupo controle. Foram também observadas diferenças estatisticamente significante na análise das emissões otoacústicas por produto de distorção, tanto no nível das respostas, quanto na relação sinal/ruído, sendo que o grupo com Vitiligo apresenta respostas em menor nível de intensidade quando comparadas ao grupo controle. CONCLUSÃO: Há prejuízo nas funções auditivas de sensibilidade para altas freqüências e emissões otoacústicas de pacientes com desordem pigmentar do tipo vitiligo quando comparadas ao grupo sem a desordem. 


\section{SUMMARY}

CARVALHO, M. Auditory thresholds in high frequencies and otoacoustic emissions in pigmentary disorder type vitiligo [dissertation]. São Paulo: Faculdade de Medicina, Universidade de São Paulo; 2004. 99p.

INTRODUCTION: Vitiligo is an illness characterized by an acquired lack of pigmentation of the skin due to loss of melanin that can affect the inner ear function. Considering the relation between pigmentary disorder and hearing, few studies have been focused on this issue. The use of the modern technology can contribute for the precocious detection of auditory disorders. OBJECTIVE To verify the contribution of the high frequency audiometry (9 to $20 \mathrm{kHz}$ ) and distortion product- otoacoustic emissions in the identification of auditory impairments in individuals with pigmentary disorder type vitiligo, comparing with the responses of the control group. METHOD: 60 white race subjects, without auditory complaint and without middle ear disorders, being 30 with and 30 without vitiligo, had been submitted to the audiological evaluation. It had been applied procedures for 0,25 to $20 \mathrm{kHz}$ pure tone audiometry, and distortion product otoacoustic emissions analyzed by the response level and sinal/noise relation. RESULTS: Differences between the groups were not evidenced in the analysis of the conventional audiometry $(0,25$ to $8 \mathrm{kHz})$. At the high frequencies ( 9 to $20 \mathrm{kHz}$ ) the differences between the groups were statistically significant, with the vitiligo group presenting high level of intensity thresholds, when compared with the control group. Significant statistical differences in the analysis of the distortion product otoacoustic emissions had also been observed, as much in the response level, as in the sinal/noise relation. The vitiligo group presented lower responses level when compared with the control group. CONCLUSION: The results suggest damage in the auditory function of sensitivity for high frequencies and for otoacoustic emissions for the group with pigmentary disorder type vitiligo. 
1. Introdução 
A presença de pigmentos na orelha interna foi descrita, inicialmente, em 1831, por Alphonse Corti. Posteriormente, alguns autores tiveram o interesse em estudar a presença e a influência de pigmentos sobre a audição, tendo relatado que a orelha interna é um local de importante concentração de melanócitos (células responsáveis pela produção de melanina, substância que dá origem à pigmentação).

A função dos melanócitos da orelha interna foi discutida por diferentes autores, com particular atenção à função de proteção da cóclea contra vários agentes estressantes, e, sobretudo, contra os efeitos dos níveis elevados de ruído. Eles descreveram que animais albinos têm capacidade de audição normal, mas são mais suscetíveis a apresentarem perda auditiva induzida por ruído. O mesmo foi relatado quanto às diferenças raciais: indivíduos da raça branca são mais vulneráveis a terem perda auditiva induzida por ruído, do que os indivíduos da raça negra.

Considerando esta relação entre pigmentação e audição, o vitiligo uma desordem pigmentar - tem sido tema de poucas pesquisas. Em grande parte destes estudos, a audiometria convencional para tons puros (250 a $8000 \mathrm{~Hz}$ ) foi usada como procedimento para identificação de comprometimento auditivo. Entretanto, o emprego deste procedimento 
isolado não foi eficaz na identificação de eventuais alterações auditivas, em tais pacientes. Com o surgimento da audiometria em altas freqüências, a qual avalia a faixa de 9000 a $20000 \mathrm{~Hz}$, tornou-se possível detectar precocemente alterações auditivas, permitindo ações de intervenção para impedir que a lesão avance para a faixa das freqüências da fala.

Outro método de avaliação da função auditiva da orelha interna, a cóclea, de maneira objetiva, não invasiva, rápida e altamente precisa, é a análise das emissões otoacústicas. Dentre os tipos existentes, encontram-se as emissões otoacústicas espontâneas (EOAE), as emissões otoacústicas evocadas transientes (EOAT), as emissões otoacústicas por estímulofreqüência (EOAEF) e as emissões otoacústicas - produto de distorção (EOAPD). As avaliações da função auditiva, por meio das EOAPD, têm como principal vantagem, quando comparadas com outros tipos, a especificidade de freqüência, a qual propicia informações cocleares mais detalhadas. As EOAPD permitem 0 registro e 0 monitoramento do funcionamento das células ciliadas externas, detectando precocemente mínimas alterações cocleares.

A partir da hipótese de haver alteração na função auditiva em decorrência da falta de melanina na cóclea de indivíduos com desordem pigmentar, este estudo buscou contribuir para o conhecimento da audição nesses pacientes. 


\subsection{Objetivos}

Esta pesquisa teve como objetivo verificar a contribuição da audiometria em altas freqüências e das emissões otoacústicas na identificação de alterações da função coclear, em indivíduos portadores de desordem pigmentar do tipo vitiligo, comparando-as com as respostas do grupo controle composto por indivíduos não portadores.

Especificamente, os objetivos buscam:

- Analisar os limiares tonais para altas freqüências, em decibel nível de audição (dBNA), no intervalo entre 9 e 20 kHz;

- Analisar o nível de resposta das emissões otoacústicas - produto de distorção (EOAPD).

- Correlacionar o nível de reposta das emissões otoacústicas e o limiar tonal para altas freqüências, em ambos os grupos. 
2. Revisão da Literatura 


\subsection{Fisiologia Coclear: Noções}

A cóclea, órgão sensorial nobre do sistema auditivo, pode ser descrita como um analisador de freqüências (DALLOS, 1992), caracterizado por um conjunto de três canais justapostos em forma de uma espira. Está ligada à orelha média pela janela oval, por onde a energia mecânica é transmitida aos líquidos da cóclea. Cada freqüência característica irá promover um padrão de deslocamento descrito como onda viajante, com capacidade de estimular melhor determinada região da cóclea. As células sensoriais, localizadas na região estimulada, são capazes de promover a transdução deste estímulo em sinal elétrico, que irá ser propagado através das fibras nervosas que partem da região coclear. Quanto mais alta a freqüência que atinge o sistema, mais restrita a estimulação à região basal da cóclea. Disposto ao longo de seu eixo longitudinal, o órgão espiral abriga células ciliadas internas e externas. As externas estão dispostas em três camadas, sendo em número, o triplo (aproximadamente) das internas. São basicamente efetoras, capazes de mudar o padrão de movimentação da membrana basilar, independente da ação das ondas viajantes, alterando sua própria posição em relação à membrana tectória, ao longo das diferentes regiões de freqüência da cóclea. 
WITHNELL et al. (2002) ressaltaram que o processo que propicia a amplificação coclear é fisiologicamente vulnerável, e dependente do nível de estímulo. Este processo, enfocado como "amplificador coclear" tem a função de amplificar as vibrações da membrana basilar, envolvendo um processo "ativo ou motor", o qual adiciona energia mecânica à membrana basilar. A ação do amplificador coclear aumenta a vibração da membrana basilar (mecanismo ativo), mas somente ao ponto de freqüência característica do tom de entrada. Longe desta freqüência característica, a vibração da membrana basilar é a mesma, tanto no mecanismo ativo, como no passivo.

Essa amplificação mecânica aprimora a sensibilidade auditiva e a seletividade de freqüências, condições que ficam comprometidas quando há lesão de células ciliadas externas.

WITHNELL et al. (2002) descrevem com detalhes o processo de amplificação coclear. Ele tem início com a vibração do estribo para a janela oval, que é propagada para a membrana basilar pelo deslocamento do volume dos líquidos cocleares. Este deslocamento de volume provoca um gradiente de pressão ao longo da membrana basilar. A deformação na membrana basilar produz um estreitamento entre a membrana tectória e a lâmina reticular, produzindo uma deflexão nos estereocílios. Tanto as células ciliadas externas, como as internas, possuem conexão de ponta que interligam os cílios adjacentes. A deflexão dos estereocílios produz uma força nos canais de transdução, por meio destas conexões, abrindo estes canais (PICKLES et al., 1984). Os íons de potássio fluem através dos canais 
de transdução abertos, aumentando o potencial intracelular e alterando a diferença através da parede basolateral, que nas células ciliadas internas $(\mathrm{CCI})$ resulta em uma liberação de neurotransmissores nas sinapses aferentes. O fluxo de íons através destes canais de transdução, localizados no alto dos estereocílios resultantes da deflexão dos cílios, é chamado de transdução mecano-elétrica. O fluxo de íons pelos canais de transdução é constante e produto de forças eletromotivas, ou carga positiva, que é mantida pela bomba de potássio, através da estria vascular; e carga intracelular negativa, ou potencial de repouso da membrana celular. Este constante fluxo de íons é chamado de "corrente estacionária". A deflexão dos estereocílios modula esta corrente estacionária, de forma que o fluxo de corrente é aumentado, quando o estereocílio é defletido para fora do modíolo (direção excitatória); e o fluxo da corrente é diminuído, quando o estereocílio é defletido na direção do modíolo (direção inibitória).

Segundo BRAY (1989), a descrição de um processo mecânico ativo não linear dentro da cóclea, inferido pela existência das emissões otoacústicas, estimulou o surgimento de inúmeras pesquisas sobre a função das células ciliadas externas da cóclea (CCE). As CCE, com sua enervação eferente, tornaram-se o foco das atenções, como fonte de energia mecânica. Nesta época, já havia sido bem estabelecido que as células ciliadas externas eram detectoras de movimento no órgão espiral, estimulando diretamente o nervo auditivo. Os filamentos de actina e de miosina, os quais eram freqüentemente associados com a função contrátil, foram encontrados nas células ciliadas externas (FLOCK \& CHEUNG, 1977; ZENNER, 1986). 
As células ciliadas internas são consideradas como sendo as células primordialmente sensoriais da cóclea, enquanto que as células sensórias externas são efetoras, aplicando um "input" mecânico à movimentação da membrana timpânica. Acredita-se que as células ciliadas externas sejam capazes de fornecer energia para as ondas viajantes em sua propagação ao longo da membrana basilar, de forma a amplificar o deslocamento da membrana. Esta característica tende a aumentar a sensibilidade da cóclea à estimulação sonora. Além disso, este aumento na amplitude da movimentação ressalta o comportamento de modo-ressonante da membrana basilar, aumentando também a seletividade de freqüência da orelha interna.

Nos mamíferos, as células ciliadas externas tiveram seu desenvolvimento posterior às células ciliadas internas. Este desenvolvimento mais tardio, provavelmente, representa uma progressão ontogenética de um sistema estritamente passivo, passando a ser um sistema que utiliza ambos os componentes não lineares, o passivo e o ativo (DALLOS, 1992). Estas mudanças ontogenéticas parecem refletir um sistema refinado de sintonia de freqüências e de limiar de sensibilidade. Um grande número de trabalhos demonstra que tanto o processo ativo, como o passivo, pode estar gravemente afetado se houver lesão ou falta de CCE, sugerindo, então, que tanto a sensibilidade, como a sintonia coclear, depende da integridade das CCE (SAHLEY et al. 1997). 


\subsection{Desordem Pigmentar do Tipo Vitiligo e Audição}

O vitiligo é uma doença caracterizada pela despigmentação adquirida (pós natal) da pele, devido à perda de melanócitos, podendo comprometer as funções da membrana mucosa, olhos, bulbos pilosos dos pêlos e orelha interna. A perda de melanócitos altera a estrutura e a função destes órgãos e tecidos, a correlacionar-se com a ausência do pigmento melanina. É uma doença crônica, a qual afeta $2 \%$ da população geral, e inicia-se entre os 4 e 6 anos de idade, (SAMPAIO e RIVITTI, 2000).

FRANZ et al. (1990) relataram que áreas pigmentadas são observadas na cóclea e no órgão vestibular de animais, sendo que a distribuição de melanócitos varia de espécie para espécie. Em humanos, a quantidade de melanócitos é numerosa. A função dos melanócitos na orelha interna tem sido discutida em alguns estudos, tendo sido enfocada, com particular atenção, a considerável afinidade que substâncias ototóxicas têm com a melanina. Observou-se, assim, uma correlação direta entre desordens da orelha interna, após o uso de drogas ototóxicas, e a quantidade de melanina.

ARDIC et al. (1998) também relataram a relação das drogas ototóxicas com a melanina. $\mathrm{O}$ uso destas drogas afeta a região basal da cóclea, região que corresponde à audição em altas freqüências. A região apical, por sua vez, só é atingida por altas doses de drogas ototóxicas. Estas substâncias têm capacidade de se unirem à melanina, presente também, e principalmente, na região basal, região que é mais vulnerável a traumas. Sendo assim, o uso de 
drogas ototóxicas destrói a melanina presente na região basal do órgão espiral, deixando-o vulnerável a lesões por ruídos elevados.

CONLEE et al (1995) relataram, também, a alta afinidade da melanina com as drogas ototóxicas. Estudaram o efeito da gentamicina em porcos albinos e pigmentados no funcionamento coclear, e observaram, dois meses após o uso da droga, a qual foi utilizada por 14 dias consecutivos, a diminuição do microfonismo coclear nos porcos albinos, quando comparados aos porcos pigmentados, mostrando, assim, uma diminuição do funcionamento coclear. Concluíram que a melanina presente na orelha interna inibe a toxicidade presente na droga por se ligar a ela.

Outra função da melanina, que é discutida, é a possível influência na função vasomotora. SAVIN (1965) observou que as células que contêm pigmentos, em animais e em humanos, estão totalmente, ou parcialmente, aderidas nas paredes dos vasos sanguíneos da orelha interna. $O$ autor relata que, nesta região, ocorre intensa atividade metabólica e a melanina presente nos vasos sanguíneos facilita a passagens de substâncias de um lado para o outro, propiciando uma atividade enzimática e regularizadora da membrana celular.

A orelha interna é um dos importantes locais onde os melanócitos estão localizados. Alguns autores têm informado que as células que contêm melanina na orelha interna protegem a cóclea contra vários agentes estressantes, particularmente, contra o nível elevado de ruído. Mostraram, ainda, que animais albinos têm capacidade de audição 
normal, mas são mais suscetíveis à perda auditiva induzida por ruído (CONLEE et al., 1986).

ROYSTER et al. (1980) estudaram as diferentes raças humanas, em relação à audição, e concluíram que a raça branca é mais vulnerável a adquirir perda auditiva induzida por ruído, do que a raça negra, mostrando que a melanina da orelha interna pode proteger a audição contra o ruído elevado.

BARRENAS (1997) pesquisou o efeito do trauma acústico nas células ciliadas externas (CCE), em porcos albinos e pretos. Os porcos foram expostos a um ruído de $1 \mathrm{kHz}$ a 105 dBNPS, por 72 horas. Um mês depois, os animais foram sacrificados, tendo sido analisado o dano nas células ciliadas externas. O autor observou uma maior perda destas células nos animais albinos, quando comparados aos pretos, concluindo que a melanina protege a orelha interna contra traumas por ruído.

TOSTI et al. (1987) mencionou a possibilidade da relação entre vitiligo e perda auditiva. A fundamentação desta hipótese seria a de que parte dos melanócitos da orelha interna estaria lesada pelo mecanismo auto-imune presente na doença. Os autores estudaram 50 indivíduos afetados pelo vitiligo e encontraram 16\% destes indivíduos já com hipoacusias neurossensoriais, quando examinados pela primeira vez.

ESCALANTE-UGALDE et al. (1991) estudaram pacientes com vitiligo, do departamento dermatológico, para avaliar possíveis perdas auditivas. Pacientes que foram expostos a algum fator responsável por hipoacucias neurosensorias, como ruído, drogas, patologias metabólicas e vasculares, 
infecções otológicas recorrentes, trauma craniano e história familiar de deficiência auditiva foram excluídos deste estudo. Foram avaliados 47 pacientes com vitiligo, comparados com um grupo controle composto por 35 sujeitos saudáveis, pareados segundo a idade. Na avaliação da audiometria para tom puro nas freqüências entre 125 e $8000 \mathrm{~Hz}$, não foi observada diferença estatística dos limiares tonais obtidos nos pacientes com vitiligo, quando comparados aos do grupo controle.

Existem poucas pesquisas que enfocam a relação entre desordem pigmentar e alteração auditiva. Em todas as pesquisas sobre esse assunto, os testes de freqüências para tom puro $(250 \mathrm{a} 8000 \mathrm{~Hz})$ foram usados. As células que contêm melanina encontram-se em maior concentração na região basal da cóclea, a qual corresponde a audição em altas freqüências. ARDIC et al. (1998) estudaram os limiares em altas freqüências (8000 a $16000 \mathrm{~Hz})$ e a latência do reflexo estapediano, em 29 pacientes com vitiligo, e compararam os achados com 41 indivíduos saudáveis, os quais foram pareados com a idade. Os resultados mostraram diferença estatística $(p<0,05)$ entre os grupos, nas freqüências de 4, 6, 8 e $10 \mathrm{kHz}$. Não foi observada diferença estatística na comparação das orelhas direita e esquerda, para ambos os grupos. Em outras freqüências e no estudo das latências do reflexo estapediano, não houve diferença estatisticamente significante.

NIKIFORIDIS et al. (1993) estudaram os potenciais auditivos evocados de tronco encefálico ( $A B R$ ), em 30 pacientes com vitiligo, e os compararam a 50 pacientes saudáveis, para detectar a possibilidade de 
anormalidades subclínicas do sistema auditivo nesta desordem. Os achados revelam um decréscimo da latência da onda I e um aumento da latência interpico das ondas I-III, estaticamente significantes, nos paciente com vitiligo, quando comparados aos do grupo controle. A diminuição da latência da onda I pode ser devido à diminuição numérica de melanócitos ativos na orelha interna, a qual resulta em um prejuízo de íon na troca entre endolinfa e perilinfa na cóclea. O aumento da latência interpico I-III pode ser esclarecido em termos de uma atividade sináptica anormal e da transmissão do potencial ativo do nervo auditivo, no complexo olivar superior.

OZUER et al. (1998) relataram um estudo com 50 pacientes com vitiligo, utilizando avaliação auditiva com ABR. As latências e amplitudes das ondas I, III e V, e intervalos interpicos I-III, III-V e I-V foram comparadas a um grupo controle. Com exceção de dois indivíduos, todos os demais pacientes apresentaram resultados audiológicos normais. Nenhuma diferença estatisticamente significante foi notada entre o grupo de estudo e o de controle, em relação à latência, ao interpico de latências e às amplitudes.

\subsection{Audiometria Em Altas Freqüências}

De acordo com FRANK \& DREISBACH (1991), a principal aplicação de audiometria, em altas freqüências, é o monitoramento de pacientes que têm, ou sobre os quais há a suspeita, de ocorrência de transtornos 
relacionados à audição. Dentre eles, merecem destaque: monitorização do efeito de drogas ototóxicas, seqüela de otite média, monitorização da audição em portadores de insuficiência renal crônica, presbiacusia, avaliação dos distúrbios de processamento auditivo, investigação do comprometimento auditivo em familiares de portadores de deficiência auditiva de origem genética, e monitorização de indivíduos com exposição freqüente ao ruído.

PEDALINI et al. (2000) estudaram as respostas auditivas para freqüências de 10,12.5, 14 e $16 \mathrm{kHz}$, em 158 indivíduos entre 4 e 60 anos, sem queixa otológica. Para medidas em altas freqüências, utilizaram audiômetro clínico com fones Sennheiser HDA 200. Encontraram média de limiares tonais próximos a $10 \mathrm{dBNA}$, para indivíduos até 30 anos, com piora gradativa dos limiares com o aumento da idade.

FRANK (2001) estudou as respostas a tons puros de altas freqüências em 100 indivíduos com audição até 15 dBNA, nas freqüências de 250 a 8000 $\mathrm{Hz}$, e idades entre 18 e 25 anos. Foi usado o audiômetro Grason Stadler GSI 61. Seu interesse foi investigar a estabilidade de respostas em medidas consecutivas tomadas no mesmo indivíduo, através do fone Seinnheser HDA 200, especialmente concebido para as avaliações de altas freqüências. Estudou o conjunto de quatro medidas tomadas no mesmo indivíduo para verificar se as mudanças nos limiares obtidos podiam ser menores que as mudanças geradas por efeito de drogas ototóxicas. Encontrou as seguintes médias de limiares em dBNPS: em 9 kHz (21.9); $10 \mathrm{kHz}$ (24.1); $11.2 \mathrm{kHz}$ 
(25.0); $12.5 \mathrm{kHz}$ (29.8); $14 \mathrm{kHz}$ (35.4); $16 \mathrm{kHz}$ (57.9) e mostrou que a variabilidade intra-sujeitos é baixa, mas a variabilidade inter-sujeitos é alta. Sugeriu o emprego da audiometria em altas freqüências (com fones tipo Seinnheser HDA 200) na monitorização do efeito de drogas ototóxicas, de acordo com a indicação de audiometrias de controle periódico, nas quais os resultados audiométricos são comparados aos resultados iniciais.

FAUSTI et al. (1993) estudaram pacientes com certos tipos de infecção e câncer, tratados rotineiramente com agentes terapêuticos com potencial ototóxico, ameaçando, assim, a perda da sensibilidade de audição, e concluíram que a monitorização da audição, em altas freqüências, detectou precocemente a ação ototóxica das drogas, com potencial para prevenção de perdas auditivas em freqüências essenciais à comunicação verbal.

Para a monitorização de drogas ototóxicas, a American Speech Language Hearing Association (ASHA, 1994) sugere que seja adotado, como critério de comprometimento da audição, a ocorrência de mudança de limiar entre 9000 e $20000 \mathrm{~Hz}$ igual ou maior a $20 \mathrm{~dB}$, em pelo menos duas freqüências consecutivas, ou ainda, ausência de respostas em três freqüências consecutivas, nas quais tenham sido encontradas respostas em audiometrias prévias.

Quanto ao monitoramento da audição em portadores de insuficiência renal, ZEIGELBOIM (2000) observou, em seus estudos de audiometria em altas freqüências, em adultos de 30 a 59 anos portadores de insuficiência renal crônica, limiares piores que os do grupo controle e, no estudo prospectivo, após 
1 ano, houve piora dos limiares no grupo de portadores de doença renal. Encontrou, ainda, declínio da sensibilidade com o avanço da idade.

ZAIA (2000) estudou, também, portadores de insuficiência renal, porém mais jovens, com idade entre 4 e 17 anos. Não encontrou diferença entre os limiares médios dos dois grupos, em todas as freqüências, e em ambas as orelhas. Encontrou maior variabilidade de limiares no grupo renal, do que no grupo controle, com significância estatística para as freqüências de $11,12,13$ e $14 \mathrm{kHz}$, para a orelha esquerda.

Em relação à presbiacusia, SAKAMOTO et al. (1998) estudaram os limiares auditivos para freqüências entre 8 e $20 \mathrm{KHz}$, em 65 indivíduos com idades variando de 10 a 65 anos. Observaram que os limiares auditivos se elevam em função do aumento das freqüências, exceto para estímulos de $12 \mathrm{KHz}$ e acima de $19 \mathrm{KHz}$, e se elevam, também, em função do aumento da idade.

JERGER \& CHMIEL (1997), em relação à presbiacusia e à avaliação dos distúrbios de processamento auditivo, estudaram a audição de 180 idosos com alteração auditiva do tipo presbiacusia, buscando analisar os fatores que estariam influenciando o processamento auditivo. Chegaram a 5 conclusões: a) o grau da perda auditiva, que determina a audibilidade para a fala, continua sendo um conceito chave para entender os problemas de compreensão de fala em idosos; b) a sensibilidade para as baixas freqüências e para as altas freqüências emergem como fatores separados; c) existe um outro fator de habilidade em compreensão de fala, não 
relacionado fortemente à audibilidade; d) o processamento auditivo para sons verbais, pelo canal direito e canal esquerdo, emergem como fatores separados; e) a auto percepção, por parte dos idosos, de seus problemas de compreensão de fala, aparentemente, não estão fortemente relacionados à audição, reconhecimento geral de fala, ou processamento central dos estímulos verbais.

DIEROFF et al. (1991) realizaram audiometria completa (convencional e de altas freqüências) num total de 181 indivíduos, com idade entre 16 e 18 anos, e concluíram que os prejuízos precoces da audição, tanto após problemas auditivos na infância, como em resultado de exposição excessiva ao ruído, são observados mais claramente nas altas freqüências do que nas freqüências convencionais da audiometria tonal.

CARVALLO et al. (2001) estudaram os limiares para altas freqüências, em crianças de 7 a 16 anos de idade, com diagnóstico audiológico de distúrbio de processamento auditivo (DPA). Encontraram limiares audiométricos em níveis de intensidade mais elevado, em dBNA, no grupo de crianças com DPA, quando comparadas a um grupo controle pareado por idade. Houve diferença estatística significante nas freqüências de 9000,10000 e $12500 \mathrm{~Hz}$. Respectivamente, nas freqüências de 9000, $10000,12500,14000,16000$ e $20000 H z$, o grupo de crianças com DPA apresentou as seguintes médias, em dBNA, (desvio padrão) de limiares em altas freqüências: 16 (11.1); 12 (9.8); 11 (12.8); 7 (14.9); 2 (18.4); 0 (11.2). $O$ grupo de crianças sem DPA apresentou as seguintes médias para a mesma 
ordem de freqüências: 11 (7.0); 8 (8.5); 6 (11.0); 3 (13.0); 0 (13.0); -2.1 (8.6). Concluíram haver co-ocorrência de limiares, em altas freqüências, em níveis de intensidade mais elevado no grupo de crianças com DPA.

RAMOS (2002) investigou a sensibilidade auditiva, para altas freqüências, e achados de processamento auditivo, em 32 crianças, concluindo que 1/3 das crianças que apresentaram alteração no processamento auditivo tiveram limiares de audição, para altas freqüências, elevados em relação aos encontrados no grupo de crianças sem alteração do processamento.

CARVALLO et al. (2002) estudaram os limiares tonais, para altas freqüências (9 a $20 \mathrm{KHz}$ ), em 148 orelhas em indivíduos, com idade entre 18 e 30 anos, com dados audiológicos dentro do padrão de normalidade para audiometria convencional, para SRT, para pressão em decapascals (daPa), para pico de admitância e para reflexos acústicos ipsi e contralaterais. As médias obtidas foram: $9000 \mathrm{~Hz}$ : 9,9 decibéis nível de audição (dBNA); 10000 Hz: 7,8 dBNA; 12500 Hz: 5,6 dBNA; 14000 Hz: 2,2 dBNA; 16000 Hz: 1,7 dBNA; $18000 \mathrm{~Hz}$ : 6 dBNA e $20000 \mathrm{~Hz}$ : -0,7 dBNA. Os resultados mostraram que houve diferença entre sexo masculino e feminino, com tendência a limiares, em níveis de intensidade, mais baixos entre as pessoas do sexo feminino. 0 equipamento utilizado, neste estudo, foi o GSI 61 - Grason Stadler.

ARNOLD et al. (1999) estudaram a habilidade das freqüências primárias 2f1-f2 das EOAPD em detectar redução na função coclear em presença de limiares normais, na audiometria convencional. Realizaram um estudo prospectivo em adultos jovens com audição normal, utilizando um 
modelo de análise por regressão simples e complexa, para estudar a relação entre limiares tonais em altas freqüências e EOAPD em baixas freqüências. Os resultados revelaram correlação entre o nível de resposta da EOAPD, no intervalo de 4 a $8 \mathrm{kHz}$, com a média dos limiares tonais no intervalo de 11.2 a $20 \mathrm{kHz}$. Não foi observado contribuição dos limiares tonais convencionais na variação do nível de resposta das EOAPD. Concluíram que a audição, em altas freqüências, influencia as EOAPD em freqüências mais baixas, porque as emissões são sensíveis a mudanças sutis nas CCE que ainda não foram detectadas pelos limiares audiométricos nestas freqüências, ou porque alterações na parte basal coclear afetam a geração de EOAPD, em baixas freqüências, originadas de regiões mais apicais da cóclea.

CARVALLO (2002) verificou o efeito da sensibilidade auditiva, para as freqüências entre 9000 e $20000 \mathrm{~Hz}$, sobre as medidas de emissões otoacústicas analisadas quanto ao nível de resposta, em indivíduos com audição preservada entre 250 e $8000 \mathrm{~Hz}$. Foram determinados dois grupos dentro da casuística, com limiares abaixo e acima do percentil $90 \%$. Os resultados evidenciaram diferença entre os grupos, sendo que o grupo com menor sensibilidade para as altas freqüências mostrou respostas em EOAs de menor amplitude, com diferença estatística significante entre os grupos em $5 \mathrm{kHz}$, em EOAT, e, em $6284 \mathrm{~Hz}$, na pesquisa de EOAPD, sugerindo influência da porção basal coclear nas respostas geradas em região mais apical. A investigação da audição, por meio da pesquisa de limiares para altas freqüências, permite a identificação de discretas alterações na função auditiva associadas a respostas menos robustas nas emissões otoacústicas. 
KOWALSKA et al. (2002) estudaram o efeito da exposição de trabalhadores, que misturam solventes, sobre a orelha interna, através da análise das EOAPD e altas freqüências. Alguns achados clínicos e laboratoriais indicam que a manipulação de solventes industriais, quando misturados, podem afetar a orelha interna. Para isso, analisaram 61 trabalhadores expostos a essa manipulação de solventes e compararam a 40 sujeitos não expostos. Encontraram perda auditiva, nas altas freqüências, em $42 \%$ no grupo exposto, contra $5 \%$ no grupo controle e, também, redução do nível de reposta das EOAPD neste grupo exposto. Concluíram que, através destes exames, foi possível identificar que solventes são ototóxicos.

LI et al. (2003) analisaram a relação entre EOAPD, audiometria convencional para tom puro e as altas freqüências, para detecção precoce de alterações auditivas. Foram analisados os registros de 42 adultos jovens, com audição normal, formando o grupo controle, e 20 trabalhadores expostos a ruído. Os resultados indicaram que o grupo exposto ao ruído apresentou limiar com nível de intensidade mais elevado na freqüência de 6 kHz, nível de resposta nas EOAPD pior nas freqüências de 4 a $6 \mathrm{kHz}$, e, na alta freqüência, de 11,2, também com nível de intensidade mais elevado, quando comparados ao grupo controle. Concluíram que as EOAPD, juntamente com as altas freqüências, possuem um potencial complementar na detecção precoce de perdas auditivas induzidas por ruído. 


\subsection{Emissões Otoacústicas}

Em 1948, enquanto estudava a função coclear em um laboratório auditivo, Thomas Gold desenvolveu uma teoria sobre os mecanismos da orelha interna, sendo o primeiro a descrever a atividade e os processos não lineares da cóclea. (VINCK et al., 1996 e HALL e MUELLER, 1997).

David Kemp, em 1978, identificou esses processos descritos, inicialmente por GOLD, mostrando que a orelha era capaz de não só receber, mas também de produzir sons. Essa habilidade da cóclea ficou conhecida por "Emissões Otoacústicas” (EOA). COUBE (1998) e LOPES FILHO (1997) definem as EOAs como sendo sons produzidos na cóclea (especificamente, pelas células ciliadas externas do órgão espiral) e captados no meato acústico externo. Os movimentos das células ciliadas externas, tanto espontâneos, como em resposta a um estímulo, produzem energia mecânica dentro da cóclea. Essa energia é transmitida de forma reversa através da orelha média e da membrana timpânica, e então, é convertida em sinal acústico dentro do canal auditivo. As EOAs podem ser detectadas no canal auditivo externo através de um microfone sensível instalado numa sonda.

A medida de EOAs traz vantagens, já que se trata de um procedimento rápido, de fácil aplicação e objetivo, pois não depende da resposta do indivíduo.

KEMP et al. (1990) relatam que o valor principal das emissões otoacústicas é que sua presença indica que o mecanismo de recepção 
coclear pré-neural (assim como o mecanismo de recepção da orelha média) é capaz de responder ao som de forma adequada. EOAs são freqüênciaespecífica e freqüência seletiva e, desta forma, é possível obter informações sobre diferentes partes da cóclea, simultaneamente.

NORTON e STOVER (1994) definem as emissões otoacústicas como sons gerados pela cóclea normal, espontaneamente, ou em resposta à estimulação acústica, sendo estas: 1) emissões otoacústicas espontâneas ausência de estimulação externa; 2) emissões otoacústicas evocadas por estímulos transientes; 3) emissões otoacústicas por estímulo - freqüência; 4) emissões otoacústicas - produto de distorção - com estimulação externa.

1) Emissões Otoacústicas Espontâneas (EOAE): consiste de sinais de faixa estreita provenientes da cóclea, sendo o único tipo das emissões que ocorre sem que haja estimulação específica. Estão presentes, em mais ou menos, $40 \%$ dos indivíduos com audição normal, e por isso, não têm aplicações clínicas.

2) Emissões Otoacústicas Evocadas por Estímulos Transientes (EOAT): são obtidas a partir de estimulação auditiva por "click" (que é um sinal acústico transitório de curta duração, com faixa de freqüência bastante abrangente - de 0,5 a $4 \mathrm{kHz}$ ). Seu registro pode ocorrer em indivíduos com limiares auditivos de até 30 dBNA.

3) Emissões Otoacústicas por Estímulo - Frequência (EOAEF): são obtidas através da apresentação de um tom puro contínuo de baixa intensidade, de modo que ocorra a excitação coclear que produza uma resposta na 
mesma freqüência do estímulo. Podem ser encontradas em indivíduos com limiares auditivos de no máximo 20 dBNA. Devido à maior dificuldade em ser gravado, esse tipo de emissão é pouco usado clinicamente.

4) Emissões Otoacústicas - Produto de Distorção (EOAPD): são definidas como energia acústica no canal auditivo, originada da interação nãolinear de dois tons puros fornecidos simultaneamente, os quais atingem a cóclea (KEMP, 1978). Podem ser captadas em orelhas de indivíduos com limiares auditivos de até 50 dBNA.

A cóclea comporta-se como um amplificador não-linear. Assim, ao amplificar um estímulo acústico bitonal (com as freqüências f1 e f2), para que este seja enviado ao sistema nervoso central, produz sons com características diferentes do estímulo fornecido inicialmente. Estes sons produzidos pela cóclea são chamados de produtos distorcidos $(\mathbf{F})$.

O equipamento é programado para emitir dois tons, sendo um de freqüência mais baixa que $\mathbf{F}$ (denominado f1) e outro de freqüência mais alta (f2). Tipicamente, a razão fixa entre as freqüências f1 e f2 é de aproximadamente $1,2(\mathfrak{f} 1 / \mathrm{f} 2=1,2)$ e $\mathbf{F}$ é equivalente a $2 \mathfrak{f 1 - f 2 .}$

Segundo MOLINI et al. (1998), a principal vantagem deste método, quando comparado às emissões otoacústicas por estímulos transientes, é a especificidade de freqüência. SHERATA-DIELER (1999) complementa dizendo que as EOAPD abrangem uma faixa mais larga de freqüências, propiciando informações cocleares mais detalhadas. LONSBURY-MARTIN 
et al. (1991) observaram, ainda, que as EOAPD não são tão prejudicadas, quanto os demais tipos de EOAs, em relação às condições de condução sonora da cóclea e da orelha média.

KAWASHIMURA (1998) observou que há correlação entre a freqüência do estímulo na captação das EOAPD e os níveis de audição, podendo, portanto, usar as EOAPD como triagem auditiva ou como exame complementar. Entretanto, BONFILS \& AVAN (1992) enfatizam que as EOAPD não podem ser usadas como um teste audiométrico mais preciso, pois não foi encontrada correlação direta entre o nível de respostas das EOAPD e o limiar auditivo exato em cada freqüência.

Além disso, foi sugerido que as EOAPD são úteis no monitoramento de mudanças discretas auditivas, ainda não detectáveis na audiometria tonal que KURC (1999) exemplificou como danos da cóclea através de exposição ao ruído, ototóxicos (como furosemide e ácito etacrínico, aspirina e aminoglicosídeos), metabólicos (doença de Menière). SLIWINSKAKOWALSK e KOTYLO (1997) estudaram a possibilidade das EOAPD serem usadas como diagnóstico diferencial de perdas auditivas causadas por ruído ocupacional, e obtiveram como resposta uma queda nas EOAPD, nas freqüências de 3-4 KHz, não sendo observadas em perdas auditivas cocleares causadas por outros fatores além do ruído.

Mesmo informando uma função auditiva que não é avaliada por nenhum outro procedimento (comportamental ou eletrofisiológico), as emissões otoacústicas não podem substituir a audiometria tonal, imitância 
acústica, ou potenciais auditivos evocados de tronco encefálico, pois cada um desses exames tem um propósito diferente e, portanto, complementar em relação ao outro. (HALL \& MUELLER, 1997).

Além disso, VOHR et al. (1993), citaram que o número de emissões coletadas, o nível de estímulo, a reprodutibilidade, a estabilidade da sonda, o estado do paciente, as secreções no conduto auditivo externo e o tempo do teste são fatores que podem interferir no exame. São vários os fatores que podem regular o registro final das EOAs e, portanto, a presença das EOAs é extremamente significativa, mas sua ausência passa a ser significativa quando houver timpanometria normal e presença de reflexos estapediano.

Neste sentido, TOPOLSKA et al. (1998) avaliaram a influência da orelha média na detecção do nível de respostas das EOAPD em crianças com disfunção tubária (60\% não apresentaram respostas na freqüência de $500 \mathrm{~Hz}$ e 27\%, na freqüência de $750 \mathrm{~Hz}$ ) e em crianças com timpanometria com curva tipo B (plana), em que $75 \%$ das respostas destas orelhas esteve ausente em 500 e $750 \mathrm{~Hz}$ e $50 \%$ das orelhas em 1 a $8 \mathrm{kHz}$, sendo que LONSBURY-MARTIN et al. (1992) não observaram alterações no nível de respostas das EOAPD em variações, dentro da normalidade, de timpanometria e de reflexos acústicos. Mas observaram que foram encontradas amplitudes menores das EOAPD em condições de ressonâncias anormais, limares do reflexo acústico mais baixo ou rigidez de freqüência específica na cadeia ossicular. DOYLE et al. (2000) e AVAN et al. (2000) estudaram a influência da orelha externa e média na triagem auditiva 
em crianças e observaram uma relação direta entre alteração das EOAs e alteração das orelhas média e externa.

HARRIS (1990) estudou a relação entre o nível de respostas das EOAPD e os limiares auditivos, em 40 sujeitos do sexo masculino entre 18 e 40 anos. Vinte sujeitos apresentaram limiares auditivos abaixo de 15 dBNA, nas freqüências de 250 a $8000 \mathrm{~Hz}$, e ausência de histórico de exposição a ruídos intensos. Os demais 20 , expostos a ruídos intensos a longo tempo, apresentaram limiares menores que 15 dBNA, entre 250 e $1000 \mathrm{~Hz}$, e de 15 a 60 dBNA, em pelo menos duas freqüências acima de $1000 \mathrm{~Hz}$. A audiometria tonal foi realizada nas freqüências de 250 a $8000 \mathrm{~Hz}$ e as EOAPD foram registradas em oito pontos, com a relação f2/f1 $=1,21$. Os resultados demonstraram que os limiares auditivos estavam associados ao nível de respostas das EOAPD, uma vez que os dois grupos se diferenciaram no número e nível de respostas das EOAPD geradas na região das freqüências mais altas. Por outro lado, os grupos comportaram-se da mesma forma nas freqüências baixas, nas quais os limiares auditivos estavam normais. O autor concluiu que a redução do nível de respostas das EOAPD, ou a sua ausência, era indicativo de limiar auditivo maior que 15 dBNA, na ausência de alterações de orelha média. Porém, não foi possível esclarecer a relação das EOAPD e limiares entre 20 e 50 dBNA.

TAKAHASHI et al. (1996) estudaram o efeito da idade do sujeito nas EOAPD e encontraram que, em indivíduos mais velhos, os níveis de EOAPD são significativamente menores nas freqüências mais altas, mesmo que a 
audiometria aponte limiares dentro da normalidade, mostrando que o nível das EOAPD pode ser um indicador sensível para relatar a disfunção coclear ocorrida com a idade. O mesmo foi constatado por MOULIN et al. (1993) em relação às EOA Espontâneas.

COLLET et al. (1992) estudaram o efeito da idade, do sexo e da perda auditiva sobre as EOAs, em 140 sujeitos. Evidenciaram ausência de EOAs sempre que o melhor limiar audiométrico da orelha testada foi encontrado em um nível de intensidade acima de 40 dBNA, ou quando o limiar de recepção de fala foi determinado acima de 45 dBNA. Quando os sujeitos foram analisados por grupo de idade, sendo um grupo com idades abaixo de 53 anos, e o outro, acima de 53 anos, não encontraram diferença na ocorrência de EOAs. Também não encontraram diferença na comparação entre os sexos feminino e masculino.

STOVER et al. (1996) verificaram se existe um nível de estimulação capaz de separar, mais eficientemente, os indivíduos que apresentam audição normal dos que possuem alterações auditivas, e se este nível se mantém consistente por todas as freqüências pesquisadas. Por fim, analisaram a necessidade em realizar o teste em múltiplas intensidades para fins diagnósticos. Avaliaram, portanto, 210 sujeitos entre 7 e 86 anos, sendo 103 com perda auditiva e 107 com audição normal. Foi realizado o registro das EOAPD em nove freqüências distintas (f2), entre 500 e $8000 \mathrm{~Hz}$, sendo $F 2 / F 1=1,2$ e $L 1=L 2+10$. Em cada banda de freqüência, a intensidade de $L 1$ e L2 variou de 75/65 dBNPS a 20/10 dBNPS, em passos de $5 \mathrm{~dB}$, 
resultando, portanto, em 12 diferentes níveis. Os resultados demonstraram que a estimulação em forte intensidade não foi capaz de predizer as perdas de audição, sendo recomendada a utilização das intensidades médias 65/55 dBNPS para L1 e L2, respectivamente. A diferença de 10 dBNPS mantida durante o teste apresentou melhor nível de respostas para L2 = 55 dBNPS, em todas as freqüências. Não foram observados resultados mais eficazes nas intensidades acima e abaixo deste valor.

Em relação ao ruído ambiental, LEE e KIM (1999) relataram que, a partir de 50 dBNA, as freqüências de 700 a $1000 \mathrm{~Hz}$ das EOAPD são afetadas, mas, para a medição a partir das freqüências médias $(1,5-2 \mathrm{kHz})$, um ruído de até 55 dBNA é aceitável. Para a captação das EOAPD abaixo de $700 \mathrm{~Hz}$, mesmo um ruído abaixo de 40 dBNA pode afetar. Entretanto, na retestagem dessas freqüências, há possibilidade de serem captadas. Neste caso, o ambiente ideal teria no máximo 35/40 dBNA de ruído de fundo. Portanto, é aconselhável que as EOAPD sejam realizadas em uma cabine acústica (ou ambiente com tratamento acústico).

Para estabelecer uma distribuição cumulativa que defina os padrões específicos de nível de respostas e os limiares das EOAPD, GORGA et al. (1996) registraram as EOAPD em 210 sujeitos com e sem perda de audição, em nove diferentes freqüências, com razão de 1,2 em intensidades variando de 75 a 20 dBNPS, as quais, por sua vez, mantiveram diferença de $10 \mathrm{~dB}$ entre si. Os resultados demonstraram que a melhor intensidade para separar ouvidos normais daqueles que apresentam alteração sensório-neural foi de 65 
e 55 dBNPS para L1 e L2, respectivamente. Além disso, o nível de respostas das EOAPD reduziu de acordo com a diminuição da intensidade do estímulo.

GORGA et al. (1997), estudaram o nível de resposta das EOAPD em 1267 orelhas de 806 sujeitos, com idade variando de 1,3 a 96,5 anos. As EOAPD foram registradas com $\mathrm{f} 2 / \mathrm{f} 1$ igual a 1,22 a cada $1 / 2$ oitava, entre as freqüências de 750 a $8000 \mathrm{~Hz}$ para f2. A intensidade utilizada para as freqüências primárias foi de 65 e 55 dBNPS para L1 e L2, respectivamente. Obtiveram que as freqüências que apresentaram maiores níveis de respostas das EOAPD foram as médias e altas, principalmente de 4 - $6 \mathrm{KHz}$, (um pouco mais baixa em $8 \mathrm{KHz}$ ), e nível de repostas muito baixos nas freqüências abaixo de 1,5 KHz; e concluíram que a transmissão de energia é mais eficiente em freqüências médias e altas, comparadas às freqüências baixas.

COUBE (2000) avaliou as EOAPD de pacientes portadores de perda auditiva sensório-neural, para estabelecer o nível de respostas das EOAPD e sua relação com a extensão da perda. As EOAPD foram registradas entre 1 e $6 \mathrm{kHz}$, a cada três pontos/ oitava de freqüência, sendo F2/F1 =1,22, e a intensidade utilizada de 70 dBNPS para L1 e L2. Foram consideradas presentes apenas as respostas $\geq 3$ dBNPS acima do ruído de fundo. Os resultados demonstraram que a mediana das EOAPD dos sujeitos com audição normal foi maior do que aquela apresentada pelos sujeitos com perda auditiva, uma vez que o nível de respostas diminuiu de acordo com o aumento dos limiares. 
3. Métodos 


\subsection{Casuística}

Foram analisados os registros dos limiares tonais em altas freqüências $(9-20 \mathrm{kHz})$ e EOAPD em 60 indivíduos da raça branca (120 orelhas), com idade entre 8 e 68 anos, 14 homens e 46 mulheres, sem história de alteração de orelha média, formando dois grupos:

- Grupo com desordem pigmentar do tipo vitiligo - composto por 30 indivíduos portadores da desordem pigmentar do tipo vitiligo, cujos sintomas tenham tido início há mais de 5 anos, sendo 5 do sexo masculino e 25 do sexo feminino, com idades entre 8 e 65 anos;

- Grupo Controle - composto por 30 indivíduos não portadores de vitiligo, com idades pareadas ao grupo experimental e audição normal, confirmada pela audiometria tonal e imitanciometria, sendo 9 do sexo masculino e 21 do sexo feminino, com idades entre 8 e 68 anos;

O tamanho da amostra foi elaborado com base em trabalhos semelhantes envolvendo o estudo de audição em portadores de vitiligo. 
$\mathrm{Na}$ Tabela 1, são apresentados os resultados na análise descritiva da variável idade para cada grupo: média, mediana, desvio padrão, mínimo, máximo, limite inferior e limite superior.

Tabela 1. Análise descritiva da variável idade para cada grupo

\begin{tabular}{lcc}
\hline \multicolumn{1}{c}{ Idade } & Controle & Vitiligo \\
\hline Média & 34,87 & 33,90 \\
Mediana & 31,50 & 31,00 \\
Desvio Padrão & 15,77 & 15,56 \\
Mínimo & 8 & 8 \\
Máximo & 68 & 65 \\
Tamanho & 30 & 30 \\
\hline
\end{tabular}

Os critérios de inclusão dos indivíduos para a seleção dos grupos envolveram ausência de fatores responsáveis por hipoacusia sensorioneural: exposição a ruído elevado; drogas ototóxicas; condições patológicas, metabólica e vascular; otite média recorrente; trauma craniano e história familiar de deficiência auditiva.

Para a garantia de que a influência da idade elevada não interferisse nos resultados, foi realizada uma segunda amostragem, da qual foram excluídos os sujeitos com idade acima de 60 anos. A análise comparativa entre as amostras não mostrou diferenças (ANEXO). Desta forma, foi possível manter a amostra inicial de 60 indivíduos. 
Os sujeitos da pesquisa foram todos voluntários, selecionados dentro da rotina de atendimento do Serviço de Audiologia Clínica do Centro de Docência e Pesquisa em Fonoaudiologia - FMUSP e no Ambulatório de Dermatologia do Hospital das Clínicas, da FMUSP. Uma vez tendo concordado em participar do estudo, assinaram o Termo de Consentimento Livre e Esclarecido, aprovado pela Comissão de Ética e Pesquisa do HCFMUSP. A pesquisa foi submetida à análise e aprovada pela comissão de Ética para Análise de Projetos de Pesquisa CAPPESq HC - FMUSP № 646/01, e aprovado pelo Conselho do Departamento de Dermatologia do HC- FMUSP, constante no Apêndice.

\subsection{Equipamento}

- Analisador de Orelha Média GSI 33 - Grason Stadler Versão 2 microprocessado e provido de três freqüências de tom na sonda de imitância: $226 \mathrm{~Hz}, 678 \mathrm{~Hz}$ e $1000 \mathrm{~Hz}$. O equipamento realiza as medidas timpanométricas de forma automática, na velocidade de 50 decapascals por segundo $(\mathrm{daPa} / \mathrm{s})$, sendo os resultados registrados em gráfico pela impressora acoplada ao sistema. Este analisador de orelha média foi calibrado para as condições de altitude da cidade de São Paulo, tomando os cuidados necessários na instalação elétrica, de modo a atender às especificações técnicas do fabricante. O equipamento está de acordo com o seguinte padrão: ANSI S3, 39 - 1987. 
- Audiômetro GSI 61 - Grason Stadler - O equipamento permite a realização de audiogramas nas freqüências de 250 a $20000 \mathrm{~Hz}$, estando de acordo com os seguintes padrões: ANSI S3,6 - 1989; ANSI S3,43 1992; IEC 645-2 (1993); ISO 389; UL 544. Para audiometria convencional (250 a $8000 \mathrm{~Hz}$ ) foram utilizados fones Telephonics TDH 50P, com impedância de 80 ohms e, para as altas freqüências (9000 a $20000 \mathrm{~Hz}$ ), os fones Sennheiser HDA-200 com impedância de 40 ohms.

- Analisador de Emissões Cocleares ILO 92 - Otodynamics, London, para a realização da pesquisa de Emissões Otoacústicas por Produto de Distorção.

\subsection{Procedimento}

Os sujeitos foram submetidos à:

- Anamnese inicial para identificação dos critérios de inclusão.

- inspeção do meato acústico externo para identificação de presença de rolha de cera ou de outras alterações que impossibilitem a realização das provas.

- timpanometria na modalidade de Admitância Compensada na altura da Membrana Timpânica (Ymt), com freqüência de sonda de $226 \mathrm{~Hz}$; pesquisa de reflexos acústicos ipsilaterais e contralaterais, 
com estímulos de $500 \mathrm{~Hz}, 1000 \mathrm{~Hz}, 2000 \mathrm{~Hz}, 4000 \mathrm{~Hz}$, e ruído de Faixa Larga (Broad Band Noise).

A realização da Imitância Acústica (timpanometria e pesquisa de reflexos acústicos) faz-se necessária para serem eliminados os casos de comprometimento de orelha média, os quais não serão aceitos neste estudo.

- audiometria tonal, de 250 a $8000 \mathrm{~Hz}$, com os fones TDH 50P; audiometria de altas freqüências, de 9000 a $20000 \mathrm{~Hz}$, com os fones HDA - 200, realizadas em cabine acústica.

Foram aceitos limiares tonais (250 a $8000 \mathrm{~Hz}$ ) em níveis de intensidade não superiores a 25 dBNA para os indivíduos do grupos controle, na faixa de 250 a $4000 \mathrm{~Hz}$.

- Emissões Otoacústicas por Produto de Distorção, realizadas com o sujeito em cabine acústica, após a inserção, no meato acústico externo, de oliva adaptada à sonda do equipamento. Foram apresentadas freqüências primárias pareadas em uma relação tal que $\mathrm{f} 1 / \mathrm{f} 2=1,2$, tendo sido mantida a intensidade de 65 dBNPS para f1 e 55 dBNPS para $\mathrm{f} 2(\mathrm{~N} 1-\mathrm{Nf} 2=10$, onde $\mathrm{N}=$ intensidade em dBNPS). Foram consideradas positivas as respostas com relação Sinal/Ruído $\geq 3$ dBNPS, em relação ao segundo desvio padrão do ruído de fundo, nas freqüências de f2 de 1001, 1257, 1587, 2002, 2515, 3174, 4004, 5042 e $6348 \mathrm{~Hz}$. As EOAPD foram captadas em ambas as orelhas de cada indivíduo. Neste estudo, 
foram analisadas os níveis de respostas das EOAPD em dBNPS e relação Sinal/Ruído, para cada freqüência, considerando o critério de: presença - respostas em sete, oito ou nove freqüências; presença parcial - respostas em quatro, cinco ou seis freqüências, e ausência - respostas em zero, uma, duas ou três freqüências.

Todos os procedimentos foram aplicados em ambas as orelhas de cada indivíduo, em uma única sessão, com duração estimada de 40 minutos.

\subsection{Método Estatístico}

As variáveis: limiares tonais; limiares em altas freqüências; níveis de respostas; e relação Sinal/Ruído das EOAPD; foram submetidas à análise descritiva, através das medidas de tendência central, e à análise inferencial, por meio de testes de comparação entre grupos.

Para este trabalho, foi utilizada a Análise de variância (ANOVA), uma técnica paramétrica que faz uma comparação de médias utilizando a variância.

Também foi utilizada a análise estatística denominada CoRRELAÇÃo DE Pearson. Essa técnica serve para mensurar o quanto as variáveis estão interligadas, ou seja, o quanto uma variável está relacionada a uma outra. Os resultados são dados em percentual. Convém ressaltar que os valores podem ser positivos e negativos. Quando a correlação for positiva, significa que à 
medida que uma variável aumenta seu valor, a outra variável, correlacionada a esta, também aumenta proporcionalmente. Porém, se a correlação for negativa, implica que as variáveis são inversamente proporcionais, ou seja, à medida que uma cresce, a outra decresce, ou vice versa. Para este estudo, por termos muitas variáveis, o resultado da correlação foi posto em forma de matriz, formando a chamada Matriz de Correlação.

Por fim, foi utilizada uma medida descritiva, a qual serve para mensurar com maior precisão a situação da amostra. Essa técnica é chamada de INTERVALO DE CONFIANÇA, e mostra o quanto a média pode variar numa determinada probabilidade de confiança.

Para todos os testes foi adotado o nível de significância de 5\%. 
4. Resultados 
Este capítulo apresenta os resultados referentes aos limiares tonais na audiometria convencional, nas altas freqüências e emissões otoacústicas -produto de distorção em sujeitos sem queixa auditiva, compondo os grupos com e sem diagnóstico de desordem pigmentar do tipo vitiligo.

Para facilitar a apresentação dos dados, o capítulo foi dividido nas seguintes partes:

4.1. Limiares tonais nas freqüências de $250 \mathrm{a} 8000 \mathrm{~Hz}$

4.2. Limiares tonais nas freqüências de 9000 a $20000 \mathrm{~Hz}$

4.3. Nível de respostas das emissões otoacústicas - produto de distorção

4.4. Nível de relação sinal / ruído das emissões otoacústicas - produto de distorção

4.5. Correlação entre limiares em altas freqüências e emissões otoacústicas - produto de distorção 


\subsection{LIMIARES TONAIS NAS FREQUÊNCIAS DE 250 A $8000 \mathrm{~Hz}$}

Inicialmente foi feito uma análise da quantidade de orelhas que apresentaram limiar audiométrico menor ou maior que 25 dBNA em pelo menos uma das freqüências de 250 a $8000 \mathrm{~Hz}$ para ambos os grupos controle e com vitiligo, que é representada pela Tabela 2

O efeito de orelha nos limiares tonais foi estudado para ambos os grupos por meio de Análise de Variância ANOVA.

A Tabela 3 representa a análise comparativa entre as orelhas para 0 grupo controle e a Tabela 4 a análise do grupo com presença de vitiligo. As Figuras 1 e 2 ilustram estas análises respectivamente. 
Tabela 2. Número de orelhas com limiares menor/ maior que 25 dBNA nos grupos controle e com vitiligo

\begin{tabular}{|c|c|c|}
\hline Número de orelhas & $\begin{array}{l}\text { Limiar menor } \\
\text { que 25 dBNA }\end{array}$ & $\begin{array}{c}\text { Limiar maior } \\
\text { que 25 dBNA }\end{array}$ \\
\hline Grupo Controle & 56 & 4 \\
\hline Grupo Vitiligo & 46 & 14 \\
\hline
\end{tabular}

Tabela 3. Comparação dos limiares tonais em dBNA para as freqüências de 250 a $8000 \mathrm{~Hz}$ nas orelhas direita e esquerda no grupo controle

\begin{tabular}{|c|c|c|c|c|c|}
\hline \multicolumn{2}{|c|}{ Limiares Tonais } & Média & $\begin{array}{l}\text { Desvio } \\
\text { Padrão }\end{array}$ & Tamanho & p-valor \\
\hline \multirow{2}{*}{$0,25 \mathrm{kHz}$} & OD & 7,33 & 4,87 & 30 & \multirow{2}{*}{0,177} \\
\hline & OE & 9,67 & 7,98 & 30 & \\
\hline \multirow{2}{*}{$0,5 \mathrm{kHz}$} & OD & 6,83 & 4,25 & 30 & \multirow{2}{*}{0,394} \\
\hline & OE & 8,00 & 6,10 & 30 & \\
\hline \multirow{2}{*}{$1 \mathrm{kHz}$} & OD & 6,33 & 6,15 & 30 & \multirow{2}{*}{0,409} \\
\hline & OE & 7,83 & 7,73 & 30 & \\
\hline \multirow{2}{*}{$2 \mathrm{kHz}$} & OD & 5,17 & 8,04 & 30 & \multirow{2}{*}{0,613} \\
\hline & OE & 6,17 & 7,15 & 30 & \\
\hline \multirow{2}{*}{$3 \mathrm{kHz}$} & OD & 6,83 & 8,56 & 30 & \multirow{2}{*}{0,697} \\
\hline & OE & 6,00 & 7,92 & 30 & \\
\hline \multirow{2}{*}{$4 \mathrm{kHz}$} & OD & 7,67 & 9,63 & 30 & \multirow{2}{*}{0,835} \\
\hline & OE & 8,17 & 8,86 & 30 & \\
\hline \multirow{2}{*}{$6 \mathrm{kHz}$} & OD & 11,67 & 11,40 & 30 & \multirow{2}{*}{0,862} \\
\hline & OE & 12,17 & 10,80 & 30 & \\
\hline \multirow{2}{*}{$8 \mathrm{kHz}$} & OD & 10,50 & 9,13 & 30 & \multirow{2}{*}{0,627} \\
\hline & OE & 9,33 & 9,35 & 30 & \\
\hline
\end{tabular}


Nos limiares tonais de 250 a $8000 \mathrm{~Hz}$, não foi encontrada nenhuma diferença média entre as orelhas que fosse estatisticamente significativa.

Assim, verificamos que no grupo controle, o efeito orelha não é significante, ou seja, pode ser desprezado.

\section{dBNA}

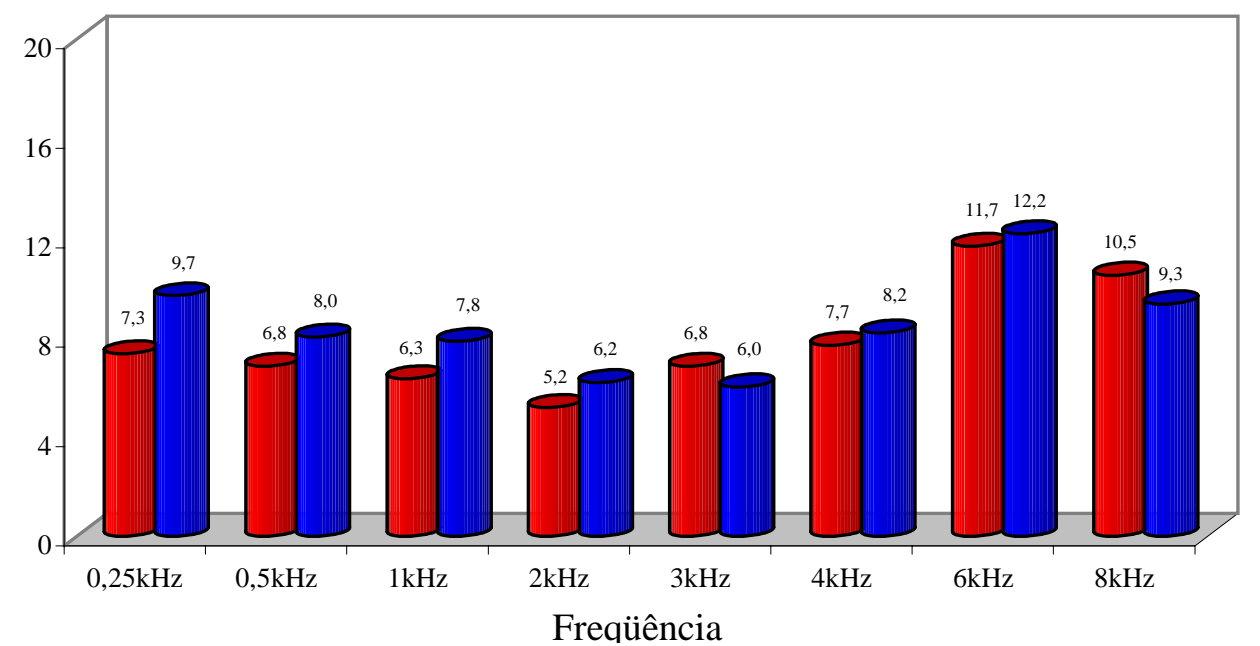

$\square$ Orelha Direita

口Orelha Esquerda

Figura 1. Média dos limiares tonais de 250 a 8000 hz do grupo controle para a orelha direita e orelha esquerda.

Após a análise para o grupo controle, foi analisado o grupo com vitiligo. 
Tabela 4. Comparação dos limiares tonais de 250 a $8000 \mathrm{~Hz}$ na orelha direita e orelha esquerda para o grupo com vitiligo

\begin{tabular}{|c|c|c|c|c|c|}
\hline \multicolumn{2}{|c|}{ Áudio Normal } & Média & $\begin{array}{l}\text { Desvio } \\
\text { Padrão }\end{array}$ & Tamanho & p-valor \\
\hline \multirow{2}{*}{$0,25 \mathrm{kHz}$} & OD & 9,67 & 7,18 & 30 & \multirow{2}{*}{0,862} \\
\hline & OE & 9,33 & 7,63 & 30 & \\
\hline \multirow{2}{*}{$0,5 \mathrm{kHz}$} & OD & 8,83 & 6,65 & 30 & \multirow{2}{*}{1,000} \\
\hline & OE & 8,83 & 8,78 & 30 & \\
\hline \multirow{2}{*}{$1 \mathrm{kHz}$} & OD & 7,00 & 5,96 & 30 & \multirow{2}{*}{0,778} \\
\hline & OE & 7,50 & 7,63 & 30 & \\
\hline \multirow{2}{*}{$2 \mathrm{kHz}$} & OD & 6,33 & 8,80 & 30 & \multirow{2}{*}{0,495} \\
\hline & OE & 8,00 & 9,97 & 30 & \\
\hline \multirow{2}{*}{$3 \mathrm{kHz}$} & OD & 7,17 & 7,95 & 30 & \multirow{2}{*}{0,502} \\
\hline & OE & 8,67 & 9,19 & 30 & \\
\hline \multirow{2}{*}{$4 \mathrm{kHz}$} & OD & 9,00 & 10,37 & 30 & \multirow{2}{*}{0,351} \\
\hline & $\mathrm{OE}$ & 11,67 & 11,55 & 30 & \\
\hline \multirow{2}{*}{$6 \mathrm{kHz}$} & OD & 14,17 & 14,02 & 30 & \multirow{2}{*}{1,000} \\
\hline & OE & 14,17 & 13,27 & 30 & \\
\hline \multirow{2}{*}{$8 \mathrm{kHz}$} & OD & 13,83 & 13,69 & 30 & \multirow{2}{*}{0,756} \\
\hline & OE & 12,67 & 15,18 & 30 & \\
\hline
\end{tabular}


Assim, é possível concluir que em nenhuma das freqüências da audiometria convencional de 250 a $8000 \mathrm{~Hz}$ existe uma diferença média significativa entre as orelhas para o grupo com vitiligo. A Figura 2 ilustra este achado.

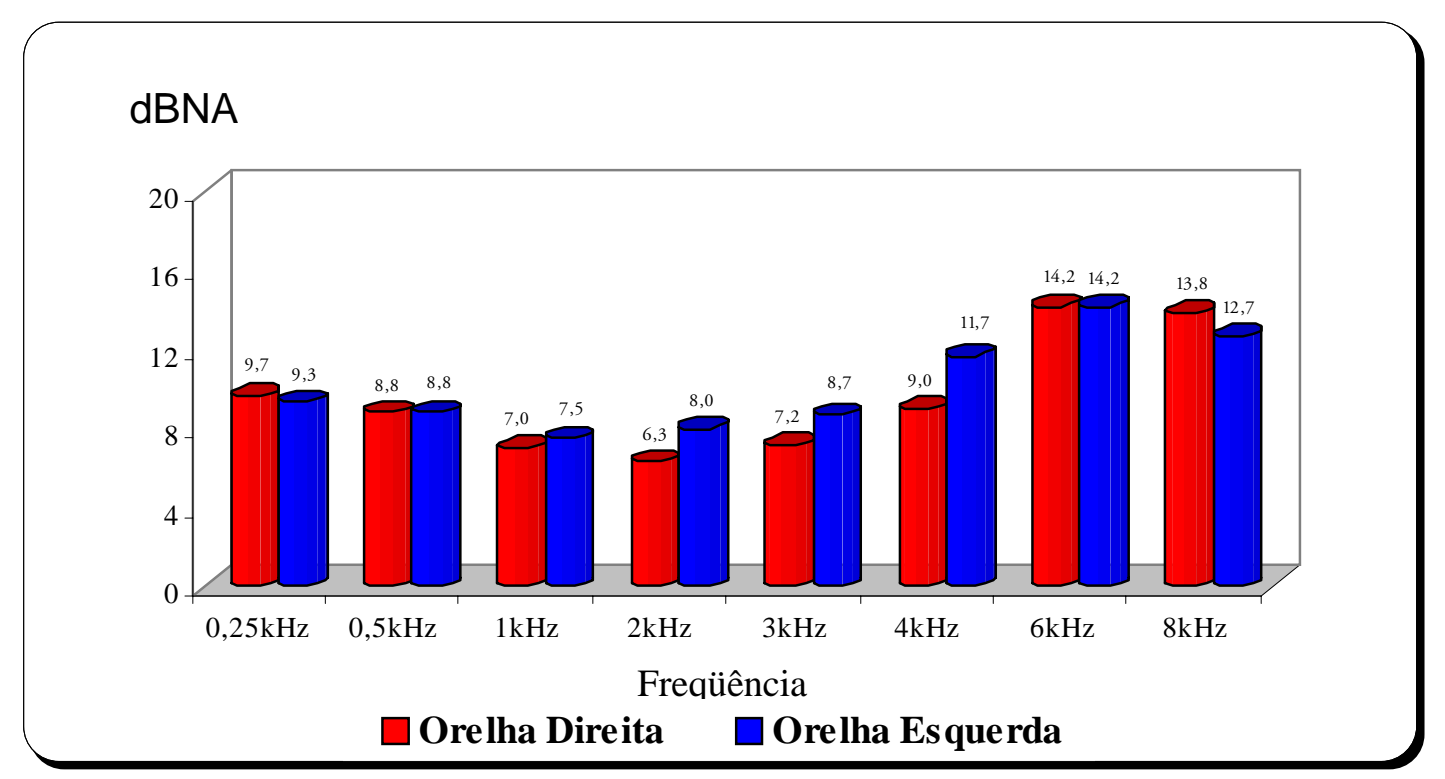

Figura 2. Distribuição das médias dos limiares tonais de 250 a $8000 \mathrm{~Hz}$ do grupo com vitiligo para a orelha direita e orelha esquerda.

Por meio dos dados apresentados, é possível concluir que também para o grupo com vitiligo não existe efeito de orelhas. Assim, como em ambos os grupos não foi encontrada diferença entre as orelhas, foi desconsiderado esse efeito e ambas as orelhas foram analisadas conjuntamente. Desta maneira foi obtida uma maior amostragem e conseqüentemente uma maior fidedignidade dos resultados que esta representada pela Tabela 5, sendo esta a análise descritiva dos limiares tonais nas freqüências de 250 a $8000 \mathrm{~Hz}$ dos grupos com e sem diagnóstico de desordem pigmentar do tipo vitiligo, sendo ilustrada pela Figura 3 e Figura 4. 
Tabela 5. Análise descritiva dos limiares tonais em dBNA nas freqüências de 250 a $8000 \mathrm{~Hz}$ do grupo controle e com vitiligo

\begin{tabular}{|c|c|c|c|c|c|c|c|c|c|}
\hline \multicolumn{2}{|c|}{ Áudio Normal } & \multirow{2}{*}{$\begin{array}{c}\text { Média } \\
8,50\end{array}$} & \multirow{2}{*}{$\begin{array}{c}\text { Mediana } \\
7,50\end{array}$} & \multirow{2}{*}{$\begin{array}{c}\begin{array}{c}\text { Desvio } \\
\text { Padrão }\end{array} \\
6,66\end{array}$} & \multirow{2}{*}{$\begin{array}{c}\text { Mínimo } \\
0\end{array}$} & \multirow{2}{*}{$\begin{array}{c}\text { Máximo } \\
6,82\end{array}$} & \multirow{2}{*}{$\begin{array}{c}\begin{array}{c}\text { Limite } \\
\text { Inferior }\end{array} \\
6,82\end{array}$} & \multirow{2}{*}{$\begin{array}{c}\begin{array}{c}\text { Limite } \\
\text { Superior }\end{array} \\
10,18\end{array}$} & \multirow{2}{*}{$\begin{array}{c}\begin{array}{c}\text { p- } \\
\text { valor }\end{array} \\
0,436\end{array}$} \\
\hline & Controle & & & & & & & & \\
\hline & Vitiligo & 9,50 & 10,00 & 7,35 & 0 & 7,64 & 7,64 & 11,36 & \\
\hline \multirow{2}{*}{$0,5 \mathrm{kHz}$} & Controle & 7,42 & 5,00 & 5,25 & 0 & 6,09 & 6,09 & 8,74 & 0,242 \\
\hline & Vitiligo & 8,83 & 5,00 & 7,72 & 0 & 6,88 & 6,88 & 10,79 & \\
\hline \multirow{2}{*}{$1 \mathrm{kHz}$} & Controle & 7,08 & 5,00 & 6,97 & 0 & 5,32 & 5,32 & 8,85 & 0,895 \\
\hline & Vitiligo & 7,25 & 5,00 & 6,79 & 0 & 5,53 & 5,53 & 8,97 & \\
\hline \multirow{2}{*}{$2 \mathrm{kHz}$} & Controle & 5,67 & 5,00 & 7,56 & 0 & 3,75 & 3,75 & 7,58 & 0,336 \\
\hline & Vitiligo & 7,17 & 5,00 & 9,36 & 0 & 4,80 & 4,80 & 9,53 & \\
\hline \multirow{2}{*}{$3 \mathrm{kHz}$} & Controle & 6,42 & 5,00 & 8,19 & 0 & 4,35 & 4,35 & 8,49 & 0,328 \\
\hline & Vitiligo & 7,92 & 5,00 & 8,55 & 0 & 5,75 & 5,75 & 10,08 & \\
\hline \multirow{2}{*}{$4 \mathrm{kHz}$} & Controle & 7,92 & 5,00 & 9,17 & 0 & 5,60 & 5,60 & 10,24 & 0,193 \\
\hline & Vitiligo & 10,33 & 10,00 & 10,96 & 0 & 7,56 & 7,56 & 13,11 & \\
\hline \multirow{2}{*}{$6 \mathrm{kHz}$} & Controle & 11,92 & 10,00 & 11,01 & 0 & 9,13 & 9,13 & 14,70 & 0,321 \\
\hline & Vitiligo & 14,17 & 10,00 & 13,53 & 0 & 10,74 & 10,74 & 17,59 & \\
\hline \multirow{2}{*}{$8 \mathrm{kHz}$} & Controle & 9,92 & 10,00 & 9,18 & 0 & 7,59 & 7,59 & 12,24 & 0,132 \\
\hline & Vitiligo & 13,25 & 10,00 & 14,35 & 0 & 9,62 & 9,62 & 16,88 & \\
\hline
\end{tabular}




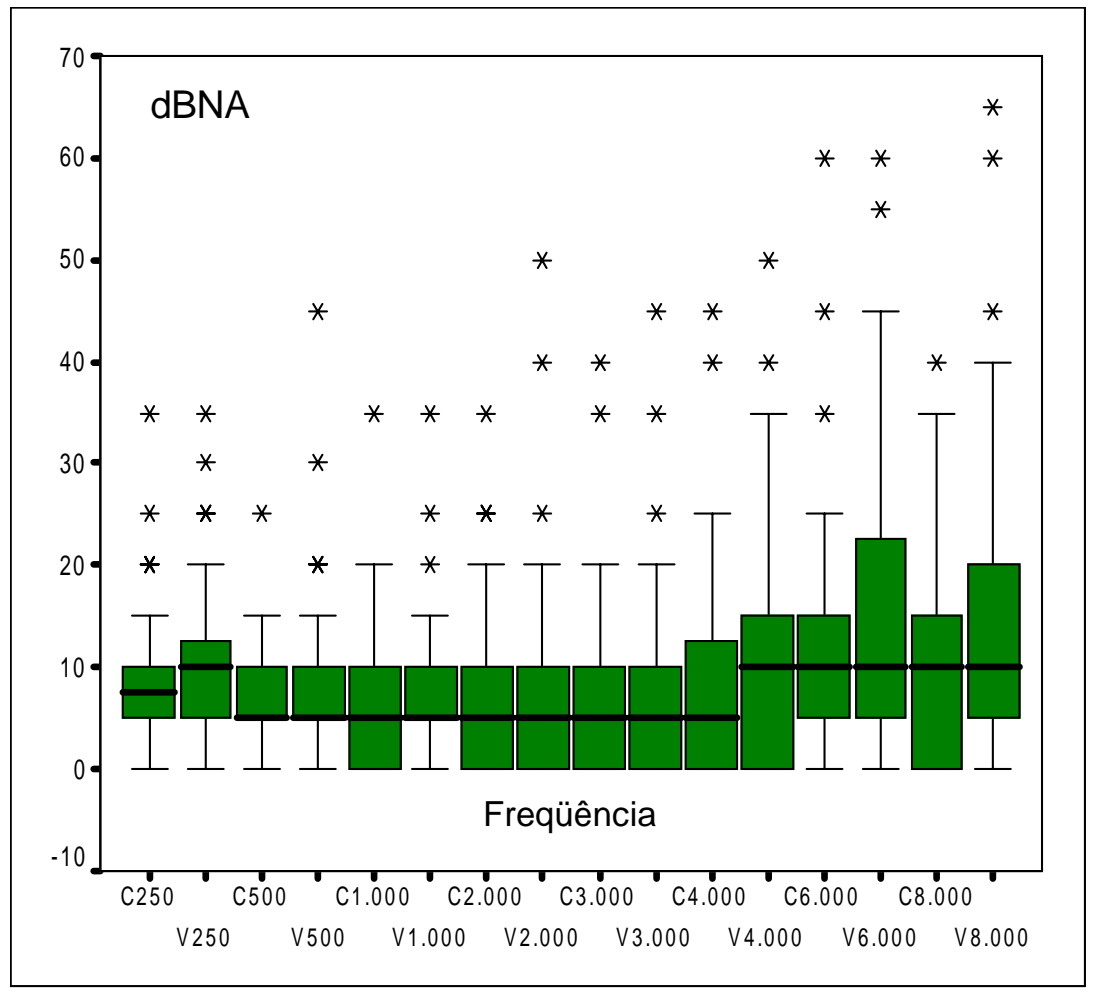

Figura 3. Box Plot dos limiares tonais de 250 a $8000 \mathrm{~Hz}$ para os grupos controle (c) e vitiligo (v).

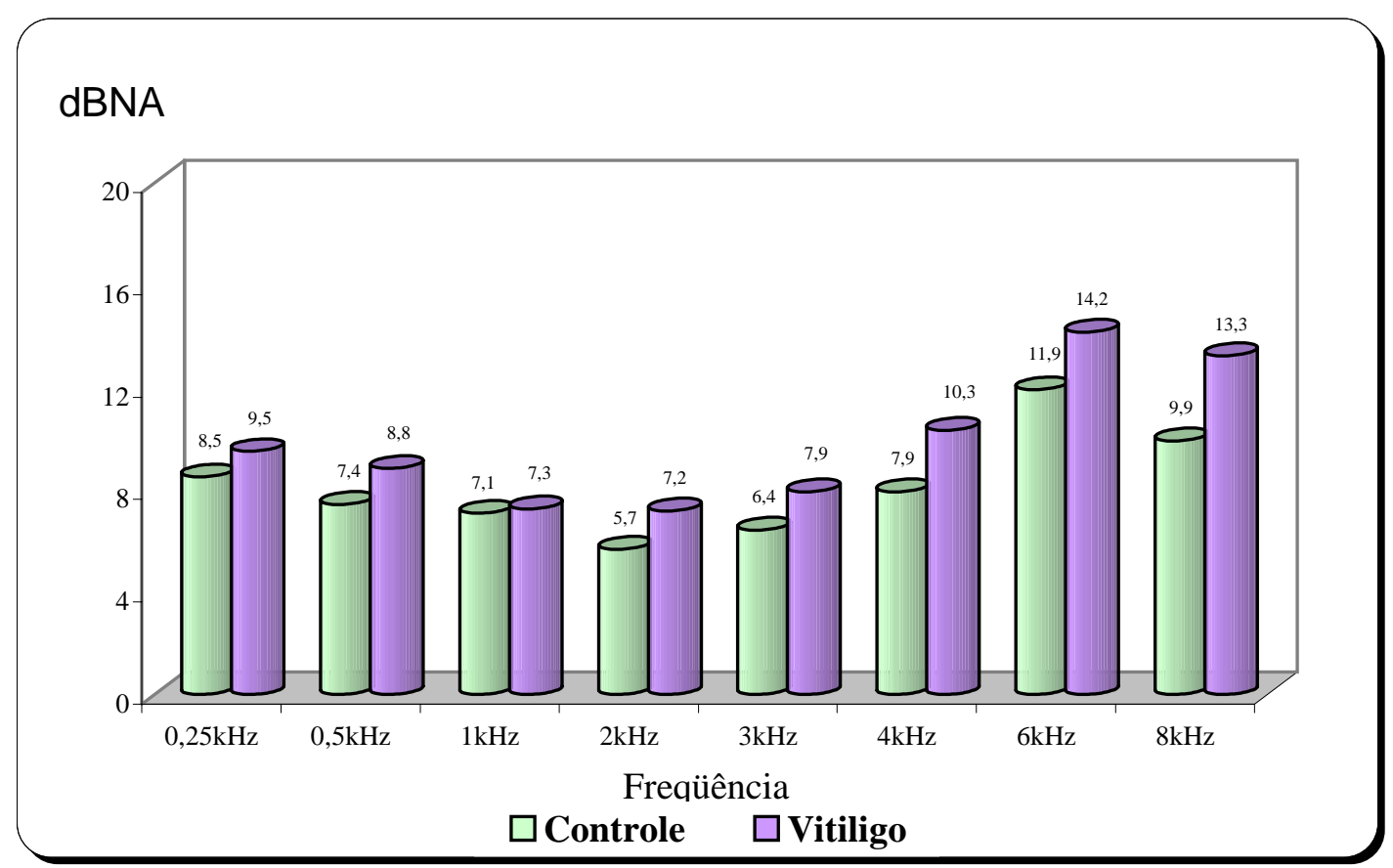

Figura 4. Diferença das médias dos limiares tonais nas freqüências de 250 a 8000 hz dos grupos controle e com vitiligo 
Pode ser observado que os limiares obtidos na análise das freqüências de 250 a $8000 \mathrm{~Hz}$, os grupos controle e com vitiligo não apresentaram diferença estatisticamente significante em nenhuma das freqüências analisadas, ou seja, no uso da audiometria convencional não houve diferença entre ambos grupos.

\subsection{LIMIARES TONAIS NAS FREQÜÊNCIAS DE 9000 A 20000 Hz}

A partir deste item, será iniciado o foco de interesse deste estudo. Primeiramente foi feita a análise dos limiares tonais nas freqüências de 9000 a $20000 \mathrm{~Hz}$ dos pacientes do grupo controle, seguido da análise do grupo com desordem pigmentar do tipo vitiligo.

Na Tabela 6 são apresentadas as análises comparativas entre as orelhas para o grupo controle e a Tabela 7 a mesma análise para o grupo com vitiligo. As comparações foram ilustradas pela Figura 5 e Figura 6. 
Tabela 6. Comparação dos limiares em altas freqüências de 9000 a 20000 $\mathrm{Hz}$ na orelha direita e orelha esquerda para o grupo controle

\begin{tabular}{|c|c|c|c|c|c|}
\hline \multicolumn{2}{|c|}{ Altas Freqüências } & Média & $\begin{array}{l}\text { Desvio } \\
\text { Padrão }\end{array}$ & Tamanho & p-valor \\
\hline \multirow{2}{*}{$9 \mathrm{kHz}$} & OD & 16,00 & 10,86 & 30 & \multirow{2}{*}{0,444} \\
\hline & OE & 14,17 & 7,20 & 30 & \\
\hline \multirow{2}{*}{$10 \mathrm{kHz}$} & OD & 15,50 & 15,72 & 30 & \multirow{2}{*}{1,000} \\
\hline & OE & 15,50 & 11,47 & 30 & \\
\hline \multirow{2}{*}{$12,5 \mathrm{kHz}$} & OD & 14,50 & 14,88 & 30 & \multirow{2}{*}{0,932} \\
\hline & OE & 14,83 & 15,06 & 30 & \\
\hline \multirow{2}{*}{$14 \mathrm{kHz}$} & OD & 13,50 & 20,73 & 30 & \multirow{2}{*}{0,924} \\
\hline & OE & 13,00 & 19,81 & 30 & \\
\hline \multirow{2}{*}{$16 \mathrm{kHz}$} & OD & 11,00 & 24,93 & 30 & \multirow{2}{*}{0,635} \\
\hline & OE & 14,00 & 23,72 & 30 & \\
\hline \multirow{2}{*}{$18 \mathrm{kHz}$} & OD & 11,17 & 19,77 & 30 & \multirow{2}{*}{1,000} \\
\hline & OE & 11,17 & 17,60 & 30 & \\
\hline \multirow{2}{*}{$20 \mathrm{kHz}$} & OD & 2,50 & 9,98 & 30 & \multirow{2}{*}{0,742} \\
\hline & OE & 1,67 & 9,50 & 30 & \\
\hline
\end{tabular}


Na média dos limiares de altas freqüências de 9000 a 20000 Hz não foi encontrada diferença média estatisticamente significante entre as orelhas no grupo controle, podendo ser eliminado o efeito de orelha para a comparação entre grupos.

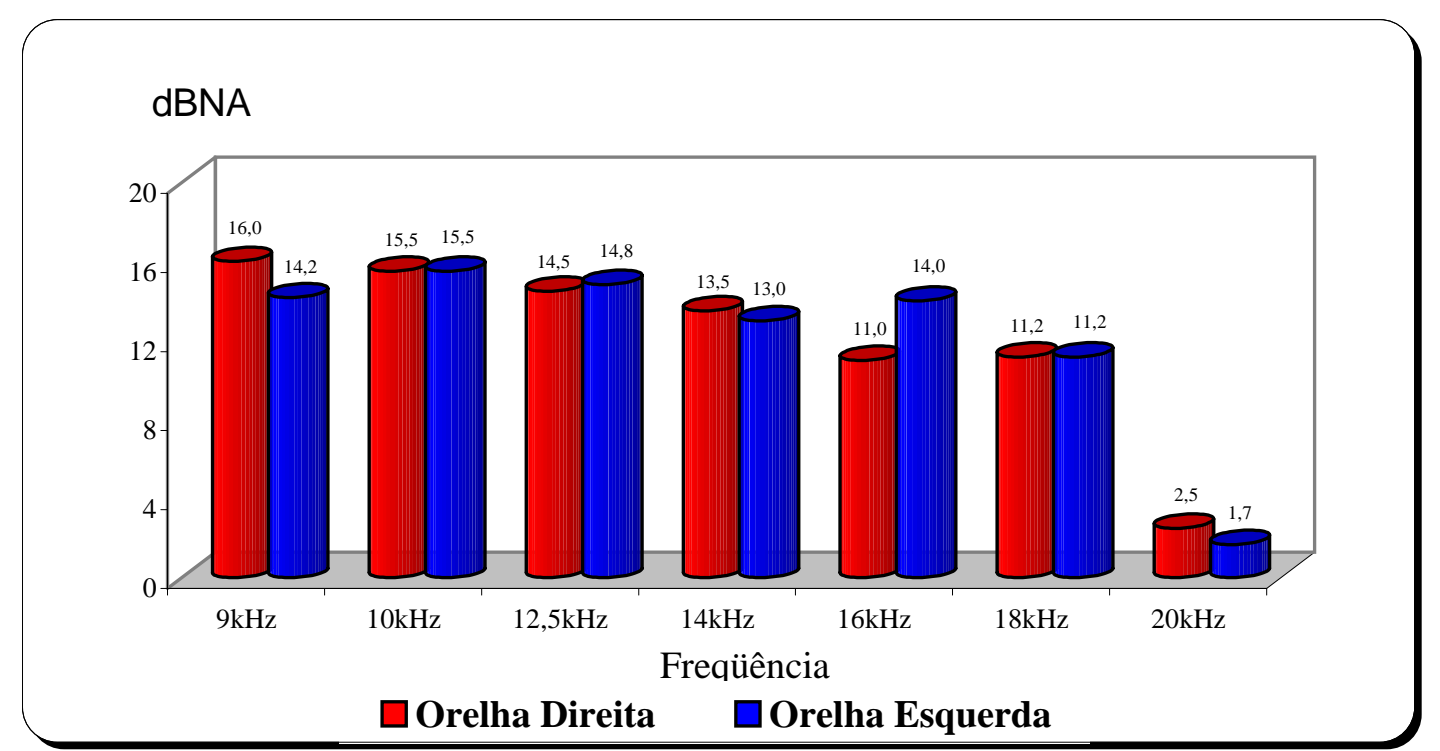

Figura 5. Média dos limiares de altas freqüências de 9000 a $20000 \mathrm{~Hz}$ do grupo controle para a orelha direita e orelha esquerda.

A próxima análise será realizada com o grupo com vitiligo. 
$\mathrm{Na}$ Tabela 7 serão apresentados os resultados obtidos na comparação da orelha direita e orelha esquerda do grupo com vitiligo.

Tabela 7. Comparação dos limiares de altas freqüências de 9000 a 20000 $\mathrm{Hz}$ para o grupo com vitiligo

\begin{tabular}{|c|c|c|c|c|c|}
\hline \multicolumn{2}{|c|}{ Altas Freqüências } & \multirow{2}{*}{$\begin{array}{l}\text { Média } \\
27,50\end{array}$} & \multirow{2}{*}{$\begin{array}{c}\text { Desvio } \\
\text { Padrão }\end{array}$} & \multirow{2}{*}{$\begin{array}{c}\text { Tamanho } \\
30\end{array}$} & \multirow{3}{*}{$\begin{array}{c}\text { p-valor } \\
1,000\end{array}$} \\
\hline \multirow{2}{*}{$9 \mathrm{kHz}$} & OD & & & & \\
\hline & OE & 27,50 & 22,04 & 30 & \\
\hline \multirow{2}{*}{$10 \mathrm{kHz}$} & OD & 26,83 & 20,19 & 30 & \multirow{2}{*}{0,901} \\
\hline & OE & 27,50 & 21,04 & 30 & \\
\hline \multirow{2}{*}{$12,5 \mathrm{kHz}$} & OD & 33,50 & 24,22 & 30 & \multirow{2}{*}{0,894} \\
\hline & $\mathrm{OE}$ & 34,33 & 24,10 & 30 & \\
\hline \multirow{2}{*}{$14 \mathrm{kHz}$} & OD & 37,83 & 24,16 & 30 & \multirow{2}{*}{0,896} \\
\hline & OE & 38,67 & 23,99 & 30 & \\
\hline \multirow{2}{*}{$16 \mathrm{kHz}$} & OD & 35,33 & 20,04 & 30 & \multirow{2}{*}{0,546} \\
\hline & OE & 38,50 & 20,39 & 30 & \\
\hline \multirow{2}{*}{$18 \mathrm{kHz}$} & OD & 26,17 & 11,50 & 30 & \multirow{2}{*}{0,821} \\
\hline & OE & 26,83 & 11,26 & 30 & \\
\hline \multirow{2}{*}{$20 \mathrm{kHz}$} & OD & 10,67 & 6,26 & 30 & \multirow{2}{*}{1,000} \\
\hline & $\mathrm{OE}$ & 10,67 & 6,66 & 30 & \\
\hline
\end{tabular}


$\mathrm{Na}$ comparação das médias dos limiares de Altas Freqüências de 9000 a $20000 \mathrm{~Hz}$ para as orelhas direita e esquerda não houve diferença média significativa entre ambas para o grupo com vitiligo. A Figura 6 ilustra este achado.

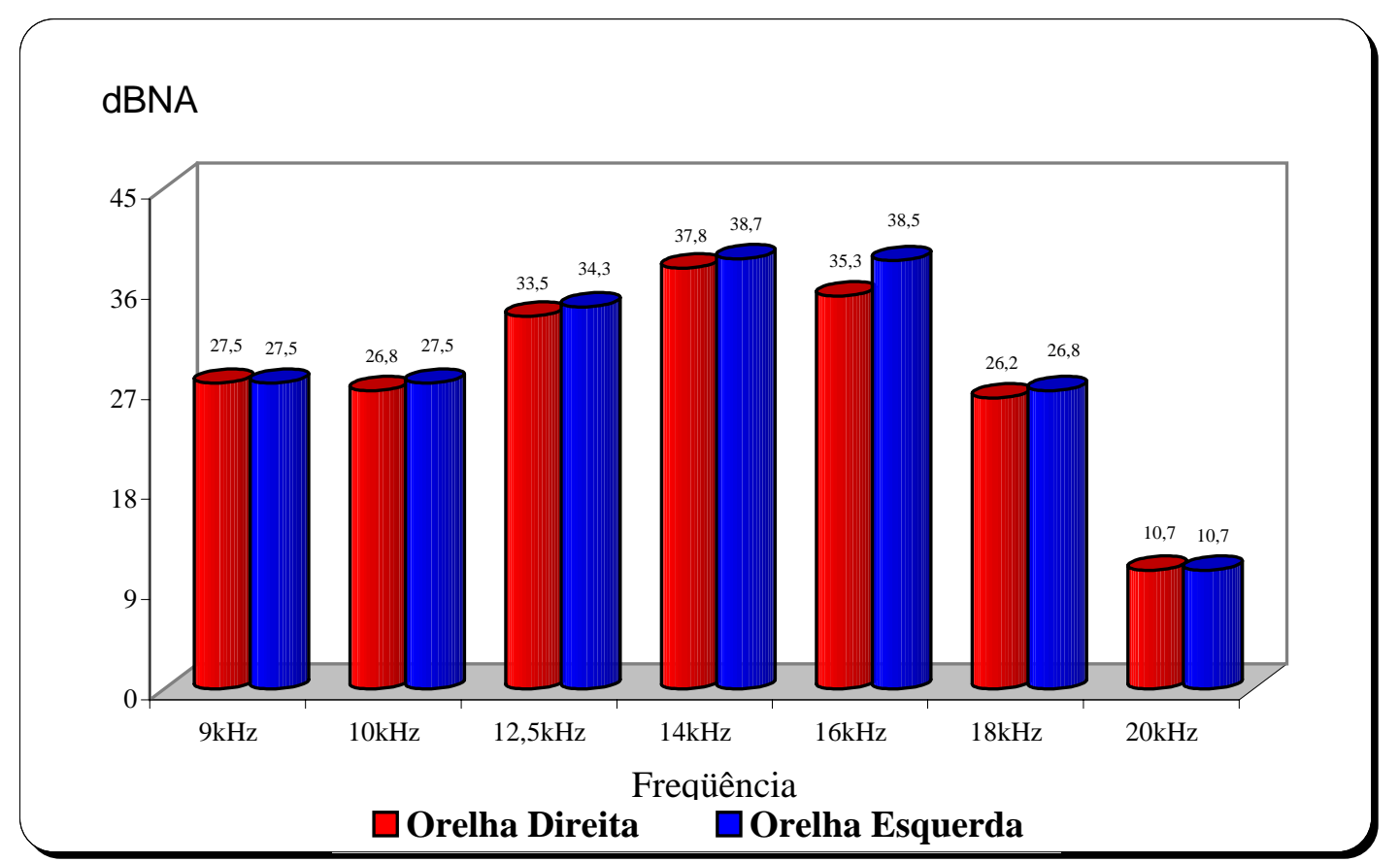

Figura 6. Média dos limiares de altas freqüências de 9 a $20 \mathrm{kHz}$ do grupo com vitiligo para a orelha direita e esquerda.

Mais uma vez o efeito da variável orelha não foi significativo para o grupo com vitiligo. Assim, como novamente não houve diferença significativa entre as orelhas, foi desconsiderado este efeito e ambas puderam ser analisadas conjuntamente. 
A Tabela 8 apresenta a análise descritiva dos limiares de altas freqüências de 9 a $20 \mathrm{kHz}$ dos grupos controle e com vitiligo e ilustrado nas Figura 7 e 8.

Tabela 8. Análise descritiva dos limiares para altas freqüências de 9000 a $20000 \mathrm{~Hz}$ do grupo controle e com vitiligo

\begin{tabular}{|c|c|c|c|c|c|c|c|c|c|}
\hline \multicolumn{2}{|c|}{ Altas Freqüências } & \multirow{2}{*}{$\begin{array}{r}\text { Média } \\
15,08\end{array}$} & \multirow{2}{*}{$\begin{array}{c}\text { Mediana } \\
15,00\end{array}$} & \multirow{2}{*}{$\begin{array}{c}\text { Desvio } \\
\text { Padrão }\end{array}$} & \multirow{2}{*}{$\begin{array}{c}\text { Mínimo } \\
-5\end{array}$} & \multirow{2}{*}{$\begin{array}{c}\text { Máximo } \\
40\end{array}$} & \multirow{2}{*}{$\begin{array}{c}\begin{array}{c}\text { Limite } \\
\text { Inferior }\end{array} \\
12,76\end{array}$} & \multirow{2}{*}{$\begin{array}{c}\begin{array}{c}\text { Limite } \\
\text { Superior }\end{array} \\
17,41\end{array}$} & \multirow{2}{*}{$\begin{array}{l}\text { p-valor } \\
<0,001^{*}\end{array}$} \\
\hline & Controle & & & & & & & & \\
\hline & Vitiligo & 27,50 & 20,00 & 20,84 & 5 & 95 & 22,23 & 32,77 & \\
\hline \multirow{2}{*}{$10 \mathrm{kHz}$} & Controle & 15,50 & 15,00 & 13,65 & -15 & 60 & 12,05 & 18,95 & $<0,001^{*}$ \\
\hline & Vitiligo & 27,17 & 20,00 & 20,45 & 5 & 95 & 21,99 & 32,34 & \\
\hline \multirow{2}{*}{$12,5 \mathrm{kHz}$} & Controle & 14,67 & 10,00 & 14,84 & -10 & 65 & 10,91 & 18,42 & $<0,001^{*}$ \\
\hline & Vitiligo & 33,92 & 25,00 & 23,95 & 5 & 95 & 27,86 & 39,98 & \\
\hline \multirow{2}{*}{$14 \mathrm{kHz}$} & Controle & 13,25 & 10,00 & 20,10 & -20 & 80 & 8,16 & 18,34 & $<0,001^{*}$ \\
\hline & Vitiligo & 38,25 & 32,50 & 23,88 & 0 & 85 & 32,21 & 44,29 & \\
\hline \multirow{2}{*}{$16 \mathrm{kHz}$} & Controle & 12,50 & 10,00 & 24,17 & -20 & 60 & 6,38 & 18,62 & $<0,001^{*}$ \\
\hline & Vitiligo & 36,92 & 37,50 & 20,11 & 5 & 70 & 31,83 & 42,00 & \\
\hline \multirow{2}{*}{$18 \mathrm{kHz}$} & Controle & 11,17 & 15,00 & 18,56 & -20 & 40 & 6,47 & 15,86 & $<0,001^{*}$ \\
\hline & Vitiligo & 26,50 & 30,00 & 11,29 & 0 & 40 & 23,64 & 29,36 & \\
\hline \multirow{2}{*}{$20 \mathrm{kHz}$} & Controle & 2,08 & 0,00 & 9,67 & -20 & 20 & $-0,36$ & 4,53 & $<0,001^{*}$ \\
\hline & Vitiligo & 10,67 & 10,00 & 6,41 & 0 & 20 & 9,05 & 12,29 & \\
\hline
\end{tabular}




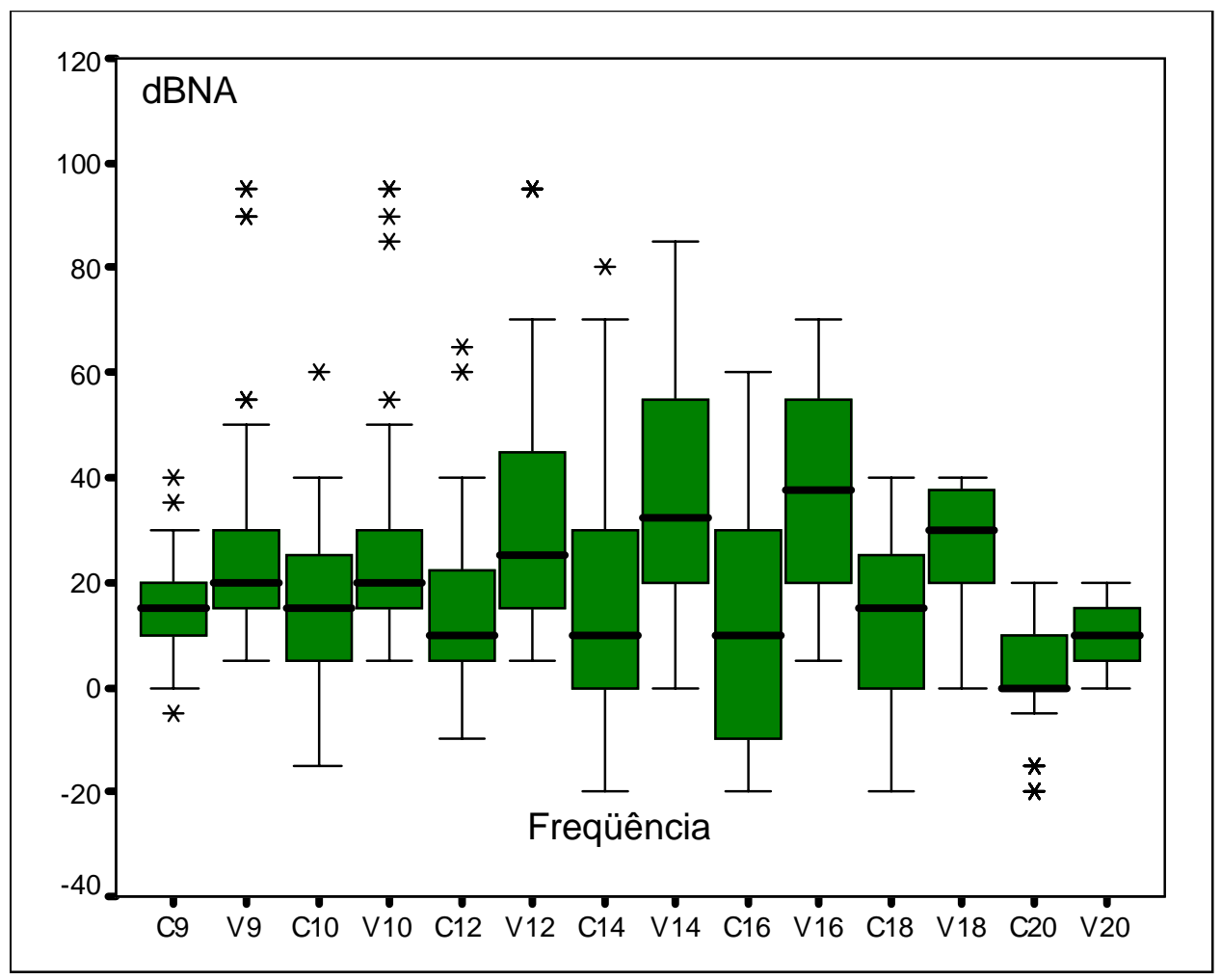

Figura 7. Box Plot dos limiares para altas freqüências de 9000 a $20000 \mathrm{~Hz}$ para os grupos controle ( c ) e com vitiligo (v).

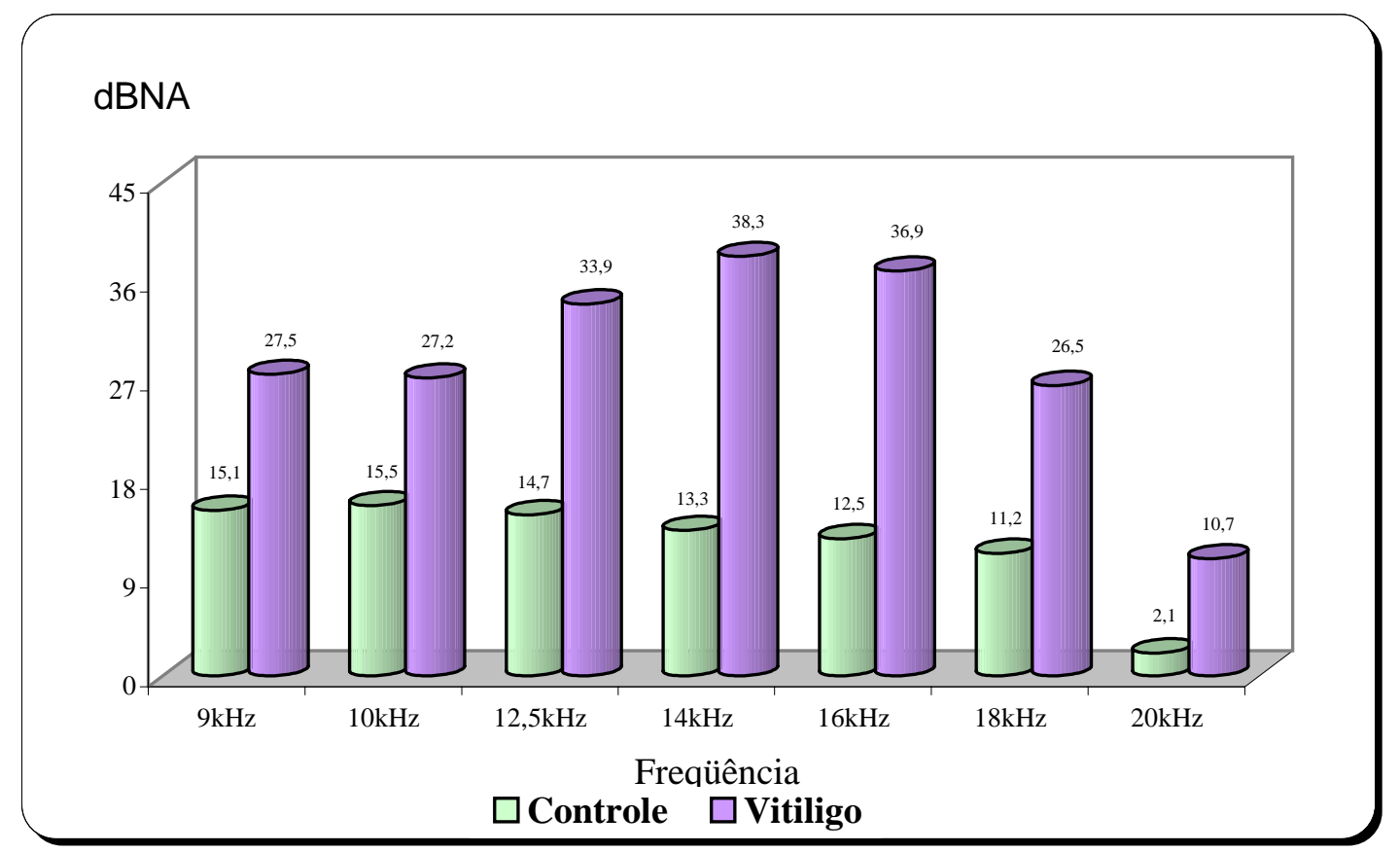

Figura 8. Diferença das médias dos limiares em altas freqüências de 9000 a 20000 $\mathrm{Hz}$ dos grupos controle e com vitiligo. 
$\mathrm{Na}$ análise dos limiares em altas freqüências foi constatado que em todas as freqüências houve diferença média altamente significante entre os grupos. Verifica-se ainda que em todas freqüências, a média do grupo de vitiligo foi maior que a do grupo controle.

\subsection{NÍVEL DE RESPOSTAS DAS EMISSÕES OTOACÚSTICAS - PRODUTO DE DISTORÇÃO}

Para a análise das emissões otoacústicas - produto de distorção será inicialmente analisado o nível de respostas das EOAPD e no próximo item a análise da relação sinal/ ruído.

A Tabela 9 apresenta o nível de respostas das EOAPD no grupo controle, comparando as orelhas direita e esquerda e a Tabela 10 representa a mesma análise no grupo com vitiligo. 
Tabela 9. Comparação das respostas das EOAPD na orelha direita e orelha esquerda para o grupo controle

\begin{tabular}{|c|c|c|c|c|c|}
\hline \multicolumn{2}{|c|}{$\begin{array}{c}\text { Respostas } \\
\text { EOAPD }\end{array}$} & \multirow{2}{*}{$\begin{array}{l}\text { Média } \\
3,99\end{array}$} & \multirow{2}{*}{$\begin{array}{c}\text { Desvio } \\
\text { Padrão } \\
7,48\end{array}$} & \multirow{2}{*}{$\begin{array}{c}\text { Tamanho } \\
30\end{array}$} & \multirow{3}{*}{$\begin{array}{c}\text { p-valor } \\
0,403\end{array}$} \\
\hline \multirow{2}{*}{1.001} & OD & & & & \\
\hline & OE & 2,20 & 8,89 & 30 & \\
\hline \multirow{2}{*}{1.257} & OD & 6,03 & 8,88 & 30 & \multirow{2}{*}{0,755} \\
\hline & OE & 5,33 & 8,49 & 30 & \\
\hline \multirow{2}{*}{1.587} & OD & 6,78 & 7,44 & 30 & \multirow{2}{*}{0,783} \\
\hline & OE & 7,38 & 9,18 & 30 & \\
\hline \multirow{2}{*}{2.002} & OD & 5,64 & 8,74 & 30 & \multirow{2}{*}{0,971} \\
\hline & OE & 5,56 & 8,30 & 30 & \\
\hline \multirow{2}{*}{2.515} & OD & 3,88 & 9,00 & 30 & \multirow{2}{*}{0,991} \\
\hline & OE & 3,86 & 6,40 & 30 & \\
\hline \multirow{2}{*}{3.174} & OD & 2,73 & 8,71 & 30 & \multirow{2}{*}{0,561} \\
\hline & OE & 3,90 & 6,67 & 30 & \\
\hline \multirow{2}{*}{4.004} & OD & 4,23 & 7,50 & 30 & \multirow{2}{*}{0,565} \\
\hline & OE & 5,37 & 7,70 & 30 & \\
\hline \multirow{2}{*}{5.042} & OD & 7,44 & 9,90 & 30 & \multirow{2}{*}{0,836} \\
\hline & OE & 8,00 & 10,83 & 30 & \\
\hline \multirow{2}{*}{6.348} & OD & 3,28 & 11,05 & 30 & \multirow{2}{*}{0,979} \\
\hline & OE & 3,36 & 11,31 & 30 & \\
\hline
\end{tabular}


$\mathrm{Na}$ comparação das médias das respostas das EOAPD para as orelhas direita e esquerda não existe diferença média significativa entre ambas para o grupo controle. A Figura 9 ilustra este achado.

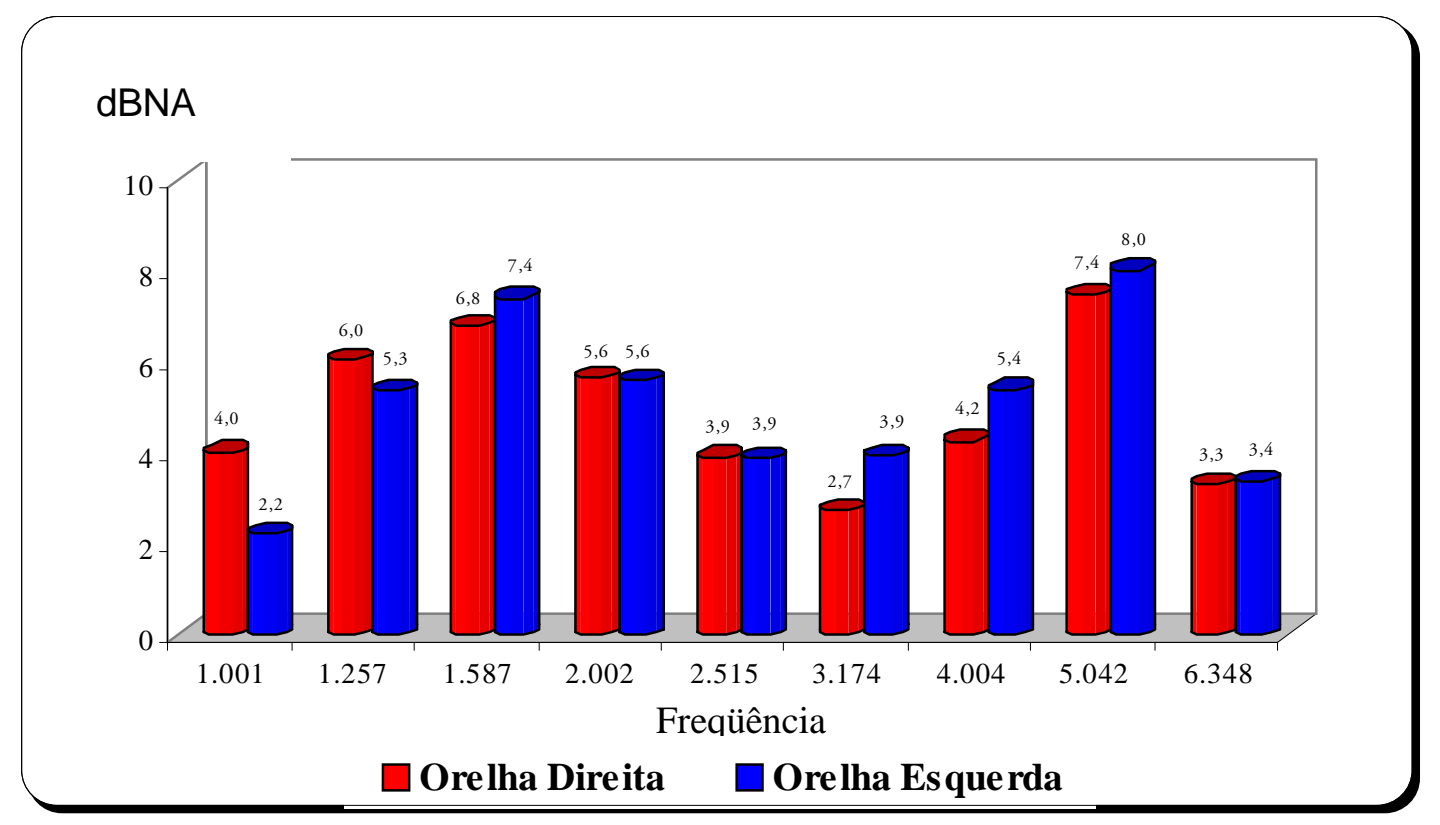

Figura 9. Média das respostas das EOAPD do grupo controle na orelha direita e orelha esquerda. 
A seguir a Tabela 10 mostra os resultados obtidos na comparação da orelha direita e orelha esquerda do grupo com vitiligo. A Figura 10 mostra estes resultados.

Tabela 10. Comparação da média das respostas das EOAPD na orelha direita e orelha esquerda do grupo com vitiligo

\begin{tabular}{|c|c|c|c|c|c|}
\hline \multicolumn{2}{|c|}{ Respostas das EOAPD } & \multirow{2}{*}{$\begin{array}{c}\text { Média } \\
-6,07\end{array}$} & \multirow{2}{*}{$\begin{array}{c}\begin{array}{c}\text { Desvio } \\
\text { Padrão }\end{array} \\
8,30\end{array}$} & \multirow{2}{*}{$\begin{array}{c}\text { Tamanho } \\
30\end{array}$} & \multirow{3}{*}{$\begin{array}{c}\text { p-valor } \\
0,953\end{array}$} \\
\hline \multirow{2}{*}{1.001} & OD & & & & \\
\hline & OE & $-6,19$ & 6,83 & 30 & \\
\hline \multirow{2}{*}{1.257} & OD & $-4,58$ & 7,88 & 30 & \multirow{2}{*}{0,527} \\
\hline & OE & $-5,78$ & 6,75 & 30 & \\
\hline \multirow{2}{*}{1.587} & OD & $-2,05$ & 6,65 & 30 & \multirow{2}{*}{0,115} \\
\hline & OE & $-4,80$ & 6,65 & 30 & \\
\hline \multirow{2}{*}{2.002} & OD & $-2,18$ & 6,80 & 30 & \multirow{2}{*}{0,105} \\
\hline & OE & $-5,92$ & 10,39 & 30 & \\
\hline \multirow{2}{*}{2.515} & OD & $-0,40$ & 6,79 & 30 & \multirow{2}{*}{0,214} \\
\hline & OE & $-2,52$ & 6,28 & 30 & \\
\hline \multirow{2}{*}{3.174} & OD & $-1,69$ & 7,34 & 30 & \multirow{2}{*}{0,255} \\
\hline & $\mathrm{OE}$ & $-3,76$ & 6,60 & 30 & \\
\hline \multirow{2}{*}{4.004} & OD & $-0,56$ & 8,05 & 30 & \multirow{2}{*}{0,213} \\
\hline & OE & $-3,12$ & 7,68 & 30 & \\
\hline \multirow{2}{*}{5.042} & OD & 1,22 & 9,47 & 30 & \multirow{2}{*}{0,399} \\
\hline & OE & $-0,89$ & 9,73 & 30 & \\
\hline \multirow{2}{*}{6.348} & OD & $-2,96$ & 8,93 & 30 & \multirow{2}{*}{0,635} \\
\hline & OE & $-1,94$ & 7,59 & 30 & \\
\hline
\end{tabular}


dBNA

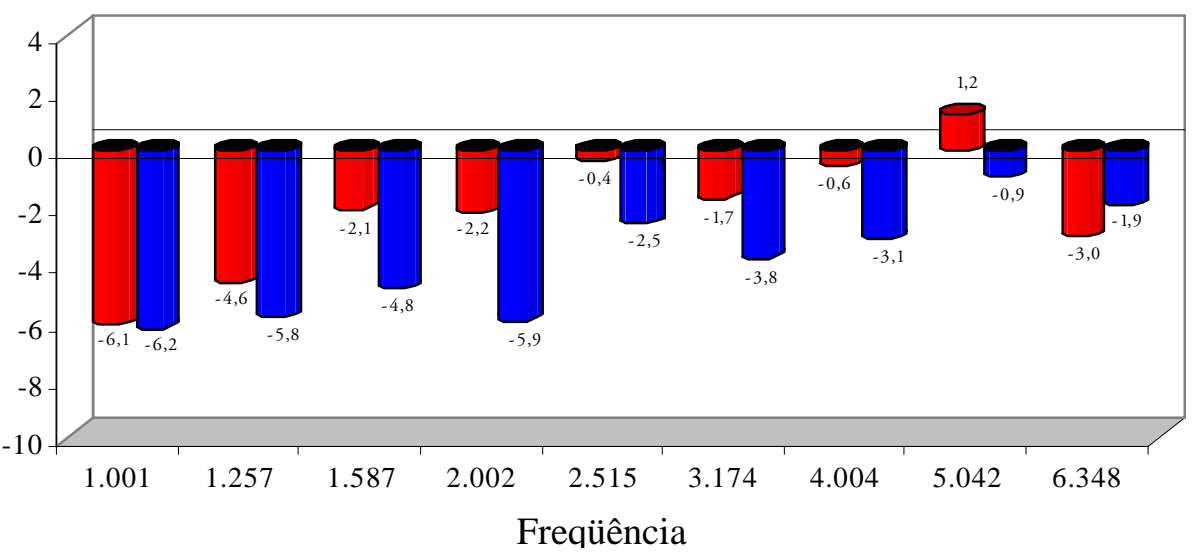

$\square$ Orelha Direita $\quad \square$ Orelha Esquerda

Figura 10. Média das respostas das EOAPD do grupo com vitiligo na orelha direita e orelha esquerda.

Também para o Grupo com Vitiligo, verificou-se que a diferença média existente entre as orelhas em todas as freqüências não chega a ser estatisticamente significativa. Portanto, como não foram encontradas diferenças significativas entre as orelhas em nenhum dos dois grupos, a análise foi realizada de uma única forma, sem a separação das orelhas. 
A Tabela 11 apresenta a análise comparativa das respostas das EOAPD dos grupos controle e com vitiligo e ilustrada na Figura 11.

Tabela 11. Comparação das respostas das EOAPD para o grupo controle e com vitiligo

\begin{tabular}{|c|c|c|c|c|c|}
\hline \multicolumn{2}{|c|}{ Respostas das EOAPD } & \multirow{2}{*}{$\begin{array}{l}\text { Média } \\
\text {-6,13 }\end{array}$} & \multirow{2}{*}{$\begin{array}{c}\text { Desvio } \\
\text { Padrão }\end{array}$} & \multirow{2}{*}{$\begin{array}{c}\text { Tamanho } \\
60\end{array}$} & \multirow{3}{*}{$\begin{array}{l}\text { p-valor } \\
<0,001^{*}\end{array}$} \\
\hline \multirow{2}{*}{1.001} & Vitiligo & & & & \\
\hline & Controle & 3,10 & 8,19 & 60 & \\
\hline \multirow{2}{*}{1.257} & Vitiligo & $-5,18$ & 7,30 & 60 & \multirow{2}{*}{$<0,001^{*}$} \\
\hline & Controle & 5,68 & 8,62 & 60 & \\
\hline \multirow{2}{*}{1.587} & Vitiligo & $-3,43$ & 6,74 & 60 & \multirow{2}{*}{$<0,001^{*}$} \\
\hline & Controle & 7,08 & 8,29 & 60 & \\
\hline \multirow{2}{*}{2.002} & Vitiligo & $-4,05$ & 8,91 & 60 & \multirow{2}{*}{$<0,001^{*}$} \\
\hline & Controle & 5,60 & 8,45 & 60 & \\
\hline \multirow{2}{*}{2.515} & Vitiligo & $-1,46$ & 6,57 & 60 & \multirow{2}{*}{$<0,001^{\star}$} \\
\hline & Controle & 3,87 & 7,74 & 60 & \\
\hline \multirow{2}{*}{3.174} & Vitiligo & $-2,73$ & 7,00 & 60 & \multirow{2}{*}{$<0,001$} \\
\hline & Controle & 3,32 & 7,71 & 60 & \\
\hline \multirow{2}{*}{4.004} & Vitiligo & $-1,84$ & 7,91 & 60 & \multirow{2}{*}{$<0,001^{\star}$} \\
\hline & Controle & 4,80 & 7,55 & 60 & \\
\hline \multirow{2}{*}{5.042} & Vitiligo & 0,17 & 9,58 & 60 & \multirow{2}{*}{$<0,001$} \\
\hline & Controle & 7,72 & 10,29 & 60 & \\
\hline \multirow{2}{*}{6.348} & Vitiligo & $-2,45$ & 8,24 & 60 & \multirow{2}{*}{$0,002^{*}$} \\
\hline & Controle & 3,32 & 11,08 & 60 & \\
\hline
\end{tabular}


dBNA

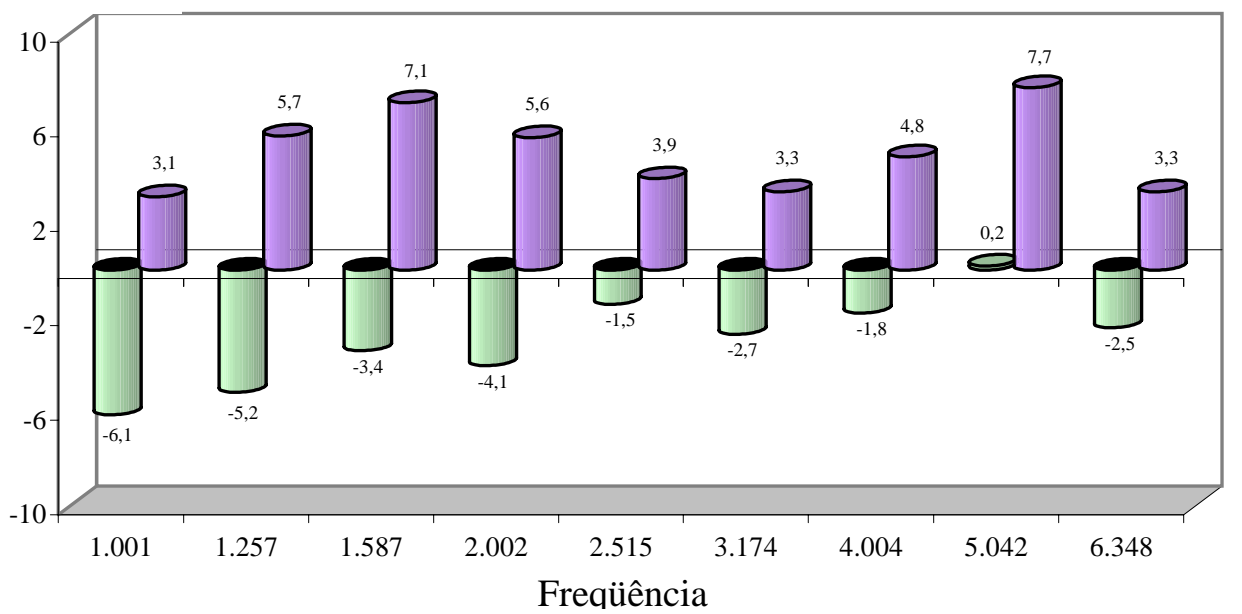

$\square$ Vitiligo $\square$ Controle

Figura 11. Diferença das médias das respostas das EOAPD dos grupos controle e com vitiligo.

$\mathrm{Na}$ análise comparativa das respostas das EOAPD foi observado que em todas as freqüências existe diferença média estatisticamente significante entre os grupos. Verificamos ainda que em todas elas, a média do grupo de vitiligo é menor que a do grupo controle. 


\subsection{RELAÇÃO SINAL/ RUÍDO DAS EMISSÕES OTOACÚSTICAS - PRODUTO DE DISTORÇÃO}

Este item mostra a segunda análise feita com as emissões otoacústicas - produto de distorção, a diferença entre o sinal e o ruído encontrado nos grupos controle e com vitiligo. Inicialmente, a Tabela 12 representa o número de orelhas de ambos os grupos que apresentaram presença; presença parcial e ausência de respostas das EOAPD através da relação sinal/ ruído.

A seguir foi feita a comparação entre as orelhas direita e esquerda no grupo controle, mostrada na Tabela 13 e ilustrada pela Figura 12.

Tabela 12. Quantidade de orelhas que apresentaram respostas nas EOAPD quanto à relação sinal/ruído

\begin{tabular}{|l|c|c|c|}
\hline EOAPD (\%) & Presente & Presente Parcial & Ausente \\
\hline Grupo Controle & $54(90 \%)$ & $4(6,6 \%)$ & $2(3,4 \%)$ \\
\hline Grupo Vitiligo & $14(23,4 \%)$ & $15(25 \%)$ & $31(51,6 \%)$ \\
\hline Total & 68 & 19 & 33 \\
\hline
\end{tabular}


Tabela 13. Comparação da relação sinal/ruído das EOAPD para a orelha direita e orelha esquerda no grupo controle

\begin{tabular}{|c|c|c|c|c|c|}
\hline \multicolumn{2}{|c|}{$\begin{array}{c}\text { Relação Sinal/ Ruído } \\
\text { EOAPD }\end{array}$} & \multirow{2}{*}{$\begin{array}{l}\text { Média } \\
4,83\end{array}$} & \multirow{2}{*}{$\begin{array}{c}\text { Desvio } \\
\text { Padrão }\end{array}$} & \multirow{2}{*}{$\begin{array}{c}\text { Tamanho } \\
30\end{array}$} & \multirow{3}{*}{$\begin{array}{r}\text { p-valor } \\
0,446\end{array}$} \\
\hline \multirow{2}{*}{1.001} & OD & & & & \\
\hline & OE & 3,21 & 8,33 & 30 & \\
\hline \multirow{2}{*}{1.257} & OD & 8,65 & 8,84 & 30 & \multirow{2}{*}{0,781} \\
\hline & OE & 8,03 & 8,53 & 30 & \\
\hline \multirow{2}{*}{1.587} & OD & 13,06 & 8,19 & 30 & \multirow{2}{*}{0,665} \\
\hline & OE & 12,06 & 9,49 & 30 & \\
\hline \multirow{2}{*}{2.002} & OD & 11,94 & 8,61 & 30 & \multirow{2}{*}{0,747} \\
\hline & OE & 11,21 & 8,86 & 30 & \\
\hline \multirow{2}{*}{2.515} & OD & 11,78 & 8,19 & 30 & \multirow{2}{*}{0,603} \\
\hline & OE & 10,78 & 6,64 & 30 & \\
\hline \multirow{2}{*}{3.174} & OD & 10,40 & 8,95 & 30 & \multirow{2}{*}{0,512} \\
\hline & OE & 11,78 & 7,09 & 30 & \\
\hline \multirow{2}{*}{4.004} & OD & 13,77 & 7,33 & 30 & \multirow{2}{*}{0,824} \\
\hline & OE & 14,23 & 8,38 & 30 & \\
\hline \multirow{2}{*}{5.042} & OD & 15,97 & 9,79 & 30 & \multirow{2}{*}{0,690} \\
\hline & OE & 17,01 & 10,21 & 30 & \\
\hline \multirow{2}{*}{6.348} & OD & 12,73 & 9,54 & 30 & \multirow{2}{*}{0,923} \\
\hline & OE & 12,99 & 11,46 & 30 & \\
\hline
\end{tabular}




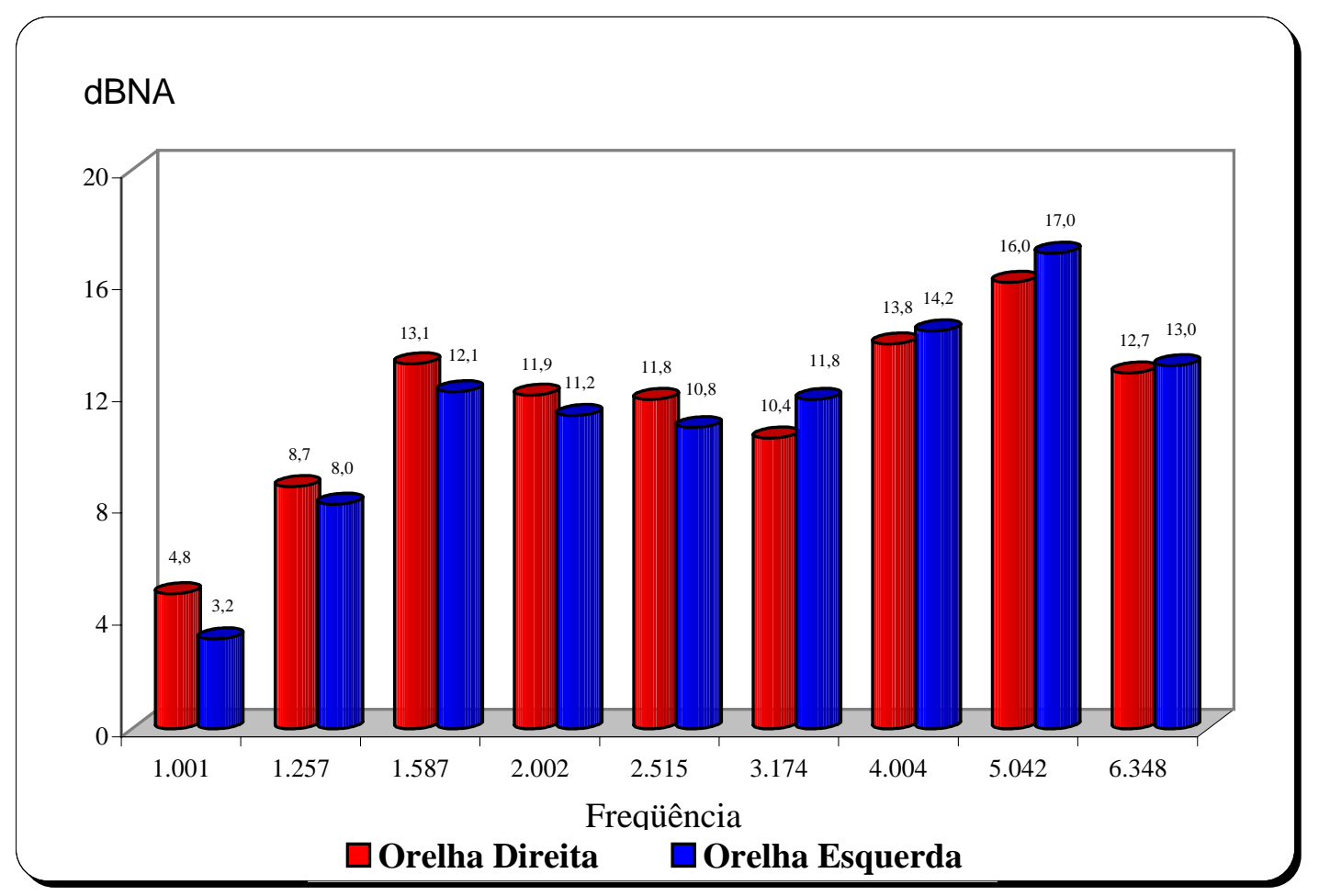

Figura 12. Média da relação sinal/ruído das EOAPD do grupo controle na orelha direita e orelha esquerda.

Observa-se que não ocorreu diferença significativa entre ambas orelhas, podendo esta comparação ser desprezada.

A seguir segue a mesma análise com o grupo com vitiligo, representado na Tabela 14 e ilustrada pela Figura 13. 
Tabela 14. Comparação da relação sinal/ruído das EOAPD para a orelha direita e orelha esquerda no grupo vitiligo

\begin{tabular}{|c|c|c|c|c|c|}
\hline \multicolumn{2}{|c|}{ EOATPD } & \multirow{2}{*}{$\begin{array}{c}\text { Média } \\
-5,05\end{array}$} & \multirow{2}{*}{$\begin{array}{c}\text { Desvio } \\
\text { Padrão }\end{array}$} & \multirow{2}{*}{$\begin{array}{c}\text { Tamanho } \\
30\end{array}$} & \multirow{3}{*}{$\begin{array}{c}\text { p-valor } \\
0,514\end{array}$} \\
\hline \multirow{2}{*}{1.001} & OD & & & & \\
\hline & OE & $-3,80$ & 6,76 & 30 & \\
\hline \multirow{2}{*}{1.257} & OD & $-1,54$ & 7,72 & 30 & \multirow{2}{*}{0,484} \\
\hline & OE & $-2,90$ & 7,21 & 30 & \\
\hline \multirow{2}{*}{1.587} & OD & 1,11 & 7,31 & 30 & \multirow{2}{*}{0,308} \\
\hline & OE & $-0,71$ & 6,33 & 30 & \\
\hline \multirow{2}{*}{2.002} & OD & 1,13 & 6,53 & 30 & \multirow{2}{*}{0,395} \\
\hline & OE & $-0,84$ & 10,79 & 30 & \\
\hline \multirow{2}{*}{2.515} & OD & 3,78 & 6,39 & 30 & \multirow{2}{*}{0,825} \\
\hline & OE & 3,42 & 6,18 & 30 & \\
\hline \multirow{2}{*}{3.174} & OD & 2,31 & 10,94 & 30 & \multirow{2}{*}{0,826} \\
\hline & OE & 1,80 & 6,39 & 30 & \\
\hline \multirow{2}{*}{4.004} & OD & 3,85 & 7,88 & 30 & \multirow{2}{*}{0,464} \\
\hline & OE & 2,38 & 7,59 & 30 & \\
\hline \multirow{2}{*}{5.042} & OD & 5,38 & 9,89 & 30 & \multirow{2}{*}{0,757} \\
\hline & OE & 4,55 & 10,75 & 30 & \\
\hline \multirow{2}{*}{6.348} & OD & 0,13 & 9,23 & 30 & \multirow{2}{*}{0,263} \\
\hline & OE & 2,64 & 7,94 & 30 & \\
\hline
\end{tabular}


dBNA

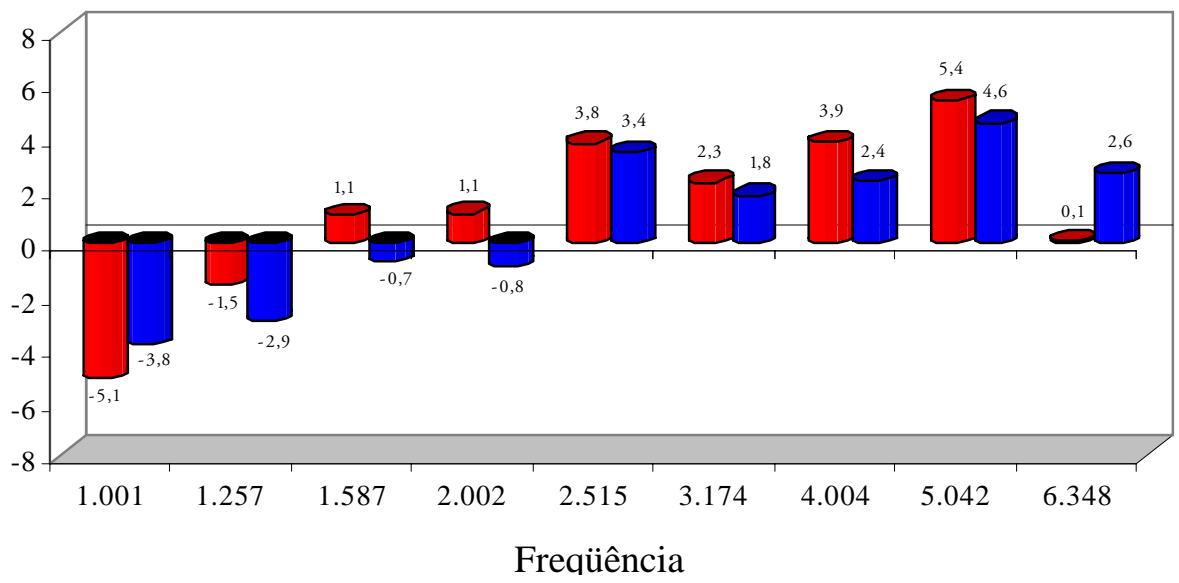

$\square$ Orelha Direita $\square$ Orelha Esquerda

Figura 13. Média da relação sinal/ruído das EOAPD do grupo com vitiligo na orelha direita e orelha esquerda

Verificamos que também para o grupo com vitiligo, a diferença média existente entre as orelhas não chega a ser estatisticamente significativa, em todas as freqüências.

Novamente como não foram encontradas diferenças significativas entre as orelhas em nenhum dos dois grupos, a análise foi realizada sem a separação das orelhas, não provocando efeito algum no resultado.

A Tabela 15 apresenta a análise descritiva da média da relação sinal/ ruído dos grupos controle e com vitiligo. Esta análise é ilustrada nas Figuras 14 e 15. 
Tabela 15. Análise descritiva da média da relação sinal/ruído do grupo controle e com vitiligo

\begin{tabular}{cccccccccc}
\hline \multicolumn{2}{c}{ EOATPD } & Média & Mediana & $\begin{array}{c}\text { Desvio } \\
\text { Padrão }\end{array}$ & Mínimo & Máximo & $\begin{array}{c}\text { Limite } \\
\text { Inferior }\end{array}$ & $\begin{array}{c}\text { Limite } \\
\text { Superior }\end{array}$ & p-valor \\
\hline \multirow{2}{*}{1.001} & Controle & 4,02 & 5,10 & 8,16 & -15 & 18 & 1,96 & 6,09 & $<0,001^{*}$ \\
\cline { 2 - 11 } & Vitiligo & $-4,43$ & $-3,30$ & 7,35 & -30 & 7 & $-6,29$ & $-2,57$ & \\
\hline \multirow{2}{*}{1.257} & Controle & 8,34 & 9,70 & 8,62 & -14 & 21 & 6,16 & 10,52 & $<0,001^{*}$ \\
\cline { 2 - 11 } & Vitiligo & $-2,22$ & $-1,05$ & 7,43 & -24 & 17 & $-4,10$ & $-0,34$ & \\
\hline \multirow{2}{*}{1.587} & Controle & 12,56 & 13,15 & 8,81 & -12 & 27 & 10,33 & 14,79 & $<0,001^{*}$ \\
\cline { 2 - 11 } & Vitiligo & 0,20 & 0,30 & 6,84 & -17 & 21 & $-1,53$ & 1,93 & \\
\hline \multirow{2}{*}{2.002} & Controle & 11,58 & 11,40 & 8,67 & -17 & 29 & 9,38 & 13,77 & $<0,001^{*}$ \\
\cline { 2 - 11 } & Vitiligo & 0,14 & 2,10 & 8,90 & -34 & 17 & $-2,11$ & 2,39 & \\
\hline \multirow{2}{*}{2.515} & Controle & 11,28 & 10,85 & 7,41 & -9 & 30 & 9,40 & 13,16 & $<0,001^{*}$ \\
\cline { 2 - 11 } & Vitiligo & 3,60 & 4,30 & 6,24 & -14 & 17 & 2,02 & 5,17 & \\
\hline \multirow{2}{*}{3.174} & Controle & 11,09 & 11,20 & 8,04 & -23 & 31 & 9,06 & 13,12 & $<0,001^{*}$ \\
\cline { 2 - 11 } & Vitiligo & 2,06 & 4,60 & 8,88 & -48 & 16 & $-0,19$ & 4,31 & \\
\hline \multirow{2}{*}{4.004} & Controle & 14,00 & 14,15 & 7,81 & -11 & 28 & 12,02 & 15,98 & $<0,001^{*}$ \\
\cline { 2 - 11 } & Vitiligo & 3,11 & 4,20 & 7,71 & -14 & 20 & 1,16 & 5,06 & \\
\hline \multirow{2}{*}{5.042} & Controle & 16,49 & 17,50 & 9,93 & -19 & 37 & 13,98 & 19,00 & $<0,001^{*}$ \\
\cline { 2 - 11 } & Vitiligo & 4,97 & 6,10 & 10,25 & -27 & 22 & 2,37 & 7,56 & \\
\hline \multirow{2}{*}{6.348} & Controle & 12,86 & 13,60 & 10,45 & -12 & 31 & 10,22 & 15,51 & $<0,001^{*}$ \\
\cline { 2 - 11 } & Vitiligo & 1,38 & 2,80 & 8,63 & -19 & 19 & $-0,80$ & 3,57 & \\
\hline
\end{tabular}




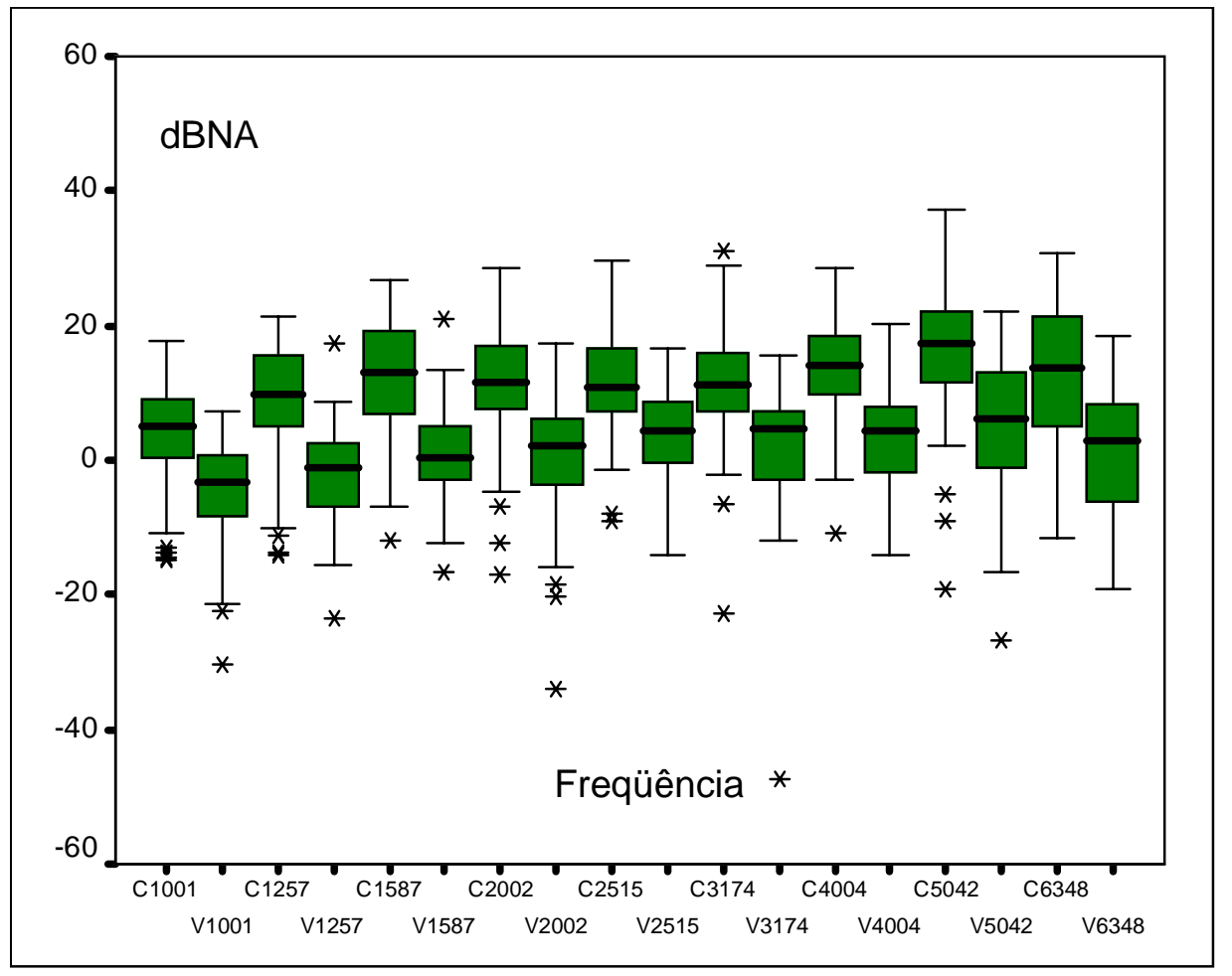

Figura 14. Box Plot do nível de resposta das EOAPD do grupo controle ( c ) e com vitiligo (v).

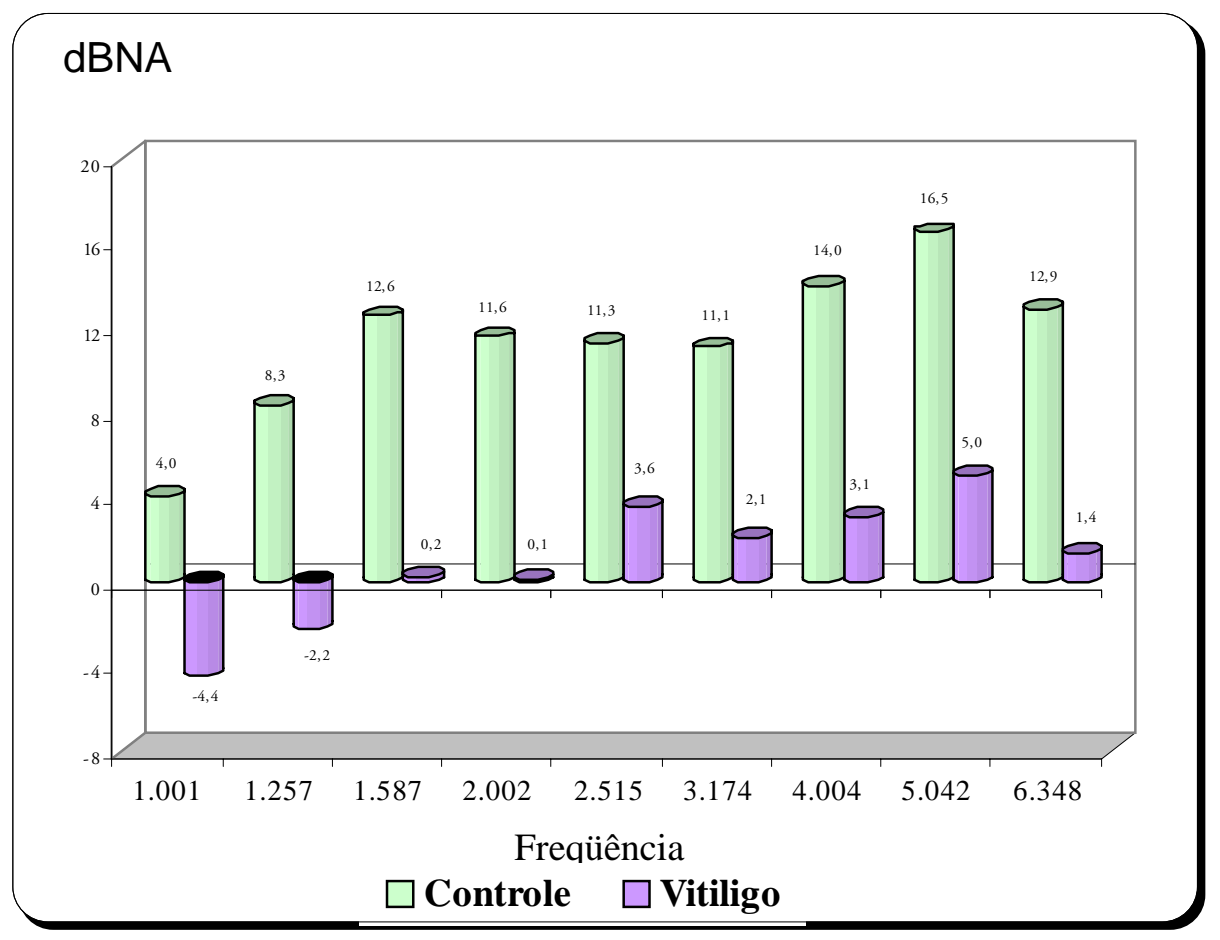

Figura 15. Comparação da média da relação sinal/ruído das EOAPD dos grupos controle e com vitiligo 
$\mathrm{Na}$ análise comparativa das médias da relação sinal/ ruído foi observado que em todas as freqüências existe diferença média estatisticamente significante entre os grupos. Verifica-se ainda que também em todas as comparações, a média do grupo com vitiligo foi menor que a do grupo controle.

4.5. Correlação entre limiares em altas freqüências e Emissões Otoacústicas - Produto de Distorção

A próxima análise realizada foi a correlação entre a média dos limiares de todas as altas freqüências e as freqüências das emissões otoacústicas - produto de distorção que esta representada pela Tabela 16.

Tabela 16. Correlação entre altas freqüências e emissões otoacústicas produto de distorção

\begin{tabular}{lcc}
\hline & Controle & Vitiligo \\
\hline F 1.001 & $-28,2 \%$ & $2,2 \%$ \\
F 1.257 & $-25,4 \%$ & $12,9 \%$ \\
F 1.587 & $-44,3 \%$ & $-21,1 \%$ \\
F 2.002 & $-48,9 \%$ & $-40,5 \%$ \\
F 2.515 & $-53,8 \%$ & $-25,6 \%$ \\
F 3.174 & $-46,1 \%$ & $-42,4 \%$ \\
F 4.004 & $-52,9 \%$ & $-35,7 \%$ \\
F 5.042 & $-60,2 \%$ & $-28,6 \%$ \\
F 6.348 & $-67,5 \%$ & $-25,3 \%$ \\
EOATPD Med & $-60,3 \%$ & $-37,7 \%$ \\
\hline
\end{tabular}

As correlações classificadas de "Boa" estão marcadas de azul e de lilás as classificadas de "Regular". 
Por fim, observa-se que as correlações são negativas, ou seja, as altas freqüências são inversamente proporcionais às freqüências de EOAPD. Desta maneira, quanto maior o limiar em altas freqüências, menor o nível de respostas das EOAPD.

Para ilustrar, as Figuras 16 e 17 mostram a correlação para a freqüência de $6348 \mathrm{~Hz}$ para os grupos controle e com vitiligo, respectivamente.

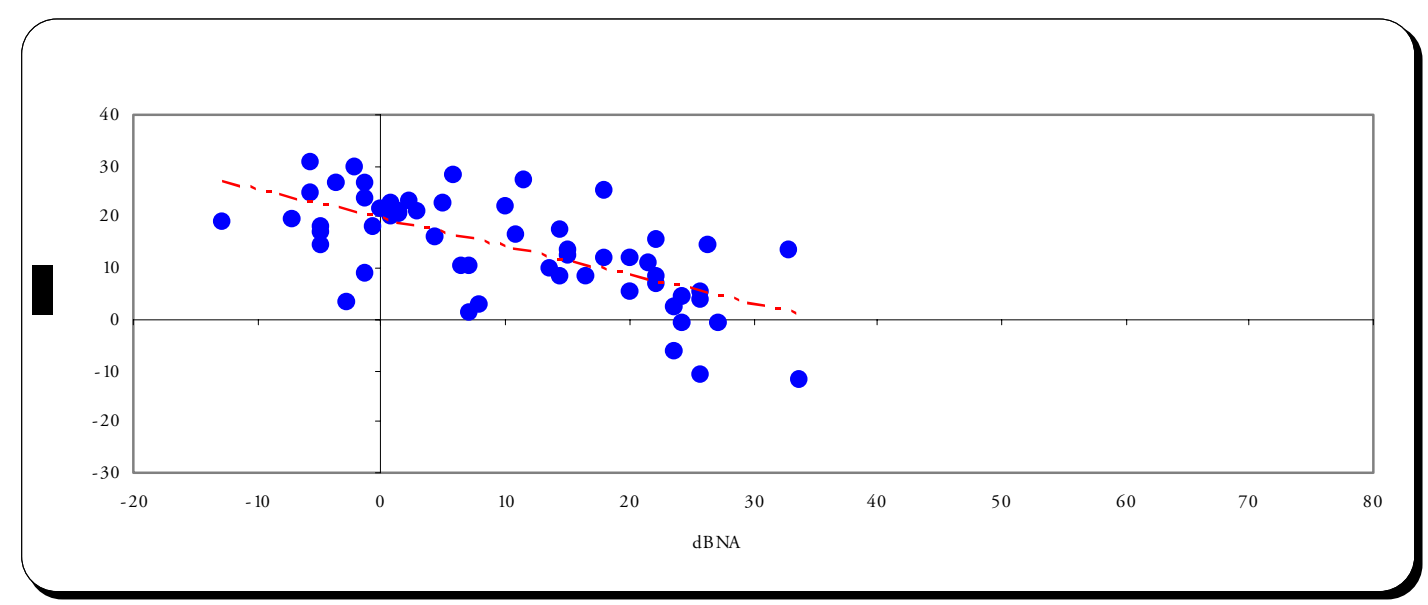

Figura 16. Gráfico de dispersão para a freqüência de $6348 \mathrm{~Hz}$ para o grupo Controle.

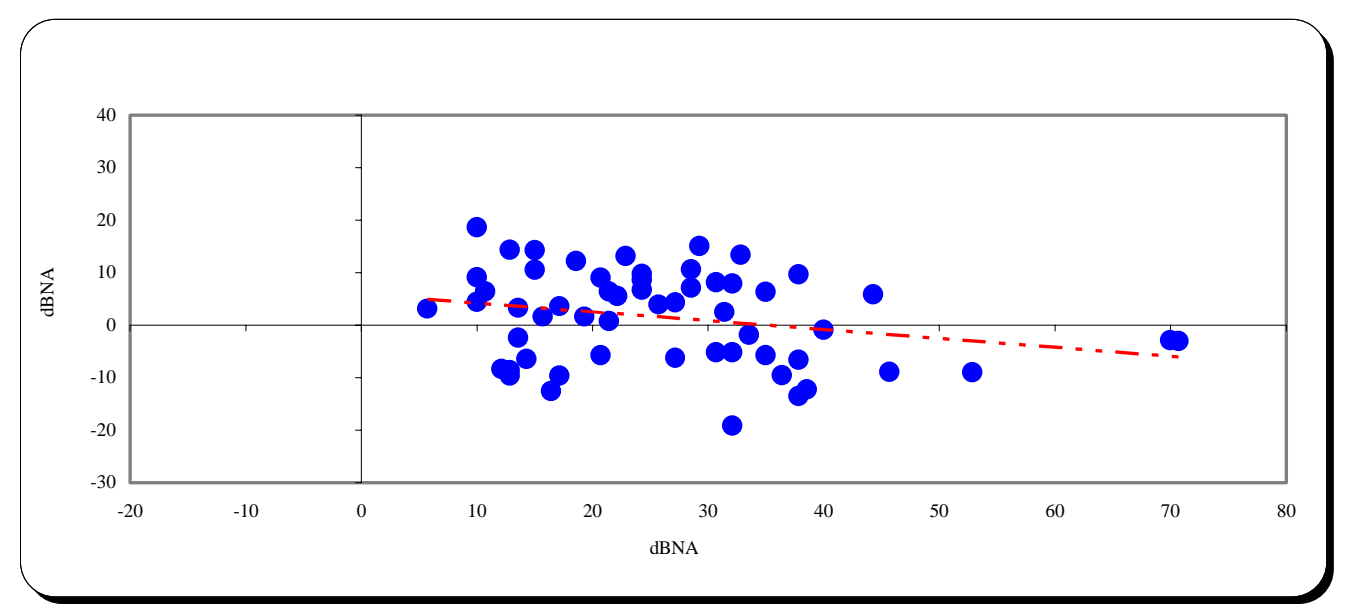

Figura 17. Gráfico de dispersão para a freqüência de $6348 \mathrm{~Hz}$ para o grupo vitiligo 
5. Discussão 
Este estudo surgiu do interesse na busca de informações sobre função auditiva em pacientes com desordem pigmentar do tipo vitiligo.

A adoção de um protocolo de avaliação audiológica, composto por audiometria em altas freqüências e emissões otoacústicas, teve como pressuposto a investigação de alterações manifestadas pela falta de melanina, primordialmente, na região basal do órgão espiral.

Desta forma, o estudo enfocou as respostas auditivas para altas freqüências e emissões otoacústicas - produto de distorção, e que poderiam ser mais afetadas pela desordem pigmentar ora estudada.

Para facilitar a discussão dos resultados encontrados, este capítulo será dividido em:

5.1 Discussão dos resultados dos limiares tonais de 250 a $8000 \mathrm{~Hz}$.

5.2 Discussão dos resultados dos limiares tonais nas freqüências de 9000 a $20000 \mathrm{~Hz}$.

5.3 Discussão dos resultados das emissões otoacústicas - produto de distorção.

5.4 Discussão dos resultados da correlação entre limiares em altas freqüências e emissões otoacústicas - produto de distorção. 


\subsection{Discussão dos resultados dos limiares tonais de 250 a $8000 \mathrm{~Hz}$}

Obedecendo aos critérios de inclusão propostos para o grupo controle, os resultados da audiometria convencional para tons puros, neste grupo, indicaram que estes sujeitos não apresentaram limiares auditivos superiores a 25 dBNA, nas freqüências de 250 a $4000 \mathrm{~Hz}$.

Já para o grupo com vitiligo, como não havia o mesmo critério de inclusão, foi observado que alguns sujeitos já apresentavam perda auditiva comprovada pela audiometria tonal, nas freqüências 250 a $8000 \mathrm{~Hz}$, com limiares auditivos superiores a $25 \mathrm{dBNA}$. Este achado confirma com trabalho realizado (TOSTI, 1987), o qual encontrou pacientes com vitiligo já apresentando algum grau de perda auditiva na primeira avaliação.

Entretanto, apesar de ter-se observado elevação nos limiares do grupo com vitiligo, na comparação entre ambos os grupos, não houve diferença estatisticamente significante, condição também já relatada por trabalho anterior (ESCALANTE-UGALDE, 1991).

A audiometria convencional, nas freqüências de 250 a $8000 \mathrm{~Hz}$, avalia a porção medial do órgão espiral, não sendo possível detectar alterações auditivas encontradas na desordem pigmentar, uma vez que a literatura relata que a melanina tem maior concentração na região basal do órgão espiral, o qual corresponde a audição em altas freqüências (ARDIC et al., 1998; BARRENAS, 1997). 
Sendo assim, neste estudo, foram utilizados procedimentos mais precisos para avaliação da porção basal, responsável pelas altas freqüências. Os dados referentes à aplicação destes procedimentos serão discutidos a seguir.

\subsection{Discussão dos resultados dos limiares tonais nas freqüências de 9000 a $20000 \mathrm{~Hz}$}

Vários estudos mostraram a grande aplicação das medidas auditivas em altas freqüências na monitorização do "status" auditivo (FAUSTI et al., 1993; ZEIGELBOIM, 2000; ZAIA, 2000). Se é esperado que as medidas permaneçam estáveis em um indivíduo saudável auditivamente, quando ocorre uma mudança de limiares em mais de $20 \mathrm{~dB}$, em pelo menos uma frequência, ou quando ocorre uma mudança acima de $10 \mathrm{~dB}$, em duas ou mais freqüências consecutivas (ASHA, 1994), tal fato estaria sugerindo uma alteração na função coclear. Por essa razão, o procedimento tem sido indicado para monitorização do uso de drogas ototóxicas e para exposição ao ruído de nível de pressão sonora elevado (FAUSTI et al., 1993; FRANK, 2001).

Uma condição que mereceu cuidado, em estudos apresentados na literatura, foi o efeito da idade sobre os limiares de altas freqüências. Este ponto não foi objeto deste estudo, mas outros trabalhos mostram variabilidade de limiares com o aumento da idade (SAKAMOTO et al., 1998; PEDALINI et al., 2000). 
Neste presente trabalho, os 60 indivíduos analisados possuíam a faixa etária de 8 a 68 anos. A fim de evitar possível viés da pesquisa, foram feitas duas análises estatísticas. A primeira englobou todos os 60 indivíduos e, na segunda, foram excluídos os indivíduos com mais de 60 anos (ANEXO). Ambas análises mantiveram o mesmo $p$-valor $<0,001$. Como já ressaltado, a ausência de diferença possibilitou a análise do total da amostra inicial.

Novamente, como na análise da audiometria convencional de 250 a $8000 \mathrm{~Hz}$, foi analisado o efeito das orelhas direita e esquerda. Como não houve diferença entre as orelhas, este efeito foi desconsiderado e ambas foram analisadas conjuntamente. Esta mesma condição foi observada em outro estudo de altas freqüências (FRANK, 2001), confirmando que a variabilidade intra-sujeitos é baixa, diferentemente da variabilidade inter-sujeitos, que é elevada, quando analisados os limiares para as altas freqüências.

Estudos iniciais da relação entre melanina e função auditiva já mostravam que a presença da melanina, na orelha interna, tem um papel importante para seu adequado funcionamento. A possível influência na função vasomotora mostra que a melanina presente nos vasos sanguíneos facilita a passagens de substâncias de um lado para o outro, propiciando uma atividade enzimática e regularizadora da membrana celular. A ausência desta desregularia a função metabólica do órgão cortical e, conseqüentemente, seu desempenho (SAVIN, 1965).

Outro importante papel da melanina, em relação à audição, seria a proteção do órgão espiral contra o ruído elevado (CONLEE et al, 1986; 
ROYSTER et al., 1980). Nos dias atuais, principalmente nos grandes centros urbanos como São Paulo, onde este estudo foi realizado, todos os indivíduos estão expostos a algum ruído, seja este de trânsito, de buzinas, de máquinas, entre outros. A melanina protegendo o órgão espiral contra estes efeitos, torna os indivíduos portadores de desordem pigmentar propensos a apresentarem alguma alteração neste órgão, refletindo na sua função auditiva.

Neste estudo, assim como no estudo de FAZIL (1998), esta alteração na função auditiva não pôde ser detectada por meio da audiometria convencional. Alternativamente, a possibilidade de estudar a função coclear nas altas freqüências, de 9 a $20 \mathrm{kHz}$, na região basal do órgão espiral, possibilita monitorar pacientes que têm, ou que suspeitam ter, patologias relacionadas à audição (FRANK \& DREISBACH, 1991).

Confirmando uma maior efetividade diagnóstica do procedimento de audiometria em altas freqüências, neste estudo, a análise estatística da média dos limiares, entre 9 e $20 \mathrm{kHz}$, confirmou que o grupo com desordem pigmentar do tipo vitiligo apresenta uma diferença média altamente significante, com $p$-valor $<0,001$, em todas as freqüências desta faixa, sendo a média do grupo com vitiligo maior que a do grupo controle; ou seja, têm limiares piores quando comparados ao grupo sem a desordem.

O Quadro 1 apresenta a variabilidade de resultados envolvendo a pesquisa de limiares audiométricos em altas freqüências. 
Quadro 1. Comparação dos limiares tonais médios em altas freqüências, de indivíduos com audição normal encontrados em outros estudos, anteriores, e os encontrados neste estudo, de indivíduos com desordem pigmentar.

\begin{tabular}{|c|c|c|c|c|c|c|c|c|}
\hline AUTOR & $\begin{array}{c}\text { dBNPS/ } \\
\text { dBNA }\end{array}$ & $9 \mathrm{kHz}$ & $10 \mathrm{kHz}$ & $12,5 \mathrm{kHz}$ & $14 \mathrm{kHz}$ & $16 \mathrm{kHz}$ & $18 \mathrm{kHz}$ & $20 \mathrm{kHz}$ \\
\hline $\begin{array}{l}\text { LAITILA et } \\
\text { al. (1997) }\end{array}$ & dBNPS & & 10,7 & 13 & 13 & 22 & 37,4 & 32 \\
\hline $\begin{array}{l}\text { HUNTER et } \\
\text { al. } \\
\text { (1997) }\end{array}$ & dBNPS & $11-33$ & $0-37$ & $17-40$ & $23-48$ & $33-70$ & $40-95$ & $60-110$ \\
\hline ZAIA (2000) & dBNPS & 20 & 20 & 20 & 35 & 50 & 65 & \\
\hline $\begin{array}{c}\text { FRANK } \\
(2001)\end{array}$ & dBNPS & 21,9 & 24,1 & 30,1 & 35,8 & 57,9 & & \\
\hline $\begin{array}{l}\text { CARVALLO } \\
\text { et al. (2002) }\end{array}$ & dBNA & 9,9 & 7,8 & 5,6 & 2,2 & 1,7 & 6 & $-0,7$ \\
\hline $\begin{array}{c}\text { CARVALHO } \\
\text { (2004) } \\
\text { Controle }\end{array}$ & dBNA & 15,8 & 15,5 & 14,67 & 13,25 & 12,5 & 11,17 & 2,8 \\
\hline $\begin{array}{c}\text { CARVALHO } \\
\text { (2004) } \\
\text { Vitiligo }\end{array}$ & dBNA & 27,5 & 27,17 & 33,92 & 38,25 & 36,92 & 26,5 & 10,67 \\
\hline
\end{tabular}

Na comparação dos resultados obtidos neste estudo com o trabalho de CARVALLO et al. (2001), realizado com indivíduos de idades entre 18 e 30 anos, e utilizando o mesmo equipamento realizado por este estudo, é valido ressaltar que os limiares obtidos, neste atual estudo, foram mais elevados, por se tratar de indivíduos com idade mais avançada (até 68 anos), na comparação com o grupo controle. Já em comparação com o grupo com vitiligo, a diferença se torna acentuada, mostrando que esta 
desordem acarreta um comprometimento na região responsável pela audição em altas freqüências.

\subsection{Discussão dos resultados das emissões otoacústicas - produto de distorção}

Os estudos de KEMP (1978), possibilitaram a utilização das emissões otoacústicas, ao sustentar e demonstrar a atividade coclear.

O registro das emissões otoacústicas - produto de distorção (EOAPD) tornou-se uma importante ferramenta no auxílio da avaliação periférica da audição, tendo em vista a especificidade e a seletividade com que analisa as células ciliadas externas, as quais são encontradas nas diferentes porções cocleares.

Rotineiramente, o nível de respostas das EOAPD tem sido analisado sob dois aspectos: presença ou ausência de respostas (HARRIS, 1990; LONSBURY-MARTIN et al., 1991; BONFILS et al., 1992; COUBE, 1998). Em contrapartida, a redução do nível de respostas vem sendo amplamente discutida como indício precoce de alterações cocleares sutis ainda não reveladas pela avaliação audiométrica tonal convencional (HARRIS, 1990; LONSBURY-MARTIN et al., 1991).

Neste estudo, houve o interesse em realizar dois tipos de análises em relação às emissões otoacústicas - produto de distorção (EOAPD). Estas análises referem-se ao nível de respostas e à relação sinal ruído. 
A investigação do nível de respostas das EOAPD partiu do pressuposto de que uma maior resposta poderia estar relacionada à integridade do sistema auditivo. Já quanto à diminuição do nível de respostas, seria indicativo de alterações do órgão espiral, por sua característica de geração de resposta coclear, ainda que alterações discretas, mas não perceptíveis em outras avaliações, como já foi observado pela a audiometria convencional, neste presente estudo.

A preocupação constante com a adequada vedação do meato acústico externo deveu-se ao fato de que ouvidos mal vedados acarretam o aumento do ruído de fundo e, conseqüentemente, dos artefatos que prejudicam, de fato, a qualidade do exame, podendo até mesmo invalidar os resultados. Além disso, o bom posicionamento da sonda garante que os estímulos sejam melhor direcionados para a membrana do tímpano, possibilitando, assim, a conclusão do exame mais rapidamente.

A intensidade de estimulação de 65/55 dBNPS, para L1/L2, foi descrita por GORGA et al. (1996 e 1997) e STOVER et al. (1996) como sendo a mais eficiente para distinguir orelhas sem alteração dos que apresentavam qualquer comprometimento coclear. Sendo assim, o presente estudo adotou as intensidades de 65/55 dBNPS para a realização do exame.

O critério utilizado para a interpretação da presença de resposta foi nível de respostas $\geq 3$ dBNPS acima do ruído de fundo no $2^{\circ}$ desvio-padrão, como descrito por HARRIS (1990), ARNOLD et al. (1999), COUBE (2000). 
Tais autores salientaram que, em situação confortável de escuta, tal como em ambiente silencioso, a sensibilidade normal para tons puros pode depender da atividade de apenas parte dos conjuntos de células ciliadas externas (CCE) e das respectivas fibras associadas a estas células. Tal fato poderia levar o indivíduo a, mesmo apresentando comprometimento das CCE, não apresentar alteração na audiometria convencional. Contudo, apresentaria elevação dos limiares de respostas de EOAPD. Esta noção tem suporte em estudos experimentais sobre a ação de ruído e de ototóxicos, nos quais a audiometria convencional não conseguiu detectar alteração, embora houvesse lesão das CCE. Os achados do estudo de ARNOLD et al. (1999) sugeriram que as altas freqüências influenciam o nível de repostas de EOAPD em freqüências mais baixas, porque as emissões seriam mais sensíveis a discretas mudanças nas CCE, que não puderam ser detectadas pelos limiares audiométricos correspondentes a estas regiões da cóclea, ou porque alterações na parte basal da cóclea afetam a geração de EOAPD de freqüências mais baixas, originadas de regiões cocleares mais apicais.

Por meio dos resultados deste presente estudo, foi evidenciado que uma maior porcentagem de indivíduos do grupo com vitiligo apresentaram ausência, ou presença parcial, das EOAPDs, analisadas quanto ao critério de relação sinal/ ruído $\geq 3 \mathrm{~dB}$ e: presença - respostas em sete, oito ou nove freqüências; presença parcial - respostas em quatro, cinco ou seis freqüências e, ausência - respostas em zero, uma, duas ou três freqüências. Já no grupo controle, foi observado que a maior porcentagem apresentou 
presença, ou presença parcial, de respostas de EOAPD. Os achados das emissões otoacústicas, tanto na relação sinal/ruído, como na análise do nível de respostas, indicou que para ambas análises houve diferença estatisticamente significante, na comparação do grupo controle e no grupo com a desordem pigmentar com p-valor $<0,001$.

Estes achados indicam que a melanina presente na orelha interna tem um importante papel para um desempenho adequado, e a sua ausência acarreta em danos evidenciados por exames específicos, como o uso das EOAPD. Estudos anteriores também evidenciaram o papel que a melanina tem na orelha interna e a possível lesão das células ciliadas externas (CCE), em animais que apresentam ausência desta substância, como o caso de animais albinos que tiveram suas CCE lesadas após traumas por ruído elevado (BARRENAS, 1997; CONLEE et al., 1986).

Em estudos anteriores, com desordem pigmentar, não foi evidenciada a aplicação das EOAPD. Entretanto, o uso destas permite o registro e o monitoramento do funcionamento das células ciliadas externas, detectando precocemente mínimas alterações cocleares. Além disso, foi sugerido que as EOAPDs são úteis no monitoramento de mudanças discretas auditivas, ainda não detectáveis na audiometria tonal, como em danos da cóclea através de exposição ao ruído, ototóxicos (como furosemide e ácidto etacrínico, aspirina e aminoglicosídeos), metabólicos (doença de Menière) (KURC, 1999). Desta forma, tendo sido evidenciado o papel da melanina na função auditiva (FRANZ et al., 1990; ARDIC et al., 1998; CONLEE et al., 
1995; SAVIN, 1965), o uso das EOAPD torna-se um importante elemento para verificar o funcionamento do órgão espiral em pacientes com desordem pigmentar do tipo vitiligo.

É importante ressaltar que, mesmo após a retirada dos pacientes com mais de 60 anos, os quais poderiam estar influenciando nos resultados finais, manteve-se a diferença altamente significativa ( $p$-valor $<0,001$ ) na comparação de ambos os grupos, com e sem a desordem pigmentar. Estes dados indicaram que pacientes com vitiligo apresentam alterações nas CCE que não são observados na audiometria convencional. Logo, é comprovado que exames complementares são necessários para verificar mais detalhadamente o funcionamento das CCE em pacientes com vitiligo, como o uso das EOAPD.

\subsection{Discussão dos resultados da correlação entre limiares em altas freqüências e emissões otoacústicas - produto de distorção.}

Nesta parte do estudo, por meio da análise da correlação, buscou-se investigar a influência das altas freqüências (9 a $20 \mathrm{kHz}$ ) com as emissões otoacústicas - produto de distorção (EOAPD). Para esta correlação, foi utilizado um valor calculado, resultante da média de todas as altas freqüências de cada indivíduo, correlacionando cada uma das freqüências das EOAPD a este valor. É possível observar, pela Tabela 16, que, no grupo controle, houve 
correlação regular nas freqüências de 1587 a 4004 Hz, e correlação boa nas freqüências de 5042 e 6348 Hz; ou seja, a correlação aumenta com o aumento das freqüências, sendo esta correlação negativa. Logo, à medida que os limiares das altas freqüências se elevam, ocorre uma diminuição do nível de respostas das EOAPD. Por se tratar de altas freqüências, é esperado que esta correlação seja maior nas freqüências das EOAPD também mais altas, assim como foi encontrado neste presente trabalho. Assim, indivíduos que apresentam menor sensibilidade para as altas freqüências, também apresentam menor nível de respostas em EOAPD.

Estudos anteriores mostraram que a aplicação conjunta destes dois procedimentos possibilita identificar discretas alterações na função auditiva (CARVALLO, 2002; KOWALSKA et al., 2002; Ll et al., 2003).

Já no grupo com desordem pigmentar do tipo vitiligo, a correlação foi regular em apenas duas freqüências, de 2002 e 3174 Hz, e as restantes não se correlacionaram. Este dado pode sugerir que a função auditiva para este grupo, tanto para altas freqüências, como para EOAPD, apresenta uma distribuição menos homogênea, com maior grau de comprometimento, reduzindo assim, a correlação entre ambos os procedimentos.

Após as considerações apresentadas, vale ressaltar que a combinação dos procedimentos de audiometria em altas freqüências e das emissões otoacústicas - produto de distorção, na avaliação da audição, pode contribuir para um maior conhecimento da função auditiva. Tais procedimentos proporcionam maior precisão na detecção precoce de comprometimento 
auditivo em portadores de desordem pigmentar do tipo vitiligo, uma vez que o uso das freqüências convencionais, como procedimento isolado, não é eficaz na detecção de pequenas alterações auditivas. 
6. Conclusões 
A análise dos resultados deste estudo permitiu as seguintes conclusões:

- Não há diferenças entre os limiares tonais nas freqüências convencionais $(0,25$ a $8 \mathrm{kHz})$, entre os grupos com e sem a desordem pigmentar;

- Não há diferença entre orelhas direita e esquerda para todos os procedimentos aplicados em ambos os grupos;

- O grupo com desordem pigmentar apresenta limiares tonais, para altas freqüências, em maior nível de intensidade do que o grupo controle, com diferença estatística significante;

- O grupo com desordem pigmentar apresenta nível de respostas das EOAPD em menor nível de intensidade e maior proporção de ausência de respostas do que o grupo controle;

- Há evidência de boa correlação entre limiares tonais para altas freqüências com o nível de respostas das EOAPD para o grupo controle, e não para o grupo com vitiligo. 
7. Anexos 
Anexo 1 - Análise dos grupos controle e com vitiligo sem os indivíduos com idade superior a 60 anos.

Tabela 17. Análise descritiva da variável idade para cada grupo sem os indivíduos com mais de 60 anos

\begin{tabular}{lcc}
\hline \multicolumn{1}{c}{ Idade } & Controle & Vitiligo \\
\hline Média & 32,64 & 31,75 \\
Mediana & 31,00 & 29,00 \\
Desvio Padrão & 13,78 & 13,71 \\
Mínimo & 8 & 8 \\
Máximo & 59 & 58 \\
Tamanho & 28 & 28 \\
Limite Inferior & 27,54 & 26,67 \\
Limite Superior & 37,75 & 36,83 \\
\hline
\end{tabular}


Tabela 18. Análise descritiva dos limiares tonais de 250 a $8000 \mathrm{~Hz}$ do grupo controle e com vitiligo sem os indivíduos com mais de 60 anos

\begin{tabular}{|c|c|c|c|c|c|c|c|c|c|}
\hline \multicolumn{2}{|c|}{ Audio Normal } & \multirow{2}{*}{$\begin{array}{c}\text { Média } \\
8,48\end{array}$} & \multirow{2}{*}{$\begin{array}{c}\text { Mediana } \\
10,00\end{array}$} & \multirow{2}{*}{$\begin{array}{c}\text { Desvio } \\
\text { Padrão }\end{array}$} & \multirow{2}{*}{$\frac{\text { Mínimo }}{0}$} & \multirow{2}{*}{$\begin{array}{c}\text { Máximo } \\
35\end{array}$} & \multirow{2}{*}{$\begin{array}{c}\begin{array}{c}\text { Limite } \\
\text { Inferior }\end{array} \\
6,74\end{array}$} & \multirow{2}{*}{$\begin{array}{c}\begin{array}{c}\text { Limite } \\
\text { Superior }\end{array} \\
10,23\end{array}$} & \multirow{2}{*}{$\begin{array}{c}\begin{array}{c}p- \\
\text { valor }\end{array} \\
0,882\end{array}$} \\
\hline & Controle & & & & & & & & \\
\hline & Vitiligo & 8,66 & 10,00 & 6,07 & 0 & 25 & 7,07 & 10,25 & \\
\hline \multirow{2}{*}{$0,5 \mathrm{kHz}$} & Controle & 7,14 & 5,00 & 5,21 & 0 & 25 & 5,78 & 8,51 & 0,537 \\
\hline & Vitiligo & 7,77 & 5,00 & 5,47 & 0 & 20 & 6,34 & 9,20 & \\
\hline \multirow{2}{*}{$1 \mathrm{kHz}$} & Controle & 6,52 & 5,00 & 6,67 & 0 & 35 & 4,77 & 8,26 & 0,751 \\
\hline & Vitiligo & 6,16 & 5,00 & 5,13 & 0 & 20 & 4,82 & 7,51 & \\
\hline \multirow{2}{*}{$2 \mathrm{kHz}$} & Controle & 5,00 & 5,00 & 6,40 & 0 & 25 & 3,32 & 6,68 & 0,454 \\
\hline & Vitiligo & 5,89 & 5,00 & 6,19 & 0 & 25 & 4,27 & 7,51 & \\
\hline \multirow{2}{*}{$3 \mathrm{kHz}$} & Controle & 5,00 & 5,00 & 5,64 & 0 & 20 & 3,52 & 6,48 & 0,172 \\
\hline & Vitiligo & 6,52 & 5,00 & 6,02 & 0 & 25 & 4,94 & 8,10 & \\
\hline \multirow{2}{*}{$4 \mathrm{kHz}$} & Controle & 6,61 & 5,00 & 6,61 & 0 & 25 & 4,88 & 8,34 & 0,220 \\
\hline & Vitiligo & 8,30 & 5,00 & 7,88 & 0 & 30 & 6,24 & 10,37 & \\
\hline \multirow{2}{*}{$6 \mathrm{kHz}$} & Controle & 10,45 & 10,00 & 8,11 & 0 & 35 & 8,32 & 12,57 & 0,394 \\
\hline & Vitiligo & 11,96 & 10,00 & 10,52 & 0 & 45 & 9,21 & 14,72 & \\
\hline \multirow{2}{*}{$8 \mathrm{kHz}$} & Controle & 8,84 & 10,00 & 7,80 & 0 & 35 & 6,80 & 10,88 & 0,300 \\
\hline & Vitiligo & 10,63 & 7,50 & 10,18 & 0 & 45 & 7,96 & 13,29 & \\
\hline
\end{tabular}


Tabela 19. Análise descritiva dos limiares para altas freqüências de 9000 a $20000 \mathrm{~Hz}$ do grupo controle e com vitiligo sem os indivíduos com mais de 60 anos

\begin{tabular}{|c|c|c|c|c|c|c|c|c|c|}
\hline \multicolumn{2}{|c|}{ Altas Freqüências } & Média & Mediana & $\begin{array}{l}\text { Desvio } \\
\text { Padrão }\end{array}$ & Mínimo & Máximo & $\begin{array}{l}\text { Limite } \\
\text { Inferior }\end{array}$ & $\begin{array}{l}\text { Limite } \\
\text { Superior }\end{array}$ & p-valor \\
\hline \multirow{2}{*}{$9 \mathrm{kHz}$} & Controle & 14,38 & 15,00 & 8,95 & -5 & 40 & 12,03 & 16,72 & $<0,001^{*}$ \\
\hline & Vitiligo & 24,20 & 20,00 & 16,54 & 5 & 95 & 19,87 & 28,53 & \\
\hline \multirow{2}{*}{$10 \mathrm{kHz}$} & Controle & 13,66 & 12,50 & 11,77 & -15 & 35 & 10,58 & 16,74 & $<0,001^{*}$ \\
\hline & Vitiligo & 24,11 & 20,00 & 16,82 & 5 & 95 & 19,70 & 28,51 & \\
\hline \multirow{2}{*}{$12,5 \mathrm{kHz}$} & Controle & 12,32 & 10,00 & 11,64 & -10 & 40 & 9,27 & 15,37 & $<0,001^{*}$ \\
\hline & Vitiligo & 30,45 & 25,00 & 20,50 & 5 & 95 & 25,08 & 35,82 & \\
\hline \multirow{2}{*}{$14 \mathrm{kHz}$} & Controle & 10,27 & 10,00 & 16,33 & -20 & 55 & 5,99 & 14,55 & $<0,001^{*}$ \\
\hline & Vitiligo & 35,36 & 27,50 & 21,93 & 0 & 85 & 29,61 & 41,10 & \\
\hline \multirow{2}{*}{$16 \mathrm{kHz}$} & Controle & 9,82 & 10,00 & 22,56 & -20 & 60 & 3,91 & 15,73 & $<0,001^{*}$ \\
\hline & Vitiligo & 35,27 & 35,00 & 19,76 & 5 & 70 & 30,09 & 40,44 & \\
\hline \multirow{2}{*}{$18 \mathrm{kHz}$} & Controle & 9,82 & 12,50 & 18,44 & -20 & 40 & 4,99 & 14,65 & $<0,001^{*}$ \\
\hline & Vitiligo & 25,54 & 27,50 & 11,07 & 0 & 40 & 22,64 & 28,43 & \\
\hline \multirow{2}{*}{$20 \mathrm{kHz}$} & Controle & 0,98 & 0,00 & 9,02 & -20 & 15 & $-1,38$ & 3,34 & $<0,001^{*}$ \\
\hline & Vitiligo & 10,00 & 10,00 & 6,11 & 0 & 20 & 8,40 & 11,60 & \\
\hline
\end{tabular}


Tabela 20. Análise descritiva da média da relação sinal/ruído do grupo controle e com vitiligo sem os indivíduos com mais de 60 anos

\begin{tabular}{|c|c|c|c|c|c|c|c|c|c|}
\hline \multicolumn{2}{|c|}{ EOAPD } & \multirow{2}{*}{$\begin{array}{c}\text { Média } \\
4,19\end{array}$} & \multirow{2}{*}{$\begin{array}{c}\text { Mediana } \\
5,30\end{array}$} & \multirow{2}{*}{$\begin{array}{c}\text { Desvio } \\
\text { Padrão }\end{array}$} & \multirow{2}{*}{$\begin{array}{c}\text { Mínimo } \\
-15\end{array}$} & \multirow{2}{*}{$\begin{array}{c}\text { Máximo } \\
18\end{array}$} & \multirow{2}{*}{$\begin{array}{c}\begin{array}{c}\text { Limite } \\
\text { Inferior }\end{array} \\
1,99\end{array}$} & \multirow{2}{*}{$\begin{array}{c}\begin{array}{c}\text { Limite } \\
\text { Superior }\end{array} \\
6,39\end{array}$} & \multirow{2}{*}{$\begin{array}{l}p \text {-valor } \\
<0,001^{*}\end{array}$} \\
\hline & Controle & & & & & & & & \\
\hline & Vitiligo & $-4,42$ & $-2,80$ & 7,42 & -30 & 7 & $-6,36$ & $-2,48$ & \\
\hline \multirow{2}{*}{1.257} & Controle & 8,78 & 10,10 & 8,38 & -14 & 21 & 6,58 & 10,98 & $<0,001^{*}$ \\
\hline & Vitiligo & $-2,16$ & $-1,05$ & 7,55 & -24 & 17 & $-4,13$ & $-0,18$ & \\
\hline \multirow{2}{*}{1.587} & Controle & 13,13 & 13,55 & 8,78 & -12 & 27 & 10,83 & 15,43 & $<0,001^{*}$ \\
\hline & Vitiligo & 0,14 & 0,30 & 7,02 & -17 & 21 & $-1,70$ & 1,98 & \\
\hline \multirow{2}{*}{2.002} & Controle & 11,99 & 13,35 & 8,82 & -17 & 29 & 9,68 & 14,30 & $<0,001^{*}$ \\
\hline & Vitiligo & 0,96 & 2,45 & 7,90 & -20 & 17 & $-1,11$ & 3,03 & \\
\hline \multirow{2}{*}{2.515} & Controle & 11,74 & 12,25 & 7,44 & -9 & 30 & 9,79 & 13,69 & $<0,001^{*}$ \\
\hline & Vitiligo & 3,66 & 4,45 & 6,31 & -14 & 17 & 2,01 & 5,32 & \\
\hline \multirow{2}{*}{3.174} & Controle & 11,49 & 11,35 & 8,16 & -23 & 31 & 9,35 & 13,63 & $<0,001^{*}$ \\
\hline & Vitiligo & 2,15 & 4,60 & 9,06 & -48 & 16 & $-0,22$ & 4,53 & \\
\hline \multirow{2}{*}{4.004} & Controle & 14,59 & 15,10 & 7,72 & -11 & 28 & 12,57 & 16,61 & $<0,001^{*}$ \\
\hline & Vitiligo & 3,53 & 4,35 & 7,47 & -14 & 20 & 1,58 & 5,49 & \\
\hline \multirow{2}{*}{5.042} & Controle & 17,32 & 19,10 & 9,64 & -19 & 37 & 14,79 & 19,84 & $<0,001^{*}$ \\
\hline & Vitiligo & 5,04 & 6,10 & 10,36 & -27 & 22 & 2,33 & 7,75 & \\
\hline \multirow{2}{*}{6.348} & Controle & 13,86 & 14,80 & 9,97 & -12 & 31 & 11,25 & 16,47 & $<0,001^{*}$ \\
\hline & Vitiligo & 1,46 & 3,20 & 8,78 & -19 & 19 & $-0,84$ & 3,77 & \\
\hline
\end{tabular}


5. Referências Bibliográficas 
AMERICAN SPEECH-LANGUAGE-HEARING ASSOCIATION Guidelines for the audiologic management of individuals receiving cochleotoxic drug therapy. Asha. 1994; 36 (Suppl. 12): 11-19.

ARDIC FN, AKTAN S, KARA CO, SANH B. High-frequency hearing and reflex latency in patients with pigment disorder. American Journal of Otolaryngology. 1998; 19 (6): 365-69.

ARNOLD DJ, LONSBURY - MARTIN B L, MARTINS GK. High frequency hearing influences lower - frequency distortion- product otoacoustic emissions. Arch Otolaryngol Head Neck Surg. 1999; 125:215- 222.

AVAN P, BUKI B, MAAT B, DORDAIN M, WIT HP. Middler ear influence on otoacoustic emission. I: noninvasive investigation of the human transmission apparatus and comparison with model results. Hear Res. 2000; 140 (1-2): 189-201.

BARRENAS ML. Hair cell loss from acoustic trauma in chloroquine- treated red, black and albino guinea pigs. Audiology. 1997; 36 (4): 187-201.

BONFILS P, AVAN P. Distortion-product otoacoustic emissions: values for clinical use. Arch Otolaryngol Head Neck Surg. 1992; 118: 1069-1076.

BRAY PJ. Click evoked otoacoustic emissions and the development of a clinical otoacoustic hearing test instrument. London. (Doctor Thesis). University College and Middlesex School of Medicini; 1989. 
CARVALLO RMM, CARVALHO M, ISHIDA IM, KOGA MC. Limiares Tonais em Altas Freqüências em ouvintes sem queixa auditiva. Acta AWHO (periódico on line) 2002 [capturado em 2002 Jul 03]; 21(1):[7 telas] Disponível em http://www.actaawho.com.br/edicao/conteudo.asp

CARVALLO RMM, CARVALHO M, ISHIDA IM. Children with and without auditory processing disorders: role of high frequencies thresholds. Proceedings of VIII IALP ; 2001; Montreal.

CARVALLO RMM. Audição em alta freqüência: repercussões no reconhecimento de fala no ruído e nas emissões otoacústicas. São Paulo, 2002. Tese (Livre-Docente) Universidade de São Paulo.

COLLET L., VEUILLET E, BERGER-VACHON C, MORGON A. Evoked otoacoustic emissions: relative importance of age, sex and sensorineural hearing-loss using a mathematical model of the audiogram. Inter. J. Neuroscience. 1992; 62: 113-122.

CONLEE JW, ABDUL-BAGI KJ, McCANDLESS GA. Differential susceptibility to noise-induced permanent threshold shift between albino and pigmented guinea pigs. Hear Res. 1986; 23: 81-91.

CONLEE JW, BENNETT ML, CREEL DJ. Differential effects of gentamicin on the distribution of cochlear function in albino and pigmented guinea pigs. Acta Otolaryngol. 1995; 115 (3): 367-374.

COUBE CZV, COSTA FILHO OA. Emissões otoacústicas: uma visão geral. In: FROTA, S. - Fundamentos em Fonoaudiologia: Audiologia. RJ: Ed. Guanabara-Koogan; 1998 cap. 8.

COUBE CZV. Emissões otoacústicas evocadas - produto de distorção: estudo de indivíduos com perda auditiva coclear. Bauru, 2000. Tese (Doutorado) Universidade de São Paulo. 
DALLOS P. The Active Cochlea. The Journal of Neuroscience. 1992; 12(12): 4575-4585.

DIEROFF HG, HULST RJAMVD, TANGE RA, URBANUS NAM. Experiences with high-frequency hearing tests in the selection of personnel for noise occupation. Laryngorhinootologie. 1991; 70: 594-8.

DOYLE KJ, RODGERS P, FUJIKAWA S, NEWMAN E. External and middle ear effects on infant hearing screening test results. Otolaryngol Head Neck Surg. 2000; 122(4): 477-81.

ESCALANTE-UGALDE C, POBLANO A, OCA EM. No evidence of hearing loss in patients with vitiligo. Arch Dermatol. 1991;127: 1240.

FAUSTI SA, FREY RH, HENRY JA, OLSON DJ, SCHAFFER HI, BAGBY GC. High-frequency testing techniques and intrumentation for early detection of ototoxicity. Journal of Rehabilitation Research and Development. 1993; 30: 333-41.

FLOCK A, CHEUNG H. Actin filaments in sensory hairs of inner ear receptor cells. J. Cell. Biol. 1977; 75:339-343.

FRANK T. High Frequency (8 to $16 \mathrm{kHz}$ ) reference thresholds and intrasubject thereshlods variability relative to ototoxicity criteria using a Sennheiser HDA 200 Earphone. Ear Hear. 2001; 22 (2): 161-168.

FRANK T, DREIBACH LE. Repeatability of high-frequency thresholds. Ear and Hearing. 1991; 12: 294-5.

FRANZ P, AHARINEJAD S, FIRBAS W. Melanocytes in the modiolus of the guinea pig cochlea. Acta Otolaryngol. 1990; 109: 221-27. 
GORGA MP, STOVER L, NEELY ST, MONTOYA D. The use of cumulative distributions to determine critical values an levels of confidence for clinical distortion product otoacoustic emission measurements. J.Acoustic. Soc. Am. 1996; 100 (1): 968-977.

GORGA MP, NEELY ST, OHLRICH B, HOOVER B, REDNER J, PETERS J. From laboratory to clinic: a large scale study of distortion product otoacoustic emissions in ear with normal hearing an ears with hearing loss. Ear Hear. 1997; 18 (6): 440-55.

HALL J W, MUELLER HG. Diagnostic Audiology Principles, Procedures and practices. In: Audiologists' Desk Reference. vol 1, Singular Publishing Group Inc.: California, 1997; cap.5: 235-288.

HARRIS FP. Distortion - product otoacoustic emissions in humans wth high frequency sensorineural hearing loss. J. Sp. Hear. Res. 1990; 33: 594-600.

JERGER J, CHMIEL R. Factor analytic structure of auditory impaiment in elderly persons. J. Am. Acad. Audiol. 1997; 8(4): 269-76.

KAWASHIMURA M. Studies of the evaluation of cochlea function with distortion product otoacoustic emission. Hokkaido Igaku Zasshi. 1998; 73 (6) : 641-62.

KEMP DT. Stimulated acoustic emissions from within the human auditory system. J. Acoustic. Soc. Am. 1978; 64: 1386-1391.

KEMP DT, RYAN S, BRAY P. A guide to the effectiva use of otoacoustic emission. Ear and Hearing. 1990; 11 (2 ): 93-105.

KOWALSKA S, MATYJA W, GUZEK W, WESOLOWSKI W, SZYMCZAK W, KOSTRZEWSKI P. Effects of occupational exposure to a mixture of solvents on the inner ear: a field study. International Journal of Occupational Medicine. 2002; 15 (3): 247-256. 
KURC M. O amplificador coclear. Arquivos da Fundação Otorrinolaringologia. 1999, 3 (2).

LEE J, KIM J. The maximum permissible ambient noise and frequencyspecific averaging time on the measurement of distortion product otoacoustic emissions. Audiology. 1999; 38(1): 19-23.

LI F, ZHAO M, ZHANG Z, NI D. Study on distortion otoacoustic emissions and expanded high frequency audiometry in noise exposure workers. Journal of Clinical Otorhinolaryngology. 2003; 17 (1): 16-19.

LONSBURY-MARTIN BL, HARRIS FP, HAWKINS MD, STAGNER BB, MARTIN GK. Distortion product emissions in humans. II. Relations to acoustic immitance and stimulus frequency and spontaneous otoacoustic emissions in normally hearing subjects. Ann Otol Rhinol Laryngol. 1992; 99: 15-28.

LONSBURY-MARTIN BL, WHITEHEAD ML, MARTIN GK. Clinical applications of otoacoustic emissions. Journal of Speech and Hearing Research. 1991; 34: 964-981.

LOPES FILHO OC, CARLOS RC. Emissões otoacústicas. In : LOPES FILHO, OC. (org) Tratado de Fonoaudiologia. Ed. Roca : SP, 1997.

MOLINI E, RICCI G, ALUNNI N, SIMONCELLI C. Otoacoustic distortion products in infants and adults: a comparative study. Acta Otorhinolaryngol Ital. 1998; 18 (2) : 74-82.

MOULIN A, COLLET LV, MORGON A. Interrelations between transiently evoked otoacoustic emissions, spontaneous otoacoustic emissions and acoustic distortion products in normally hearing subjects. Hear Res. 1993; 65 (1-2): 216-33. 
NIKIFORIDIS GC, TSAMBAOS DG, KARAMITSOS DS, KOUTSOJANNIS CC, GEORGIOU SV. Abnormalities of the auditory brainstem response in vitiligo. Scand Audiol. 1993; 22 (2): 97-100.

NORTON SJ, STOVER LV. Otoacoustic emissions: An emerging clinical tools. In: KATZ J. - Handbook of Clinical Audiology; 4르 Edição; Ed. Willians \& Wilkins: Baltimore; 1994.

OZUER MZ, SAHINER T, AKTAN S, SANLI B, BAYRAMOGLU I. Auditory evoked potentials in vitiligo patients. Scand Audiol. 1998; 27 (4): 255-58.

PEDALINI MEB, SANCHEZ TG, ANTONIO AD, ANTONIO WD, BALBANI A, HACHIYA A, LIBERMAN S, BENTO RF. Média dos limiares tonais na audiometria de alta Freqüência em indivíduos normais de 4 a 60 anos. Pró-Fono. 2000; 12 (2): 17-20.

PICKLES JO, COMIS SD, OSBORNE MP. Cross-links between stereocilia in the guinea pig organ of corti, anda their possible relation to sensory transduction. Hear. Res. 1984; 15:103-112.

RAMOS CS. Processamento Auditivo e sensibilidade auditiva para altas Freqüências. São Paulo, 2002. Monografia (Especialização) Universidade Federal de São Paulo - Escola Paulista de Medicina.

ROYSTER LH, ROYSTER JD, THOMAS WG. Representative hearing levels by race and sex in North Caroline industry. Journal Acoust Soc Am. 1980; 68: 551-66.

SAHLEY TL, NODAR RH, MUSIEK FE Efferent Auditory System: structure and function. San Diego, Singular Publishing Group, 1997, 28p.

SAKAMOTO M, SUGASAWA M, KAGA K, KAMIO T. Average thresholds in the 8 to $20 \mathrm{KHz}$ range as a function of age. Scand. Audio. 1998; 27: 189-192. 
SAMPAIO SAP, RIVITTI EA. Leucodermias adquiridas. In: Dermatologia ; 2ª Ed; Artes Médicas, 2000.

SAVIN MSC. The blood vessels and pigmentary cells of the inner ear. Ann Otol Rhinol Laryngol. 1965; 74: 611-23.

SHERATA-DIELER WE, DIELER R, TEICHERT K, MOSER LM. Intra and intersubject variability of acoustically evoked otoacoustic emissions. II. distortion product otoacoustic emissions. Laryngorhinootologie. 1999; 78 (6) : 345-50.

SLIWINSKA-KOWALSKA M, KOTYLO P. Is otoacoustic emission useful in the differential diagnosis of occupational noise-induced hearing loss. Med Pr. 1997; 48 (6): 613-20.

STOVER L, GORGA MP, NEELY ST, MONTOYA D. Toward optimizing the clinical utility of distortion product otoacoustic emission measurements. J. Acoust. Soc. Am. 1996; 100 (2 Pt 1): 956-67.

TAKAHASHI S, IKEDA K, KOBAYASHI T, TAKASAKA T, OHYAMA K, WADA $\mathrm{H}$. Effect of aging on distortion product otoacoustic emissions. Nippon Jibiinkoka Gakkai Kaiho. 1996; 99 (7): 978-84.

TOPOLSKA MM, HASSMANN-POZNANSKA E, MUSIATOWICZ MP. The influence of the middle ear status on the measurement of evoked otoacoustic emissions (DPOAE). Otolaryngol Pol. 1998; 52(4): 451-5.

TOSTI A, BARDAZZI F, TOSTI G, MONTI L. Audiologic abnormalities in cases of vitiligo. Journal Am Acad Dermatol. 1987; 17: 230-33.

VINCK BM, VEL ED, XU ZM, CAUWENBER PBV. Distortion product otoacoustic emissions : A normative study. Audiology. 1996; 35: 231-245. 
VOHR BR, WHITE KR, MAXON AB, JOHNSON MJ. Factors affecting the interpretation of transient evoked otoacoustic emission results in neonatal hearing screening. Seminars in Hearing. 1993; 14 (1): 57-72.

WHITNELL RH, SHAFER LA, LILLY DJ. What drives mechanical amplification in the mammalian cochlea? Ear Hear. 2002; 23(1): 49-57.

ZAIA EH. Avaliação audiológica de indivíduos com insuficiência renal crônica em tratamento conservador: estudo das emissões otoacústicas Evocadas por produto de distorção e da audição em altas freqüências. São Paulo, 2000. Dissertação (Mestrado) Universidade Federal de São Paulo - Escola Paulista de Medicina.

ZEIGELBOIM BS. Os limiares de audibilidade nas altas freqüências em pacientes com insuficiência renal crônica submetidos a tratamento conservador. São Paulo, 2000. Tese (Doutorado) Universidade Federal de São Paulo - Escola Paulista de Medicina.

ZENNER HPM. Motile responses in outer hair cells. Hear. Res. 1986; 22:83-90. 
Apêndice 